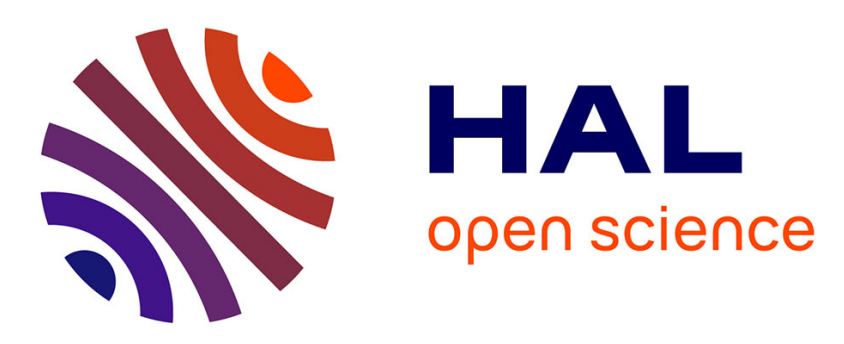

\title{
Review of "Universal " Rules Governing Bone Composition, Organization, and Elasticity Across Organizational Hierarchies
}

\author{
Viktoria Vass, Claire Morin, Stefan Scheiner, Christian Hellmich
}

\section{To cite this version:}

Viktoria Vass, Claire Morin, Stefan Scheiner, Christian Hellmich. Review of " Universal " Rules Governing Bone Composition, Organization, and Elasticity Across Organizational Hierarchies. Multiscale Mechanobiology of Bone Remodeling and Adaptation, 2018. hal-01671668

\section{HAL Id: hal-01671668 \\ https://hal.science/hal-01671668}

Submitted on 22 Dec 2017

HAL is a multi-disciplinary open access archive for the deposit and dissemination of scientific research documents, whether they are published or not. The documents may come from teaching and research institutions in France or abroad, or from public or private research centers.
L'archive ouverte pluridisciplinaire HAL, est destinée au dépôt et à la diffusion de documents scientifiques de niveau recherche, publiés ou non, émanant des établissements d'enseignement et de recherche français ou étrangers, des laboratoires publics ou privés. 


\section{Metadata of the chapter that will be visualized in SpringerLink}

\begin{tabular}{|c|c|c|}
\hline Book Title & \multicolumn{2}{|c|}{ Multiscale Mechanobiology of Bone Remodeling and Adaptation } \\
\hline \multicolumn{3}{|l|}{ Series Title } \\
\hline Chapter Title & \multicolumn{2}{|c|}{$\begin{array}{l}\text { Review of "Universal" Rules Governing Bone Composition, Organization, and Elasticity Acros } \\
\text { Organizational Hierarchies }\end{array}$} \\
\hline Copyright Year & \multicolumn{2}{|l|}{2018} \\
\hline Copyright HolderName & \multicolumn{2}{|c|}{ CISM International Centre for Mechanical Sciences } \\
\hline \multirow[t]{9}{*}{ Author } & Family Name & Vass \\
\hline & Particle & \\
\hline & Given Name & Viktoria \\
\hline & Prefix & \\
\hline & Suffix & \\
\hline & Division & Institute for Mechanics of Materials and Structures \\
\hline & Organization & TU Wien - Vienna University of Technology \\
\hline & Address & Vienna, Austria \\
\hline & Email & \\
\hline \multirow[t]{12}{*}{ Author } & Family Name & Morin \\
\hline & Particle & \\
\hline & Given Name & Claire \\
\hline & Prefix & \\
\hline & Suffix & \\
\hline & Division & Ecole Nationale Supérieure des Mines de Saint Etienne \\
\hline & Organization & CIS-EMSE, SAINBIOSE \\
\hline & Address & F-42023, Saint-Etienne, France \\
\hline & Division & \\
\hline & Organization & INSERM U1059, SAINBIOSE \\
\hline & Address & F-42023, Saint-Etienne, France \\
\hline & Email & claire.morin@emse.fr \\
\hline \multirow[t]{9}{*}{ Author } & Family Name & Scheiner \\
\hline & Particle & \\
\hline & Given Name & Stefan \\
\hline & Prefix & \\
\hline & Suffix & \\
\hline & Division & Institute for Mechanics of Materials and Structures \\
\hline & Organization & TU Wien - Vienna University of Technology \\
\hline & Address & Vienna, Austria \\
\hline & Email & \\
\hline \multirow[t]{5}{*}{ Corresponding Author } & Family Name & Hellmich \\
\hline & Particle & \\
\hline & Given Name & Christian \\
\hline & Prefix & \\
\hline & Suffix & \\
\hline
\end{tabular}


Division

Organization

Address

Email
Institute for Mechanics of Materials and Structures

TU Wien - Vienna University of Technology

Vienna, Austria

christian.hellmich@tuwien.ac.at
Abstract

Keywords (separated by '-')
"Universal" organizational patterns in bone are reviewed and presented, in terms of mathematically expressed rules concerning the composition and elasticity of a large variety of tissues. Firstly, experimental data sets gained from dehydration-demineralization tests, dehydration-deorganification tests, and dehydration-ashing tests are thoroughly analyzed. On this basis, bilinear relations can be identified, between the mass density of the extracellular bone matrix on the one hand, and the apparent mass densities of its basic constituents (water, hydroxyapatite, and organic matter), on the other hand. Secondly, the question as to how hydroxyapatite is distributed in bone tissue is addressed. To that end, mass and volume measurements gained from wet, dehydrated, and demineralized tissue samples, as well as optical densities provided by transmission electron microscopy, are studied, confirming a rule on how the mineral is partitioned between fibrillar and extrafibrillar spaces in the ultrastructure of bone. Thirdly, a swelling rule for hydrating collagen is validated through processing of experimental data from X-ray diffraction, vacuum drying, and mass measurements, quantifying the change of the bone tissue composition upon hydration. And fourthly, application of the mass conservation law to extracellular bone matrix considered as closed thermodynamic system, allows for studying the change of bone tissue composition during mineralization. Finally, these compositional rules, which are shown to be "universally" valid throughout the vertebrate kingdom, enter a micromechanical homogenization scheme for upscaling the experimentally accessible elastic properties of the elementary mechanical building blocks of bone (hydroxyapatite minerals, type I collagen, and water with non-collageneous organics) to the macroscopic scale of cortical and trabecular bone.

Bone mechanics - Elasticity - Strength - Micromechanics - Multiscale modeling




\title{
Review of "Universal" Rules Governing Bone Composition, Organization, and Elasticity Across Organizational Hierarchies
}

\author{
Viktoria Vass, Claire Morin, Stefan Scheiner and Christian Hellmich
}

\begin{abstract}
Universal" organizational patterns in bone are reviewed and presented, in terms of mathematically expressed rules concerning the composition and elasticity of a large variety of tissues. Firstly, experimental data sets gained from dehydrationdemineralization tests, dehydration-deorganification tests, and dehydration-ashing tests are thoroughly analyzed. On this basis, bilinear relations can be identified, between the mass density of the extracellular bone matrix on the one hand, and the apparent mass densities of its basic constituents (water, hydroxyapatite, and organic matter), on the other hand. Secondly, the question as to how hydroxyapatite is distributed in bone tissue is addressed. To that end, mass and volume measurements gained from wet, dehydrated, and demineralized tissue samples, as well as optical densities provided by transmission electron microscopy, are studied, confirming a rule on how the mineral is partitioned between fibrillar and extrafibrillar spaces in the ultrastructure of bone. Thirdly, a swelling rule for hydrating collagen is validated through processing of experimental data from X-ray diffraction, vacuum drying, and mass measurements, quantifying the change of the bone tissue composition upon hydration. And fourthly, application of the mass conservation law to extracellular bone matrix considered as closed thermodynamic system, allows for studying the change of bone tissue composition during mineralization. Finally, these compositional rules, which are shown to be "universally" valid throughout the vertebrate kingdom, enter a micromechanical homogenization scheme for upscaling the experimentally accessible elastic properties of the elementary mechanical building blocks
\end{abstract}

V. Vass $\cdot$ S. Scheiner $\cdot$ C. Hellmich $(\bowtie)$

Institute for Mechanics of Materials and Structures,

TU Wien - Vienna University of Technology, Vienna, Austria

e-mail: christian.hellmich@tuwien.ac.at

C. Morin

Ecole Nationale Supérieure des Mines de Saint Etienne,

CIS-EMSE, SAINBIOSE, F-42023 Saint-Etienne, France

e-mail: claire.morin@emse.fr

C. Morin

INSERM U1059, SAINBIOSE, F-42023 Saint-Etienne, France

(C) CISM International Centre for Mechanical Sciences 2017 
of bone (hydroxyapatite minerals, type I collagen, and water with non-collageneous organics) to the macroscopic scale of cortical and trabecular bone.

Keywords Bone mechanics $\cdot$ Elasticity $\cdot$ Strength $\cdot$ Micromechanics $\cdot$ Multiscale modeling

\section{Nomenclature}

A fourth-order strain concentration tensor

$\mathbb{C}, \mathbb{C}$ fourth-order elasticity tensor at the "microscopic" and "macroscopic" scale, respectively

d lateral/equatorial diffraction spacing

r characteristic length of the heterogeneities inside the RVE

div divergence (mathematical operator)

$\mathbb{D}$ fourth-order compliance tensor

$D_{i j k l} \quad$ component $i j k l$ of tensor $\mathbb{D}$

$D \quad$ axial diffraction spacing / axial macroperiod

$d \mathbf{x}_{i} \quad$ line element along the principal direction $i$

E Young's modulus

E macroscopic strain tensor

$f \quad$ volume fraction

$g \quad$ gravitational acceleration

GRAD gradient operator at the structure scale

II fourth-order identity tensor

$J \quad$ Jacobian, quantifying volume change during hydration process

$k \quad$ elastic bulk modulus

$\ell \quad$ characteristic length of the RVE

$\mathscr{L} \quad$ characteristic length of the structure built up by RVEs, or of its loading

$M \quad$ mass concerning a millimeter-sized bone sample

min minimum value (mathematical operator)

$N_{r} \quad$ number of phases

n outwardly pointing vector normal to a surface element of an RVE

$\mathbb{P}_{r}^{S} \quad$ fourth-order Hill tensor of inclusion with shape $r$ (or phase $r$ ) embedded in matrix with stiffness $\mathbb{C}_{\tau_{1}}$ (or $\mathbb{C}^{0}$ if $s=0$ ), or with symmetry property $s$ otherwise

\section{$\mathscr{R} \quad$ water-to-organic mass ratio}

$R V E \quad$ Representative Volume Element

T traction vector

$v \quad$ velocity

$V \quad$ volume quantity concerning a millimeter-sized bone sample

$W \quad$ weight quantity concerning a millimeter-sized bone sample

$\mathscr{W} \quad$ work

$W F \quad$ weight fraction

$\mathbf{x} \quad$ location vector

$\beta \quad$ proportionality constant between extrafibrillar space and fibrillar space increase during hydration 


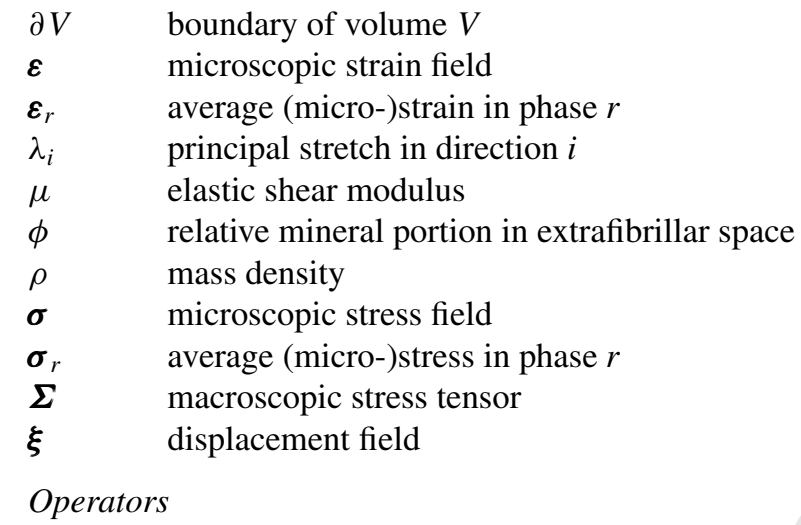

\section{Subscripts}

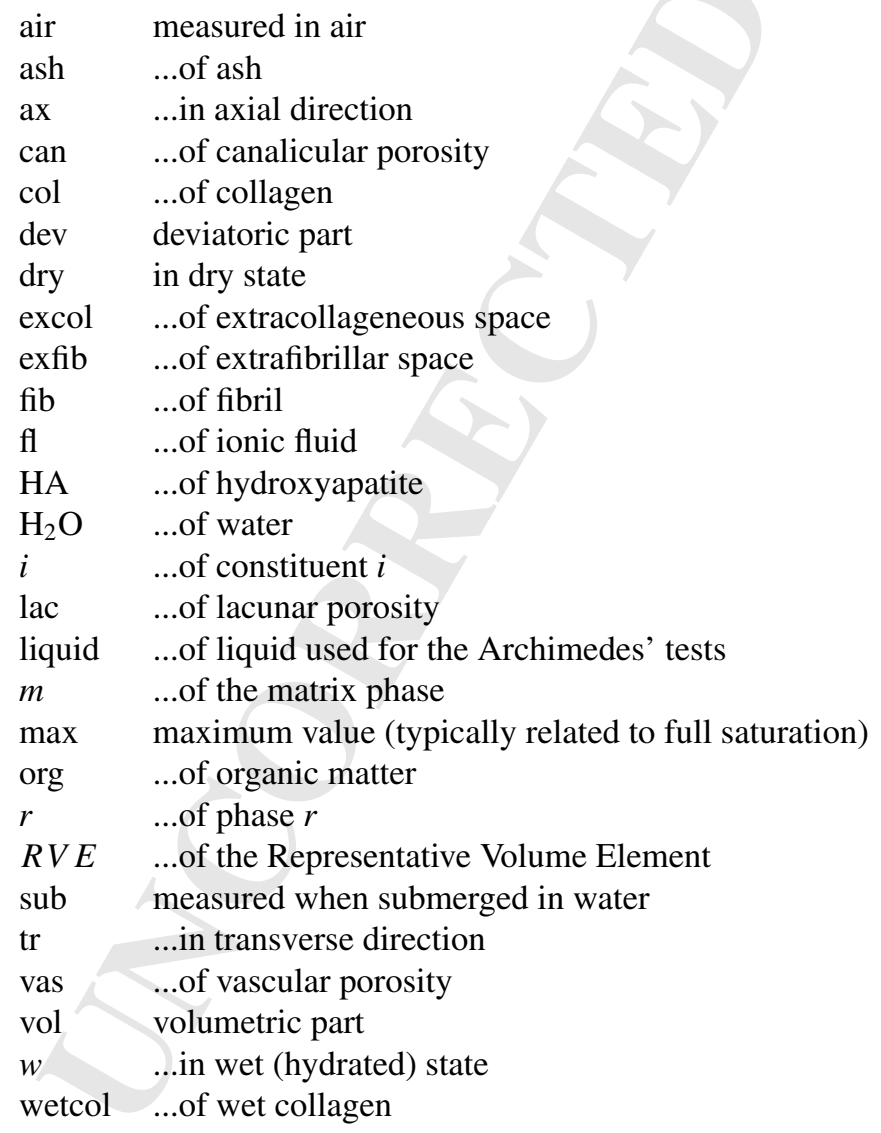




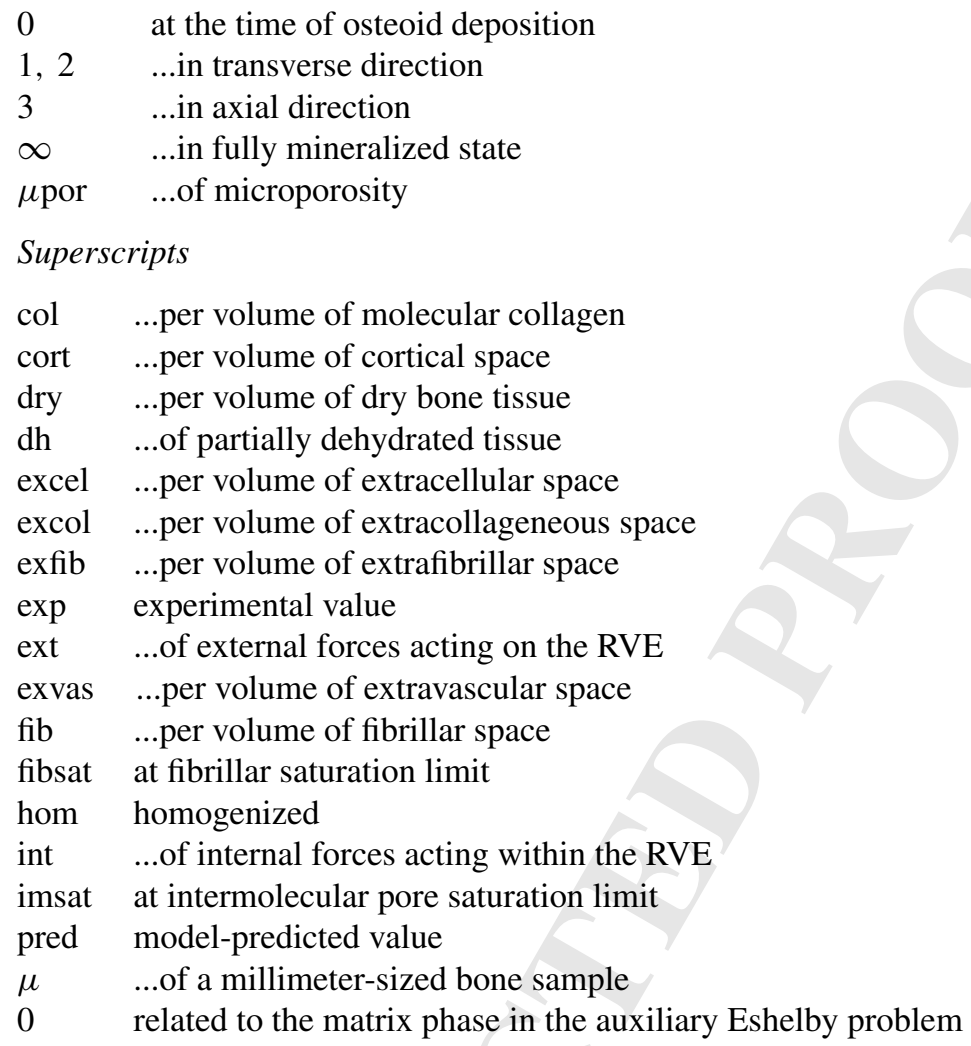

\section{Introduction}

Many tasks in the diverse field of biomedical engineering involve ensuring the mechanical integrity of structures made up by biological tissues. The mechanical integrity of structures depends on the mechanical loading to which they are subjected, on the specific shapes of the structures (i.e. of the organs), and last, but not least on the mechanical properties of the materials (i.e. of the biological tissues) making up the structures. The aforementioned tissue properties, changing in time and space across the organs, depend on tissue composition and on the micro- and nanostructures within a piece of tissue. The present contribution reviews rigorously derived mathematical relations describing corresponding structure-property relations.

This topic is closely linked to the question on whether there are any non-changing, "universally" valid rules governing the composition and microstructure of biological tissues. Inspired by Rupert Riedl (1925-2005), the eminent Austro-American zoologist of the second half of the twentieth century, who stressed that "the living world happens to be crowded by universal patterns of organizations, which, most obviously, find no direct explanation through environmental conditions or adaptive radiation" 
[127], we here report on the successful finding of mathematical rules reflecting the aforementioned patterns. Therefore, we apply an engineering science approach to the structural biology of bone tissue, also assessing how such rules or patterns affect the mechanical properties of bone tissue. For this purpose, we take into account the well-known fact that bone tissue features a distinctive hierarchical organization [46, 78, 150], as seen in Fig. 1 and described in greater detail in Sect. 2. The involved organizational patterns (specific arrangements of water, hydroxyapatite-type mineral, and organic matter) can be found throughout different anatomical locations, different organs, and different species. However, the dosages of distinctive features within a specific material microstructure may well differ. These dosages follow the aforementioned "universal" composition rules, which arise from a vast amount of experimental data available in literature.

In particular, dehydration-demineralization tests, dehydration-deorganification tests, and dehydration-ashing tests were analyzed in order to quantify the relations between the mass density of extracellular bone matrix and the apparent mass densities of water, hydroxyapatite, and organic matter, see Sect. 3. Furthermore, mass and volume measurements on wet, dehydrated, and demineralized bone tissue samples, as well as optical densities obtained from transmission electron microscopy (TEM) of similar tissues are employed for assessing the distribution of hydroxyapatite within extracellular bone matrix, see Sect.4. Thereafter, a swelling rule for hydrating collageneous tissues derived from processing and comparing data collected from X-ray diffraction, vacuum drying, and mass measurements, is presented in Sect. 5. Based on a mass conversation law formulated for closed systems representing both the bone ultrastructure, as well as the fibrillar and extrafibrillar spaces, the bone tissue evolution during mineralization can be predicted, see Sect. 6. Finally, we present how the hierarchical organization of bone tissue can be "translated" into a corresponding multiscale homogenization scheme, which allows for prediction of the macroscopic tissue stiffness. The corresponding microelastic model also incorporates the aforementioned four composition rules, so that they eventually govern "universal" structure-property relations in bone, as described in Sect. 7.

\section{Morphological Patterns of Bone}

Bone materials are characterized by an astonishing variability and diversity. Still, the fundamental hierarchical organization, or "once-chosen" basic "construction plans" of bone materials have remained largely unchanged during biological evolution; this has been coined, by Gould and Lewontin [52], as an "architecturally constrained" situation. The aforementioned construction plans are reflected by typical morphological features (or patterns) which can be discerned across most bone organs and tissues occurring in the vertebrate kingdom. The corresponding hierarchical organization of bone can be described by means of the following five levels [78]: 
(a)

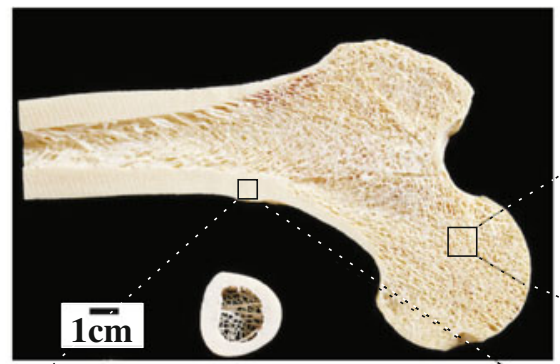

(b)

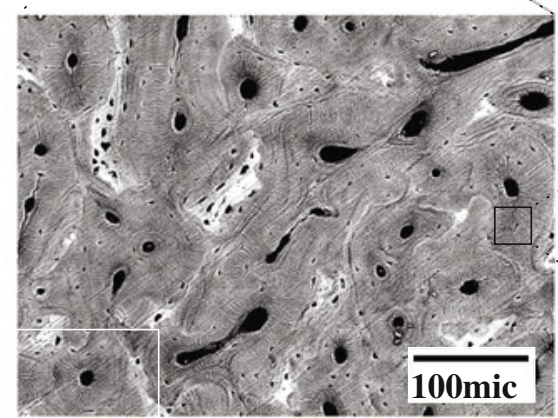

(g)

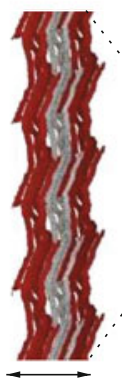

$10 \mathrm{~nm}$ (e)

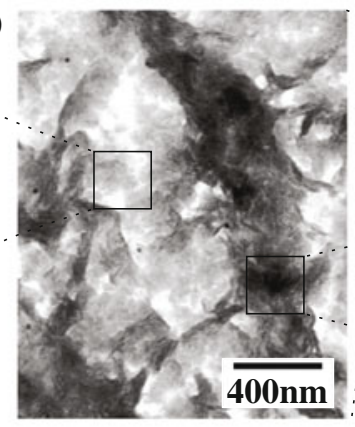

(c)

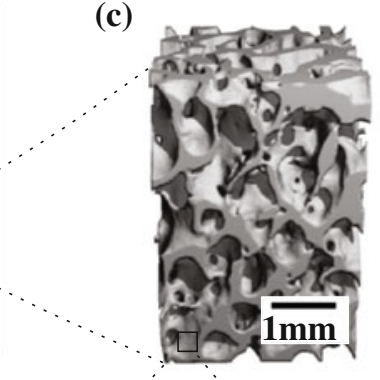

(d)
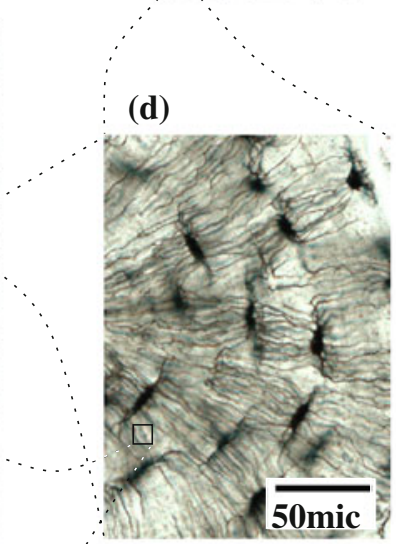

(f)

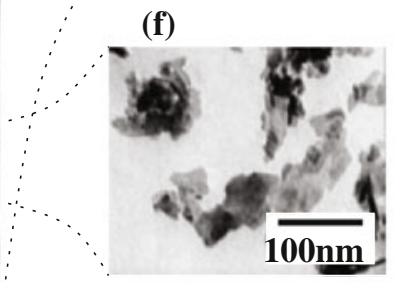

Fig. 1 Hierarchical organization of bone: a photograph of a cross-section through and across a whole long bone (copyright Ralph Hutchings/Visuals Unlimited, Inc.), showing the macrostructure; microstructure featuring either b osteonal cortical bone, acquired by SEM [58], or $\mathbf{c}$ trabecular struts making up trabecular bone, visualized based on micro-computed tomography data [103]; d osteocytic lacunae (brightfield light microscopy image taken by Tim Arnett); e ultrastructure, [122]; $\mathbf{f}$ hydroxyapatite crystals, obtained by means of SEM [150]; $\mathbf{g}$ wet collagen, electron density map of [112] (permission for reproduction requested from publisher: $\mathbf{b}$ The Royal Society; $\mathbf{c}$ ASME; d Annual Reviews; e Springer; $\mathbf{g}$ PNAS) 
- The macrostructure, with a characteristic length of several millimeters to centimeters, features cortical (or compact) bone and trabecular (or spongy) bone, see Fig. 1a.

- Zooming out pieces of cortical bone, see Fig. 1b, or trabecular bone, see Fig. 1c, reveals that actually both materials are porous in nature: The corresponding vascular porosity hosts various biological cells as well as blood vessels; in cortical bone this porosity is organized in a tree-type branching structure of canals (called Haversian canals if parallel to the main bone axis, and Volkmann canals at the branching junctions [24, 29]); and in trabecular bone, these canals are penetrating each other, yielding eventually a microstructure made up by single plates or struts [54]. The vascular pore channels are connected, via much smaller channels called canaliculi, to cave-like single pores called lacunae [138], populated by individual osteocytes, and seen as small black dots in Fig. 1d.

- The entire domain outside the vascular, lacunar, and canalicular porosities is called extracellular space or matrix. It appears as a nanocomposite with a characteristic size of several micrometers, see Fig. 1e. Within this extracellular space, collagenrich domains, see the light areas in Fig. 1e, and collagen-free domains, see the dark areas in Fig. 1e, can be distinguished, the characteristic length of both of which is several hundred nanometers. Commonly, these domains are referred to as fibrils and extrafibrillar space [122].

- Finally, the so-called elementary components of mineralized tissues can be distinguished, with a characteristic lengths in the range of nanometers:

- plate-shaped mineral crystals consisting of impure hydroxyapatite (HA, $\mathrm{Ca}_{10}\left[\mathrm{PO}_{4}\right]_{6}[\mathrm{OH}]_{2}$ ) with typical $1-5 \mathrm{~nm}$ thickness, and $25-50 \mathrm{~nm}$ length [150], see Fig. 1f;

- slender, helically round collagen molecules with a diameter of about $1.2 \mathrm{~nm}$ and a length of about $300 \mathrm{~nm}[21,112,120]$, which are self-assembled in staggered organizational schemes (fibrils) with characteristic diameters of $50-500 \mathrm{~nm}[35$, 95, 105, 122, 125, 142, 150, 151], see Fig. 1g - several covalently bonded fibrils are sometimes referred to as fibers;

- different non-collagenous organic molecules, predominantly lipids and proteins $[73,146] ;$ and

- water.

Both the amount of these components, as well as their distribtution across the hierarchical levels described above, are the focus of the subsequent sections.

\section{Mineral and Collagen Dosages in Extracellular Bone Matrix}

Data from bone drying, demineralization, and deorganification tests, collected over a time span of more than 80 years [13, 25, 51, 57, 87, 90-92, 96], evidence a myriad of different chemical compositions of different bone materials. However, careful 
analysis of the data, as to extract the chemical concentrations of hydroxyapatite, water, and organic matter ${ }^{1}$ in the extracellular bone matrix, reveals an astonishing fact [147]: it appears that there exists a unique bilinear relationship between organic concentration and mineral concentration, across different species, different organs, and different age groups, from early childhood to old age.

Corresponding experimental endeavors typically started with the determination of the "macroscopic" mass density, i.e. that associated to millimeter-sized bone samples, by means of Archimedes' principle. Therefore, the mass of the (wet) bone sample is first measured in air, delivering the quantity $M_{\text {air }}^{\mu}$. Thereafter, the weight of the bone sample when submerged in a liquid, is quantified as $W_{\text {sub }}^{\mu}$. Both quantities then give access to the volume of the millimeter-sized sample, through

$$
V^{\mu}=\frac{1}{\rho_{\text {liquid }}}\left(M_{\text {air }}^{\mu}-\frac{W_{\text {sub }}^{\mu}}{g}\right),
$$

with $\rho_{\text {liquid }}$ as the mass density of the employed liquid, and $g$ as the gravitational acceleration, $g=9.81 \mathrm{~m} / \mathrm{s}^{2}$. Finally, the macroscopic mass density of the investigated samples follows from

$$
\rho^{\mu}=\frac{M_{\mathrm{air}}^{\mu}}{V^{\mu}} .
$$

After having determined their samples' mass density, the experimenters typically turned towards determination of the samples' chemical composition; by one of three different experimental modalities, as described next.

\section{Dehydration-Demineralization Tests}

In a series of seminal experimental campaigns [87, 90, 91, 96], see Tables 1, 2 and 3, numerous millimeter-sized bone samples were first dried in a vacuum desiccator at room temperature, until a constant mass was observed, namely the mass of the dehydrated bone sample, $M_{\mathrm{dry}}^{\mu}$. The difference between the mass of wet sample in air and the mass of dehydrated sample obviously equals the mass of water which was originally contained in the sample, $M_{\mathrm{H}_{2} \mathrm{O}}^{\mu}=M_{\mathrm{air}}^{\mu}-M_{\mathrm{dry}}^{\mu}$. This water had filled all the bone pore spaces, from the vascular pore space seen in Fig. 1b, c, via the lacunar and canalicular pore spaces seen in Fig. 1d, down to the inter-crystalline and intermolecular pore spaces, as seen in Fig. 1e, f, g. Next, the samples were rehydrated and then demineralized in a 0.5 Methylenediaminetetraacetic acid (EDTA) solution at $p \mathrm{H} 7.5$, until no calcium was detected anymore by an atomic absorption spectrometer. After drying such a demineralized sample in vacuum, one is left with the organic mass which had been contained in the originally mineralized and wet bone sample, $M_{\text {org }}^{\mu}$. Finally, knowledge of the masses of organic matter and water gives access to the hydroxyapatite mass, $M_{\mathrm{HA}}^{\mu}=M_{\mathrm{air}}^{\mu}-M_{\mathrm{org}}^{\mu}-M_{\mathrm{H}_{2} \mathrm{O}}^{\mu}$. Thereafter, the constituent masses can be readily converted into weight fractions, through

\footnotetext{
${ }^{1} 90 \%$ of which is collagen [146].
} 
Table 1 Bone composition from dehydration-demineralization experiments of Lees et al. [91] ${ }^{\mathrm{a}}$ and Lees et al. [96] ${ }^{\mathrm{b}}$

\begin{tabular}{|c|c|c|c|c|}
\hline Tissue & $\rho^{\mu}\left(\mathrm{g} / \mathrm{cm}^{3}\right)$ & $\mathrm{WF}_{\mathrm{HA}}^{\mu}(-)$ & $\mathrm{WF}_{\mathrm{org}}^{\mu}(-)$ & $\mathrm{WF}_{\mathrm{H}_{2} \mathrm{O}}^{\mu}(-)$ \\
\hline Bovine tibia $^{a}$ & 2.06 & 0.658 & 0.219 & 0.123 \\
\hline Bovine tibia $^{a}$ & 2.05 & 0.656 & 0.219 & 0.126 \\
\hline Bovine tibia $^{a}$ & 2.02 & 0.621 & 0.239 & 0.140 \\
\hline Bovine tibia $^{a}$ & 2.02 & 0.627 & 0.232 & 0.140 \\
\hline Bovine tibia $^{\mathrm{a}}$ & 2.00 & 0.643 & 0.227 & 0.129 \\
\hline Bovine tibia $^{a}$ & 2.05 & 0.643 & 0.230 & 0.127 \\
\hline Bovine tibia $^{a}$ & 2.10 & 0.671 & 0.211 & 0.118 \\
\hline Bovine tibia $^{a}$ & 2.08 & 0.664 & 0.216 & 0.120 \\
\hline Bovine tibia $^{\mathrm{a}}$ & 2.12 & 0.661 & 0.215 & 0.123 \\
\hline Bovine tibia $^{a}$ & 2.08 & 0.663 & 0.221 & 0.116 \\
\hline Bovine tibia $^{\mathrm{a}}$ & 2.10 & 0.647 & 0.224 & 0.129 \\
\hline Bovine tibia $^{a}$ & 1.98 & 0.654 & 0.217 & 0.128 \\
\hline Bovine tibia $^{\mathrm{a}}$ & 2.05 & 0.644 & 0.227 & 0.129 \\
\hline Bovine tibia $^{a}$ & 2.11 & 0.649 & 0.229 & 0.122 \\
\hline Bovine tibia $^{a}$ & 2.03 & 0.638 & 0.213 & 0.123 \\
\hline Bovine tibia $^{a}$ & 2.06 & 0.699 & 0.184 & 0.117 \\
\hline Bovine tibia $^{\mathrm{a}}$ & 2.02 & 0.658 & 0.219 & 0.123 \\
\hline Bovine tibia $^{a}$ & 1.99 & 0.656 & 0.219 & 0.126 \\
\hline Bovine tibia $^{\mathrm{a}}$ & 1.95 & 0.640 & 0.228 & 0.131 \\
\hline Bovine tibia $^{\mathrm{a}}$ & 2.01 & 0.659 & 0.218 & 0.123 \\
\hline Bovine tibia $^{a}$ & 2.04 & 0.638 & 0.242 & 0.121 \\
\hline Bovine tibia $^{a}$ & 2.05 & 0.674 & 0.210 & 0.116 \\
\hline Whale malleus ${ }^{\mathrm{b}}$ & 2.49 & 0.860 & 0.100 & 0.040 \\
\hline Whale malleus ${ }^{\mathrm{b}}$ & 2.45 & 0.800 & 0.130 & 0.070 \\
\hline Whale incus ${ }^{\mathrm{b}}$ & 2.50 & 0.860 & 0.090 & 0.050 \\
\hline Whale stapes ${ }^{\mathrm{b}}$ & 2.42 & 0.810 & 0.130 & 0.060 \\
\hline Whale stapes ${ }^{b}$ & 2.36 & 0.800 & 0.140 & 0.060 \\
\hline Whale periotic $^{\mathrm{b}}$ & 2.40 & 0.810 & 0.130 & 0.070 \\
\hline Whale periotic $^{\mathrm{b}}$ & 2.48 & 0.830 & 0.110 & 0.060 \\
\hline Whale periotic $^{\mathrm{b}}$ & 2.52 & 0.850 & 0.100 & 0.050 \\
\hline Whale periotic $^{\mathrm{b}}$ & 2.52 & 0.850 & 0.100 & 0.050 \\
\hline Whale periotic $^{\mathrm{b}}$ & 2.58 & 0.870 & 0.090 & 0.040 \\
\hline Whale t. bulla ${ }^{\mathrm{b}}$ & 2.48 & 0.850 & 0.100 & 0.050 \\
\hline
\end{tabular}


Table 2 Mineralized tendon composition from dehydration-demineralization experiments of Lees and Page [90]

\begin{tabular}{|c|c|c|c|c|}
\hline Tissue & $\rho^{\mu}\left(\mathrm{g} / \mathrm{cm}^{3}\right)$ & $\mathrm{WF}_{\mathrm{HA}}^{\mu}(-)$ & $\mathrm{WF}_{\text {org }}^{\mu}(-)$ & $\mathrm{WF}_{\mathrm{H}_{2} \mathrm{O}}^{\mu}(-)$ \\
\hline $\begin{array}{l}\text { Mineralized } \\
\text { turkey leg tendon }\end{array}$ & 1.33 & 0.286 & 0.250 & 0.465 \\
\hline $\begin{array}{l}\text { Mineralized } \\
\text { turkey leg tendon }\end{array}$ & 1.50 & 0.445 & 0.239 & 0.316 \\
\hline $\begin{array}{l}\text { Mineralized } \\
\text { turkey leg tendon }\end{array}$ & 1.50 & 0.410 & 0.217 & 0.374 \\
\hline $\begin{array}{l}\text { Mineralized } \\
\text { turkey leg tendon }\end{array}$ & 1.51 & 0.437 & 0.217 & 0.346 \\
\hline $\begin{array}{l}\text { Mineralized } \\
\text { turkey leg tendon }\end{array}$ & 1.52 & 0.454 & 0.239 & 0.308 \\
\hline $\begin{array}{l}\text { Mineralized } \\
\text { turkey leg tendon }\end{array}$ & 1.52 & 0.437 & 0.219 & 0.343 \\
\hline $\begin{array}{l}\text { Mineralized } \\
\text { turkey leg tendon }\end{array}$ & 1.52 & 0.396 & 0.244 & 0.360 \\
\hline $\begin{array}{l}\text { Mineralized } \\
\text { turkey leg tendon }\end{array}$ & 1.53 & 0.443 & 0.222 & 0.335 \\
\hline $\begin{array}{l}\text { Mineralized } \\
\text { turkey leg tendon }\end{array}$ & 1.54 & 0.459 & 0.244 & 0.297 \\
\hline $\begin{array}{l}\text { Mineralized } \\
\text { turkey leg tendon }\end{array}$ & 1.58 & 0.473 & 0.228 & 0.299 \\
\hline $\begin{array}{l}\text { Mineralized } \\
\text { turkey leg tendon }\end{array}$ & 1.58 & 0.462 & 0.217 & 0.321 \\
\hline $\begin{array}{l}\text { Mineralized } \\
\text { turkey leg tendon }\end{array}$ & 1.59 & 0.476 & 0.228 & 0.297 \\
\hline $\begin{array}{l}\text { Mineralized } \\
\text { turkey leg tendon }\end{array}$ & 1.60 & 0.487 & 0.230 & 0.283 \\
\hline $\begin{array}{l}\text { Mineralized } \\
\text { turkey leg tendon }\end{array}$ & 1.61 & 0.459 & 0.230 & 0.310 \\
\hline $\begin{array}{l}\text { Mineralized } \\
\text { turkey leg tendon }\end{array}$ & 1.61 & 0.495 & 0.244 & 0.261 \\
\hline $\begin{array}{l}\text { Mineralized } \\
\text { turkey leg tendon }\end{array}$ & 1.62 & 0.500 & 0.228 & 0.272 \\
\hline $\begin{array}{l}\text { Mineralized } \\
\text { turkey leg tendon }\end{array}$ & 1.64 & 0.506 & 0.228 & 0.266 \\
\hline
\end{tabular}

$$
\mathrm{WF}_{i}^{\mu}=\frac{M_{i}^{\mu}}{M_{\text {air }}^{\mu}}, \quad i=\text { org, } \mathrm{HA}, \mathrm{H}_{2} \mathrm{O},
$$

see Tables 1, 2 and 3. The weight fractions obviously fulfill

$$
\mathrm{WF}_{\mathrm{H}_{2} \mathrm{O}}^{\mu}+\mathrm{WF}_{\mathrm{HA}}^{\mu}+\mathrm{WF}_{\mathrm{org}}^{\mu}=1 \text {. }
$$


Table 3 Bone composition from dehydration-demineralization experiments of Lees [87]

\begin{tabular}{l|l|l|l|l}
\hline Tissue & $\mathrm{WF}_{\mathrm{HA}}^{\mu}(-)$ & $\mathrm{WF}_{\mathrm{org}}^{\mu}(-)$ & $\mathrm{WF}_{\mathrm{H}_{2} \mathrm{O}}^{\mu}(-)$ & $\rho^{\mu}\left(\mathrm{g} / \mathrm{cm}^{3}\right)$ \\
\hline Horse metacarpal & 0.55 & 0.25 & 0.2 & 1.79 \\
\hline Horse metacarpal & 0.57 & 0.26 & 0.17 & 1.84 \\
\hline Horse metacarpal & 0.55 & 0.26 & 0.19 & 1.80 \\
\hline Horse metacarpal & 0.54 & 0.28 & 0.18 & 1.79 \\
\hline Horse metacarpal & 0.62 & 0.26 & 0.12 & 1.96 \\
\hline Horse metacarpal & 0.62 & 0.27 & 0.11 & 1.97 \\
\hline Horse metacarpal & 0.62 & 0.26 & 0.12 & 1.96 \\
\hline Horse metacarpal & 0.61 & 0.26 & 0.13 & 1.94 \\
\hline Horse metacarpal & 0.62 & 0.25 & 0.13 & 1.95 \\
\hline Horse metacarpal & 0.54 & 0.23 & 0.23 & 1.75 \\
\hline Horse metacarpal & 0.53 & 0.24 & 0.23 & 1.74 \\
\hline Horse metacarpal & 0.54 & 0.27 & 0.19 & 1.79 \\
\hline Horse metacarpal & 0.63 & 0.22 & 0.15 & 1.94 \\
\hline Horse metacarpal & 0.62 & 0.25 & 0.13 & 1.95 \\
\hline Horse metacarpal & 0.62 & 0.26 & 0.12 & 1.96 \\
\hline Horse metacarpal & 0.64 & 0.23 & 0.13 & 1.98 \\
\hline Horse metacarpal & 0.62 & 0.26 & 0.12 & 1.96 \\
\hline Horse metacarpal & 0.66 & 0.23 & 0.12 & 1.99 \\
\hline Horse metacarpal & 0.63 & 0.24 & 0.13 & 1.96 \\
\hline & & &
\end{tabular}

\section{Dehydration-Deorganification Tests}

Gong et al. [51] weighed several (macroscopic) bone samples in the wet state, as well as after drying at $80^{\circ} \mathrm{C}$ for $72 \mathrm{~h}$ - thereby getting access to their wet and dry masses, $M_{\mathrm{air}}^{\mu}$ and $M_{\mathrm{dry}}^{\mu}$. As before, their difference is equal to the mass of water in the investigated bone sample, $M_{\mathrm{H}_{2} \mathrm{O}}^{\mu}=M_{\text {air }}^{\mu}-M_{\text {dry }}^{\mu}$. Next, the samples were freed from fat and other organic material, using, in a soxhlet apparatus, a mixture of $80 \%$ ethyl ether and $20 \%$ ethanol, as well as an $80 \%$ aqueous solution of ethylene diamine. After drying such a deorganified sample at $80^{\circ} \mathrm{C}$ (until constant weight is attained), one is left with the hydroxyapatite mass contained in the investigated bone sample, $M_{\mathrm{HA}}^{\mu}$. Finally, when knowing the mass of hydroxyapatite and water contained in the originally wet bone sample, as well as its original mass, the mass of the organic matter can be readily determined through $M_{\mathrm{org}}^{\mu}=M_{\mathrm{air}}^{\mu}-M_{\mathrm{HA}}^{\mu}-M_{\mathrm{H}_{2} \mathrm{O}}^{\mu}$, together with the corresponding weight fractions according to Eq. (3), see Table 4.

\section{Dehydration-Ashing Tests}

In an interesting experimental campaign of Biltz and Pellegrino [13], cortical bone samples were dried until a constant mass, i.e. the dry bone mass, $M_{\text {dry }}^{\mu}$, was attained, which, together with the original mass of the sample in air, $M_{\text {air }}^{\mu}$, gives access to the mass of water in the investigated bone sample, $M_{\mathrm{H}_{2} \mathrm{O}}^{\mu}$. Next, the dried bones were 
Table 4 Bone composition from dehydration-deorganification experiments of Gong et al. [51]

\begin{tabular}{l|l|l|l|l}
\hline Tissue & $\rho^{\mu}\left(\mathrm{g} / \mathrm{cm}^{3}\right)$ & $\mathrm{WF}_{\mathrm{HA}}^{\mu}(-)$ & $\mathrm{WF}_{\mathrm{org}}^{\mu-)}$ & $\mathrm{WF}_{\mathrm{H}_{2} \mathrm{O}}^{\mu}(-)$ \\
\hline Steer tibial shaft & 2.00 & 0.630 & 0.244 & 0.126 \\
\hline Dog femoral shaft & 2.00 & 0.630 & 0.259 & 0.111 \\
\hline $\begin{array}{l}\text { Humar femur and } \\
\text { tibia }\end{array}$ & 1.99 & 0.642 & 0.239 & 0.119 \\
\hline Monkey femur & 2.04 & 0.643 & 0.239 & 0.117 \\
\hline Steer atlas bone & 1.93 & 0.588 & 0.266 & 0.146 \\
\hline $\begin{array}{l}\text { Dog lumbar } \\
\text { vertebrae }\end{array}$ & 1.91 & 0.582 & 0.265 & 0.153 \\
\hline $\begin{array}{l}\text { Human thoracic } \\
\text { and lumbar } \\
\text { vertebrae }\end{array}$ & 1.92 & 0.601 & 0.258 & 0.140 \\
\hline $\begin{array}{l}\text { Monkey lumbar } \\
\text { vertebrae }\end{array}$ & 1.88 & 0.582 & 0.274 & 0.144 \\
\hline
\end{tabular}

gently incinerated until all organic matter was burned off. Subsequent weighing evidenced the ash weight, $M_{\text {ash }}^{\mu}$. As also some inorganic matter, namely $6.6 \%$ of the ash weight, is burned at an ashing temperature of $600^{\circ} \mathrm{C}$ [51], the ash mass provides access to the mineral mass, according to $\mathrm{M}_{\mathrm{HA}}^{\mu}=1.066 \times \mathrm{M}_{\text {ash }}^{\mu}$. The mass of organic matter follows from $M_{\mathrm{org}}^{\mu}=M_{\mathrm{air}}^{\mu}-M_{\mathrm{HA}}^{\mu}-M_{\mathrm{H}_{2} \mathrm{O}}^{\mu}$. The corresponding weight fractions can be determined through Eqs. (3) and (4), which, in turn, provide access to $\rho^{\mu}$, through

$$
\rho^{\mu}=\left(\frac{\mathrm{WF}_{\mathrm{org}}^{\mu}}{\rho_{\mathrm{org}}}+\frac{\mathrm{WF}_{\mathrm{HA}}^{\mu}}{\rho_{\mathrm{HA}}}+\frac{\mathrm{WF}_{\mathrm{H}_{2} \mathrm{O}}^{\mu}}{\rho_{\mathrm{H}_{2} \mathrm{O}}}\right)^{-1},
$$

where $\rho_{\text {org }}=1.42 \mathrm{~g} / \mathrm{cm}^{3}, \rho_{\mathrm{HA}}=3 \mathrm{~g} / \mathrm{cm}^{3}$, and $\rho_{\mathrm{H}_{2} \mathrm{O}}=1 \mathrm{~g} / \mathrm{cm}^{3}$ are the constituents' real mass densities [51, 60, 86]. For a compilation of data derived from [13], see Table 5. For the sake of completeness, it should be noted that [13] actually reported the volume fraction of water

$$
f_{\mathrm{H}_{2} \mathrm{O}}^{\mu}=\frac{M_{\mathrm{air}}^{\mu}-M_{\mathrm{dry}}^{\mu}}{V^{\mu}},
$$

and the weight fraction of ash per mass of dried bone

$$
\mathrm{WF}_{\mathrm{ash}}^{\mathrm{dry}}=\frac{M_{\mathrm{ash}}^{\mu}}{M_{\mathrm{air}}^{\mu}-M_{\mathrm{H}_{2} \mathrm{O}}^{\mu}} .
$$

Similar test campaigns were performed by $[25,57]$, see Table 6 for a compilation of test results. 
Table 5 Bone composition from dehydration-ashing experiments of Biltz and Pellegrino [13]

\begin{tabular}{l|l|l|l|l}
\hline $\begin{array}{l}\text { Femoral and } \\
\text { tibial samples of }\end{array}$ & $\rho^{\mu}\left(\mathrm{g} / \mathrm{cm}^{3}\right)$ & $\mathrm{WF}_{\mathrm{HA}}^{\mu}(-)$ & $\mathrm{WF}_{\mathrm{Org}}^{\mu}(-)$ & $\mathrm{WF}_{\mathrm{H}_{2} \mathrm{O}}^{\mu}(-)$ \\
\hline Fish & 1.80 & 0.507 & 0.273 & 0.220 \\
\hline Turtle & 1.81 & 0.529 & 0.266 & 0.204 \\
\hline Frog & 1.93 & 0.572 & 0.246 & 0.182 \\
\hline Polar bear & 1.92 & 0.583 & 0.245 & 0.172 \\
\hline Man & 1.94 & 0.657 & 0.263 & 0.080 \\
\hline Elephant & 2.00 & 0.658 & 0.242 & 0.100 \\
\hline Monkey & 2.09 & 0.653 & 0.237 & 0.110 \\
\hline Cat & 2.05 & 0.652 & 0.233 & 0.115 \\
\hline Horse & 2.02 & 0.648 & 0.228 & 0.124 \\
\hline Chicken & 2.04 & 0.653 & 0.227 & 0.120 \\
\hline Dog & 1.94 & 0.637 & 0.219 & 0.144 \\
\hline Goose & 2.04 & 0.669 & 0.218 & 0.113 \\
\hline Cow & 2.05 & 0.660 & 0.212 & 0.128 \\
\hline Guinea Pig & 2.10 & 0.669 & 0.212 & 0.119 \\
\hline Rabbit & 2.12 & 0.685 & 0.199 & 0.116 \\
\hline Rat & 2.24 & 0.713 & 0.197 & 0.090
\end{tabular}

\section{Determination of Tissue-Specific Volume Fractions}

Determination of the extracellular volume fractions of mineral and collagen, $f_{\mathrm{HA}}^{\text {excel }}$ and $f_{\mathrm{col}}^{\text {excel }}$, rests on the aforementioned volume and weighing measurements on wet, dehydrated, and demineralized bone specimens, and on techniques revealing the bone microstructure, such as light microscopy, confocal microscopy, or micro-computed tomography. These imaging techniques give access to the so-called microporosity $f_{\mu \mathrm{por}}$, the sum of the vascular, lacunar, and canalicular porosities,

$$
f_{\mu \text { por }}=f_{\text {vas }}+f_{\text {lac }}+f_{\text {can }} \text {. }
$$

Vascular porosity in cortical bone, also called Haversian porosity in that context, ranges from $2 \%$ to typically $8 \%[19,20,30,36,140]$. Under severe conditions such as bone disease like osteoporosis, overtraining, or drug treatment, it may increase up to $20 \%$ [140]. In trabecular bone, the vascular porosity ranges from 30 to $90 \%$ [27]. On the other hand, the much smaller lacunar and canalicular porosities lie within a much narrower range of values; in recent years, they were quantified by microcomputed tomography. In this context, [137, 138] reported 1.3 and $0.7 \%$ lacunar and canalicular porosity values, respectively. These values are close to those reported by Palacio-Mancheno [113], Tommasini et al. [144], and Hesse et al. [70]. Considering $3 \%$ vascular porosity as relevant for mammalian bone of medium-to-large-sized animals (see e.g. evaluation of microscopic images of Lees et al. [91] as reported in 
Table 6 Bone composition from dehydration-ashing experiments of Burns [25] ${ }^{\mathrm{a}}$ and Hammett $[57]^{\mathrm{b}}$

\begin{tabular}{|c|c|c|c|c|}
\hline Tissue & $\mathrm{WF}_{\mathrm{HA}}^{\mu}(-)$ & $\mathrm{WF}_{\text {org }}^{\mu}(-)$ & $\mathrm{WF}_{\mathrm{H}_{2} \mathrm{O}}^{\mu}{ }^{(-)}$ & $\rho^{\mu}\left(\mathrm{g} / \mathrm{cm}^{3}\right)$ \\
\hline $\begin{array}{l}\text { Rabbit limb } \\
\text { bones }^{\mathrm{a}}\end{array}$ & 0.267 & 0.202 & 0.392 & 1.38 \\
\hline $\begin{array}{l}\text { Rabbit limb } \\
\text { bones }^{\mathrm{a}}\end{array}$ & 0.210 & 0.194 & 0.581 & 1.25 \\
\hline Rat leg bones ${ }^{\mathrm{a}}$ & 0.389 & 0.231 & 0.313 & 1.54 \\
\hline Rat leg bones ${ }^{\mathrm{a}}$ & 0.345 & 0.224 & 0.375 & 1.46 \\
\hline Rat leg bones $^{\mathrm{a}}$ & 0.398 & 0.232 & 0.318 & 1.54 \\
\hline Rat leg bones ${ }^{\mathrm{a}}$ & 0.378 & 0.218 & 0.334 & 1.52 \\
\hline Rat leg bones ${ }^{\mathrm{a}}$ & 0.376 & 0.230 & 0.344 & 1.51 \\
\hline Humerus of rat ${ }^{\mathrm{b}}$ & 0.171 & 0.180 & 0.650 & 1.20 \\
\hline Humerus of rat ${ }^{\mathrm{b}}$ & 0.176 & 0.191 & 0.633 & 1.21 \\
\hline Humerus of rat ${ }^{\mathrm{b}}$ & 0.235 & 0.199 & 0.567 & 1.27 \\
\hline Humerus of rat ${ }^{\mathrm{b}}$ & 0.315 & 0.210 & 0.475 & 1.37 \\
\hline Humerus of rat ${ }^{\mathrm{b}}$ & 0.337 & 0.208 & 0.456 & 1.40 \\
\hline Humerus of rat ${ }^{\mathrm{b}}$ & 0.378 & 0.215 & 0.407 & 1.46 \\
\hline Humerus of rat ${ }^{\mathrm{b}}$ & 0.434 & 0.222 & 0.344 & 1.55 \\
\hline Humerus of rat ${ }^{\mathrm{b}}$ & 0.175 & 0.194 & 0.631 & 1.21 \\
\hline Humerus of rat ${ }^{\mathrm{b}}$ & 0.180 & 0.193 & 0.627 & 1.21 \\
\hline Humerus of rat ${ }^{\mathrm{b}}$ & 0.264 & 0.205 & 0.532 & 1.31 \\
\hline Humerus of rat ${ }^{b}$ & 0.315 & 0.209 & 0.476 & 1.37 \\
\hline Humerus of rat ${ }^{\mathrm{b}}$ & 0.362 & 0.209 & 0.429 & 1.44 \\
\hline Humerus of rat ${ }^{b}$ & 0.420 & 0.219 & 0.361 & 1.53 \\
\hline Humerus of rat ${ }^{\mathrm{b}}$ & 0.451 & 0.229 & 0.320 & 1.58 \\
\hline Femur of rat ${ }^{b}$ & 0.133 & 0.182 & 0.685 & 1.17 \\
\hline Femur of rat ${ }^{b}$ & 0.144 & 0.191 & 0.665 & 1.18 \\
\hline Femur of rat ${ }^{b}$ & 0.201 & 0.204 & 0.595 & 1.24 \\
\hline Femur of rat ${ }^{b}$ & 0.283 & 0.217 & 0.500 & 1.34 \\
\hline Femur of rat ${ }^{b}$ & 0.315 & 0.210 & 0.475 & 1.37 \\
\hline Femur of rat ${ }^{b}$ & 0.356 & 0.217 & 0.427 & 1.43 \\
\hline Femur of rat ${ }^{b}$ & 0.413 & 0.230 & 0.357 & 1.52 \\
\hline Femur of rat ${ }^{b}$ & 0.143 & 0.197 & 0.660 & 1.18 \\
\hline Femur of rat ${ }^{\mathrm{b}}$ & 0.150 & 0.195 & 0.655 & 1.19 \\
\hline Femur of rat ${ }^{\mathrm{b}}$ & 0.235 & 0.208 & 0.557 & 1.28 \\
\hline Femur of rat ${ }^{b}$ & 0.288 & 0.213 & 0.499 & 1.34 \\
\hline Femur of rat ${ }^{b}$ & 0.338 & 0.214 & 0.448 & 1.41 \\
\hline Femur of rat ${ }^{\mathrm{b}}$ & 0.401 & 0.222 & 0.377 & 1.50 \\
\hline Femur of rat ${ }^{\mathrm{b}}$ & 0.430 & 0.235 & 0.336 & 1.55 \\
\hline
\end{tabular}


Fritsch and Hellmich [46]), we account for $5 \%$ microporosity $f_{\mu \text { por }}$ when assessing the extracellular (ultrastructural) characteristics of the bones tested by Biltz and Pellegrino [13], Burns [25], Gong et al. [51], Hammet [57], Lees [87], Lees et al. [91]. Accordingly, the extracellular mass density reads as

$$
\rho^{\text {excel }}=\frac{\rho^{\mu}-\rho_{\mathrm{H}_{2} \mathrm{O}} \times f_{\mu \mathrm{por}}}{1-f_{\mu \mathrm{por}}},
$$

and the weight fraction of water-filled micropores (i.e. vascular, lacunar, and canalicular pores) in (wet) bone specimens reads as

$$
\mathrm{WF}_{\mu \mathrm{por}}^{\mu}=\frac{\rho_{\mathrm{H}_{2} \mathrm{O}} \times f_{\mu \mathrm{por}}}{\rho^{\mu}} .
$$

$\mathrm{WF}_{\mu \text { por }}^{\mu}$ allows for scale transition from the macroscopic (microstructural) to the extracellular (ultrastructural) scale,

$$
\begin{gathered}
\mathrm{WF}_{\mathrm{HA}}^{\text {excel }}=\frac{\mathrm{WF}_{\mathrm{HA}}^{\mu}}{1-\mathrm{WF}_{\mu \mathrm{por}}^{\mu},} \\
\mathrm{WF}_{\mathrm{org}}^{\text {excel }}=\frac{\mathrm{WF}_{\mathrm{org}}^{\mu}}{1-\mathrm{WF}_{\mu \mathrm{por}}^{\mu}}, \\
\mathrm{WF}_{\mathrm{H}_{2} \mathrm{O}}^{\text {excel }}=1-\mathrm{WF}_{\mathrm{HA}}^{\text {excel }}-\mathrm{WF}_{\mathrm{org}}^{\text {excel }} .
\end{gathered}
$$

From Eqs. (5), (11)-(13), one can determine the apparent mass densities of organics, water, and hydroxyapatite through

$$
\rho_{\mathrm{i}}^{\text {excel }}=\mathrm{WF}_{\mathrm{i}}^{\text {excel }} \rho^{\text {excel }}, \quad i=\text { org, } \mathrm{HA}, \mathrm{H}_{2} \mathrm{O} .
$$

The microporosity is negligible in size as regards the mineralized turkey leg tendon [34] and otic bones [159]. Thus, weight fractions and mass densities are not to be differentiated between the microstructural and the ultrastructural scale, as concerns the tissue samples of Lees and Page [90] and Lees et al. [96].

\section{"Universal" Rules in Bone Fibrillogenesis and Mineralization}

Applying the presented evaluation procedures to the collected experimental data, see Tables 1, 2, 3, 4, 5 and 6, results in a remarkable finding concerning the apparent mass densities of hydroxyapatite mineral, organic, and water; i.e. the masses of these constituents found in a millimeter-sized sample divided by the volume of the extracellular portion within this millimeter-sized sample; across a great variety of species, organs, and ages. The aforementioned apparent mass densities (or concentrations) strongly correlate with each other, see Fig. 2, as well as with the bone tissue mass density, see Fig. 3. Interestingly, all these correlations can be represented by bilinear functions, whereby the increasing branch depicted in Fig. 2a relates to tissues taken 
from growing organisms (being in the states of childhood and adolescence), while the descending branch relates to tissues taken from adult organisms. The apparent mass densities can be translated into volume fractions through

$$
f_{\mathrm{i}}^{\text {excel }}=\frac{\rho_{\mathrm{i}}^{\text {excel }}}{\rho_{\mathrm{i}}}, \quad i=\text { org, } \mathrm{HA}, \mathrm{H}_{2} \mathrm{O} .
$$

so that the constituents' volume fractions can be expressed by the following regression functions depending on the extracellular mass density,

$$
\text { if } \rho^{\text {excel }} \leq 1.978 \mathrm{~g} / \mathrm{cm}^{3} \quad\left\{\begin{array}{l}
f_{\mathrm{HA}}^{\text {excel }}=\frac{1}{\rho_{\mathrm{HA}}}\left(1.3275 \rho^{\text {excel }}-1.3938\right), \\
f_{\mathrm{org}}^{\text {excel }}=\frac{1}{\rho_{\text {org }}}\left(0.3888 \rho^{\text {excel }}-0.2393\right), \\
f_{\mathrm{H}_{2} \mathrm{O}}^{\text {excel }}=1-f_{\mathrm{HA}}^{\text {excel }}-f_{\mathrm{org}}^{\text {excel }}
\end{array}\right.
$$

relating to growing organisms, and

$$
\text { if } \rho^{\text {excel }} \geq 1.978 \mathrm{~g} / \mathrm{cm}^{3} \quad\left\{\begin{array}{l}
f_{\mathrm{HA}}^{\text {excel }}=\frac{1}{\rho_{\mathrm{HA}}}\left(1.7298 \rho^{\text {excel }}-2.1895\right), \\
f_{\mathrm{org}}^{\text {excel }}=\frac{1}{\rho_{\text {org }}}\left(-0.5180 \rho^{\text {excel }}+1.5541\right), \\
f_{\mathrm{H}_{2} \mathrm{O}}^{\text {excel }}=1-f_{\mathrm{HA}}^{\text {excel }}-f_{\mathrm{org}}^{\text {excel }},
\end{array}\right.
$$

relating to aging organisms. As $90 \%$ of the organic matter in bone is collagen [146], the extracellular volume fraction of collagen follows as

$$
f_{\text {col }}^{\text {excel }}=0.9 \times f_{\text {org }}^{\text {excel }} \text {. }
$$

\section{Cell Biology Aspects}

It is interesting to discuss the mineral-versus-organics concentration relation of Fig. 2 a from the viewpoint of cell biology: during growth, the mineral-to-organic mass apposition ratio in extracellular bone tissue is a constant, $\mathrm{d} \rho_{\mathrm{HA}}^{\text {excel }} / \mathrm{d} \rho_{\mathrm{org}}^{\text {excel }}=3.4$, universally valid throughout different tissues of different growing species at different ages. This constant reflects the working mode of osteoblasts (cuboidal or polygonal bone cells with several tens of micrometers characteristic length $[1,17,74,111,115$, 129, 158]. Pre-osteoblasts [41, 97, 115] deposit new osteoid, in the form of seams of some 8 to $10 \mu \mathrm{m}$ thickness, made of proteoglycan gel reinforced by fairly randomly oriented collagen fibrils [26, 41, 155], see Fig. 4a. Thereafter, osteoblasts order the collagen fibrils through stretching [41], and mediate, through budding of matrix vesicles from cell processes [3], the precipitation of hydroxyapatite, see Fig. 4b. This results in the so-called primary mineralization [115], with a characteristic time of hours to days [152]. From a chemical viewpoint, specially synthesized matrix molecules, such as bone sialoprotein, osteopontin, or osteocalcin [153], induce mineral formation, and such non-collagenous organic molecules typically make up $10 \%$ of the overall organic volume fraction [24, 86, 146], regardless of the magnitude of the latter. Accordingly, one would expect the more mineral precipitation, the more 
(a)

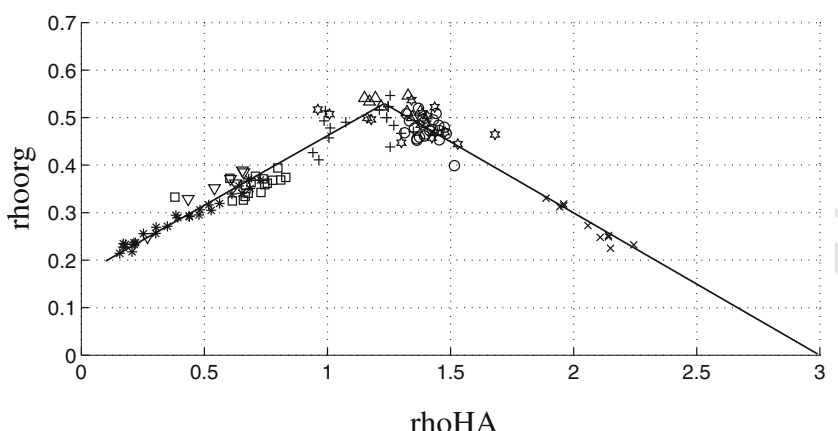

(b)

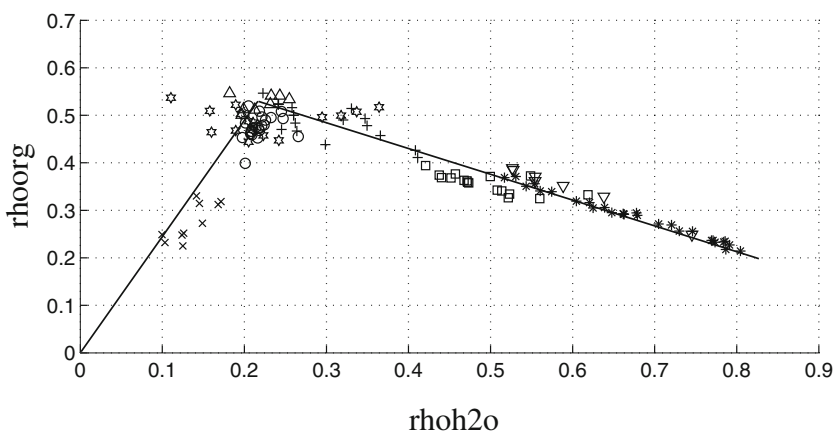

(c)

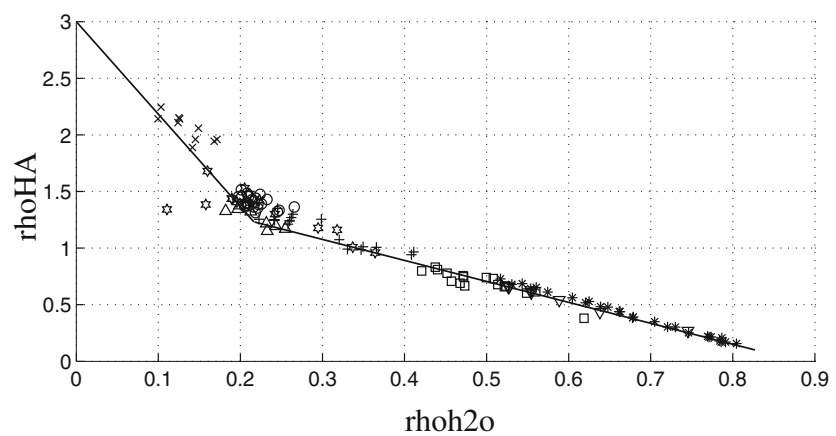
bovine
+ whale
* turkey
$\triangle$ gong
$\square$ vertebrae
$\nabla$ burns
is horse
$\times$ rat

Fig. 2 Relations between apparent mass densities in extracellular bone matrix in the line of Vuong and Hellmich [147]: a hydroxyapatite versus organic matter, b water versus organic matter, and c water versus hydroxyapatite; across different species, organs, and ages 

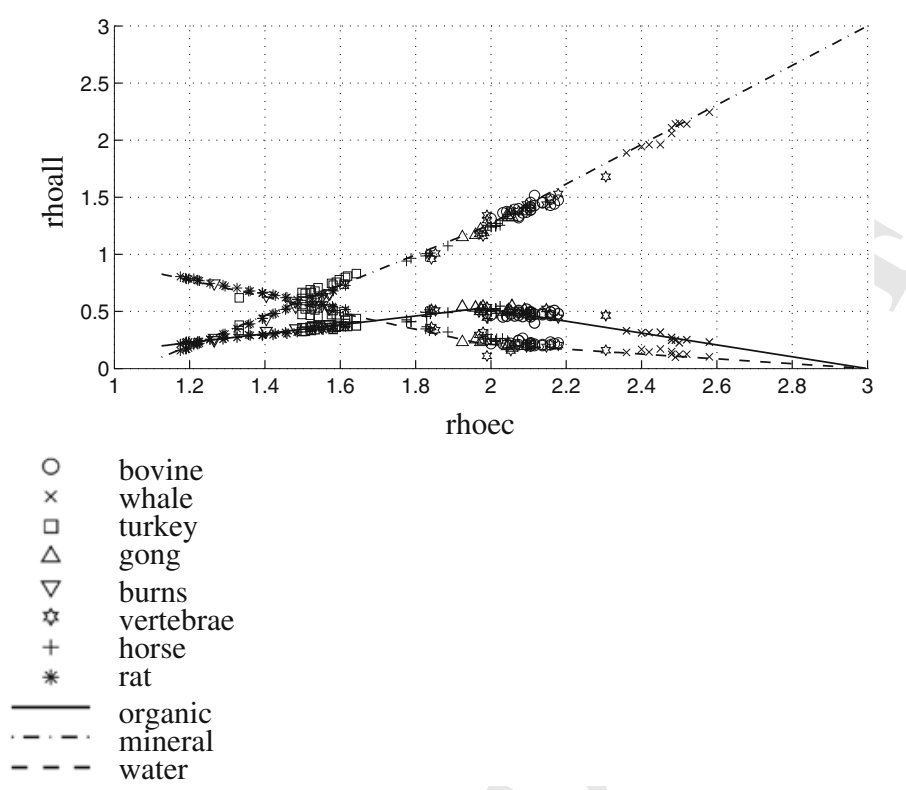

Fig. 3 Apparent mass densities of water, hydroxyapatite, and organic matter, versus overall mass density of extracellular bone matrix, $\rho^{\text {excel }}$, across different species, organs, and ages

non-collagenous organics present, the amount of the latter being proportional to that of the overall organic matter. This is perfectly consistent with the aforementioned tissue- and species-independent, "universal" mineral-per-organics apposition ratio of 3.4 , suggesting primary mineralization as the dominant mineralization mechanism in growing organisms.

In such organisms, the mineral is hindered from further precipitation in the highly ionic fluids, through the action of the most abundant biological bone cells, namely the osteocytes $[1,10,11,18,111,115,143]$, residing in the lacunar porosity of extravascular bone matrix. Originating from osteoblasts which were buried in the course of ongoing osteoid formation and mineralization, osteocytes maintain a widely spread network, through channels called canaliculi, among themselves and with the osteoblasts located at the bone tissue surface. This network is thought to effectively transfer mechanical stimuli related to tissue deformation, to the osteoblasts $[17,32]$, so as to trigger their bone formation activity, as described before. In addition to mechanosensing, osteocytes may inhibit mineralization around their lacunae [18], and therefore set an upper limit to the asymptotic mineral concentration which may be attained during the process called secondary mineralization. This process exhibits a characteristic time of weeks to months [9], see Fig. 4c, and before reaching its asymptote, secondary mineralization is not controlled by the local biological cells, but by the diffusion and composition properties of the fluids saturating the extracellular bone tissue [115]. However, at higher ages, the aforementioned inhibitive activity of osteocytes steadily decreases, so that, in the end, even the lacunae themselves 
(a)

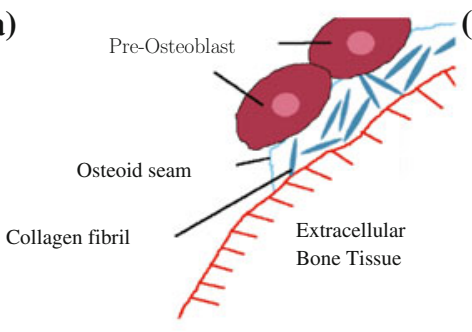

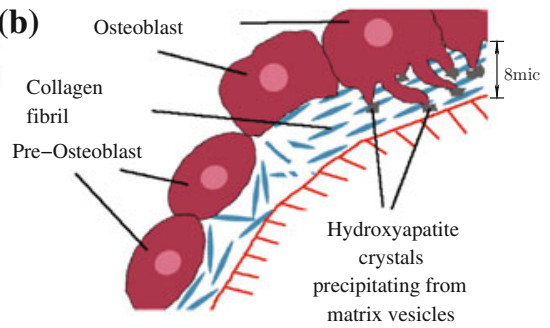

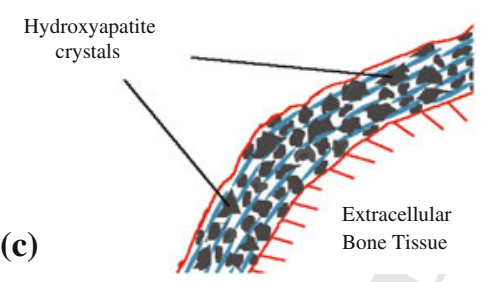

Fig. 4 Working mode of pre-osteoblasts and osteoblasts: primary and secondary mineralization of an unmineralized osteoid; a pre-osteoblasts lay down an osteoid seam, reinforced by randomly oriented collagen fibrils; $\mathbf{b}$ primary mineralization: osteoblasts order the collagen fibrils through celldriven stretch, and mediate, through budding of matrix vesicles from cell processes, the precipitation of hydroxyapatite; $\mathbf{c}$ secondary mineralization: crystals grow without control of local biological cells

may be filled with mineral, as evidenced by [11, 49, 75]. As a consequence, the organic-to-mineral concentration ratio decreases and the mineral-to-organic mass apposition ratio is not equal to 3.4 anymore. At the same time, osteoblastic activity also decreases at more advanced ages [1], leading to a reduction of the (absolute) organic concentration in extracellular bone matrix. This combined effect of both osteoblastic and osteocytic activity reduction is expressed by a (negative) mineralgrowth-to-organic-removal ratio, see Fig. 2a, which reveals secondary mineralization as the dominant mineralization mechanism in adult, aging organisms.

We also remark that the results presented here refer to physiologically normal conditions, while drug treatments may lead to considerable deviations from these rules for fibrillogenesis and mineralization, see [147] for further details.

\section{Mineral Distribution in Extracellular Bone Matrix}

At the ultrastructural observation scale $(1-10 \mu \mathrm{m})$ of fully mineralized tissues, transmission electron micrographs (TEM) reveal that hydroxyapatite is situated both within and outside of the collagen fibrils, and that the majority of hydroxyapatite lies outside the fibrils $[2,101,121,122,139,159]$. The question arises whether the distribution of mineral between the fibrillar and extrafibrillar spaces follows a general rule. And indeed, Hellmich and Ulm [63] found out that the average mineral con- 


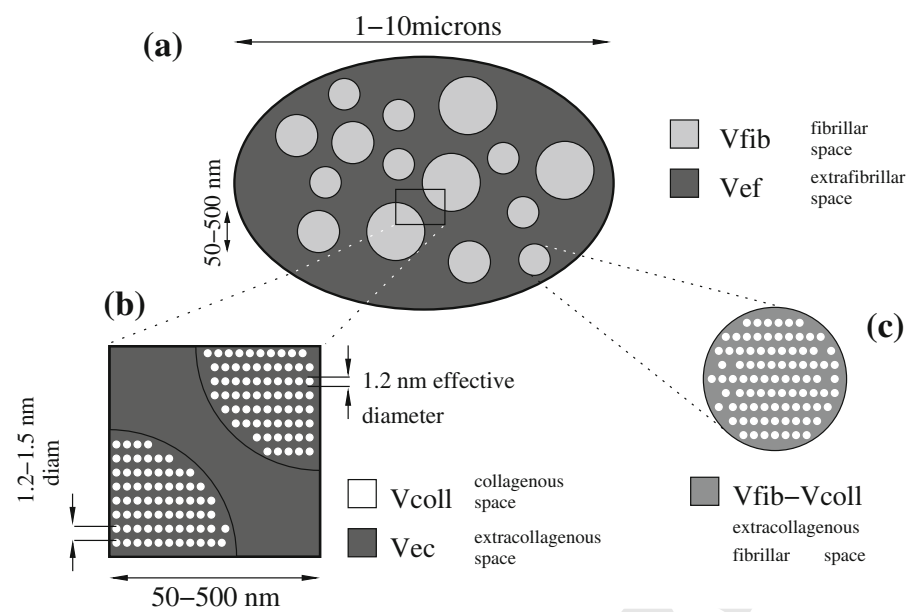

Fig. 5 Schematical sketch of spaces in the extracellular bone matrix or ultrastructure, a section through the ultrastructural representative volume element perpendicular to the direction of the fibrils, b and $\mathbf{c}$ close-ups

centration in the extrafibrillar space equals that in the extracollageneous space. The underlined arguments are as follows: The ultrastructural volume element with a characteristic size of some micrometers, consists of fibrillar and extrafibrillar space; see Fig. 5a, with corresponding volumes $V_{\text {fib }}^{\text {excel }}$ and $V_{\text {exfib }}^{\text {excel }}$. The fibrils are made up by collagen molecules exhibiting a triple helix structure arranged more or less cylindrically, with diameters ranging from 50 to $500 \mathrm{~nm}[35,95,105,122,125,142,150,151]$. The fibrillar volume $V_{\text {fib }}^{\text {excel }}$ comprises all fibrils within the ultrastructural (or extracellular) volume $V^{\text {excel }} . V_{\mathrm{col}}^{\mathrm{fib}}$, the volume of collagen within the fibrils, is a subspace of $V_{\mathrm{fib}}^{\text {excel }}$, as is $\left(V_{\mathrm{fib}}^{\text {excel }}-V_{\mathrm{col}}^{\mathrm{fib}}\right)$. The latter is the volume within the fibrils which is not occupied by collagen molecules, subsequently referred to as extracollagenous fibrillar volume, $V_{\mathrm{excol}}^{\mathrm{fib}}$. The space within the ultrastructure (or extracellular bone matrix) that is not occupied by fibrils is called extrafibrillar space, $V_{\text {exfib }}^{\text {excel }}=V^{\text {excel }}-V_{\text {fib }}^{\text {excel }}$. The union of the spaces $V_{\text {exfib }}^{\text {excel }}$ and $V_{\text {excol }}^{\text {fib }}, V_{\text {exfib }}^{\text {excel }}+V_{\text {excol }}^{\text {fib }}=V^{\text {excel }}-V_{\text {col }}^{\text {excel }}=V_{\text {excol }}^{\text {excel }}$, is the total extracollagenous space within the extracellular bone.

Based on these notions, the aforementioned rule would imply that the ratio of the mass of the extrafibrillarly located mineral $\left(M_{\mathrm{HA}}^{\text {exfib }}\right)$, over the volume of the extrafibrillar space needs to be equal to the ratio of the entire mineral mass $\left(M_{\mathrm{HA}}\right)$, over the extracollageneous volume

$$
\rho_{\mathrm{HA}}^{\text {exfib }}=\frac{M_{\mathrm{HA}}^{\text {exfib }}}{V_{\text {exfib }}^{\text {excel }}} \equiv \frac{M_{\mathrm{HA}}}{V_{\text {excol }}^{\text {excel }}}=\rho_{\mathrm{HA}}^{\text {excol }},
$$

with $\rho_{\mathrm{HA}}^{\text {exfib }}$ and $\rho_{\mathrm{HA}}^{\text {excol }}$ being the apparent mineral densities relating to the extrafibrillar and the extracollagenous volumes, respectively. Equation (19) can be rearranged as follows 


$$
\phi_{\mathrm{HA}}^{\text {exfib }}=\frac{M_{\mathrm{HA}}^{\text {exfib }}}{M_{\mathrm{HA}}} \equiv \frac{V_{\text {exfib }}^{\text {excel }}}{V_{\text {excol }}^{\text {excel }}}=\frac{f_{\text {exfib }}^{\text {excel }}}{1-f_{\text {col }}^{\text {excel }}},
$$

where $f_{\text {exfib }}^{\text {excel }}=V_{\text {exfib }}^{\text {excel }} / V^{\text {excel }}$ is the extrafibrillar volume fraction, $f_{\text {col }}^{\text {excel }}=V_{\text {col }}^{\text {excel }} /$ $V^{\text {excel }}$ is the collagen volume fraction, both quantified within the volume of extracellular bone, and $\phi_{\mathrm{HA}}^{\mathrm{exfib}}$ is the relative amount of extrafibrillar mineral.

Two independent sets of experimental observations covering a large range of tissue mass densities were considered for checking the relevance of Eq. (20), as discussed next.

\section{Experimental Set I: Mass and Volume Measurements}

First, $f_{\text {exfib }}^{\text {excel }} /\left(1-f_{\text {col }}^{\text {excel }}\right)$ is determined from weighing experiments and diffraction spacing measurements. In order to determine the apparent mass density of collagen, we adopt a value of $\rho_{\text {org }}=1.42 \mathrm{~g} / \mathrm{cm}^{3}[76,86]$, and consider the fact that collagen constitutes approximately $90 \%$ by weight of the organic matter in mineralized tissues $[13,86,146,150]$. The mass of organic matter can be determined from weighing experiments on demineralized and dehydrated specimens [13, 86, 90, 91], harvested from different anatomical locations of different vertebrates at different ages, see Sect. 2, in particular Tables 1, 2, 3 and 5. On the other hand, the determination of the extrafibrillar volume fraction $f_{\text {exfib }}^{\text {excel }}=1-f_{\text {fib }}^{\text {excel }}$ requires quantification of the fibrillar space within the mineralized tissue. This can be achieved by application of a model for the organization of collagen: we use Lees' generalized packing model $[16,86]$, as the simplest model to quantify the average crosslink length between collagen molecules, see also [63].

\section{Experimental Set II: Transmission Electron Microscopy}

As a second, independent set of observations, we consider optical density measurements from TEMs, in order to determine $\phi_{\mathrm{HA}}^{\text {exfib }}$. Figure 6 displays three TEMs of cross sections of mineralized tissues, covering a wide range of extracellular mass densities; from $\rho^{\text {excel }}=1.5 \mathrm{~g} / \mathrm{cm}^{3}$ for mineralized turkey leg tendon, see Fig. 6a, to $\rho^{\text {excel }}=2.6 \mathrm{~g} / \mathrm{cm}^{3}$ for the rostrum of whale, see Fig. 6c. These micrographs reflect the electron density of material phases. The higher the electron density, the darker the respective area of the TEM images. Since hydroxyapatite exhibits by far the largest electron density of all elementary components, the TEM images displayed in Fig. 6 highlight that hydroxyapatite is mainly located outside the fibrils. First, the relative optical density is determined using the protocol of Lees et al. [95]: the TEM images are scanned and then captured by a frame grabber [22]. The optical density is considered to be linearly proportional to the number of electrons transmitted through the particular area [95], the number of electrons to be linearly proportional to the local hydroxyapatite mass density in the fibrillar or extrafibrillar space. The average densities are then related to the apparent mineral densities, allowing for the determination of the extrafibrillar volume fraction of tissues, $f_{\text {exfib }}^{\text {excel }}$, shown in TEM images. $f_{\text {exfib }}^{\text {excel }}$ turns out to be $60 \%$ for the mineralized turkey leg tendon micrograph of Fig. 6a $\left(\rho^{\text {excel }}=1.5 \mathrm{~g} / \mathrm{cm}^{3}\right), 53 \%$ for the human tibia $\left(\rho^{\text {excel }}=2.0 \mathrm{~g} / \mathrm{cm}^{3}\right)$, see Fig. $6 \mathrm{~b}$, and $85 \%$ for the whale rostrum $\left(\rho^{\text {excel }}=2.6 \mathrm{~g} / \mathrm{cm}^{3}\right)$, see Fig. $6 \mathrm{c}$. 
(a)

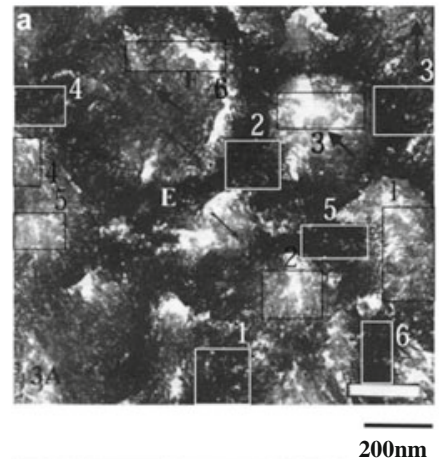

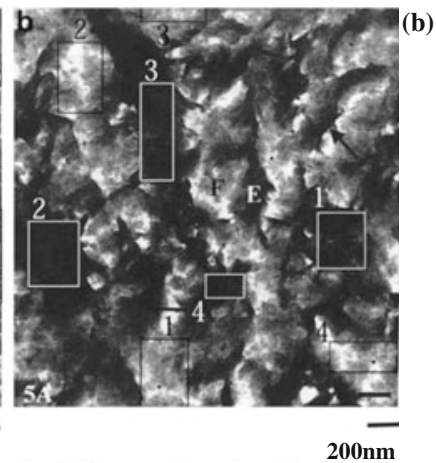

(c)

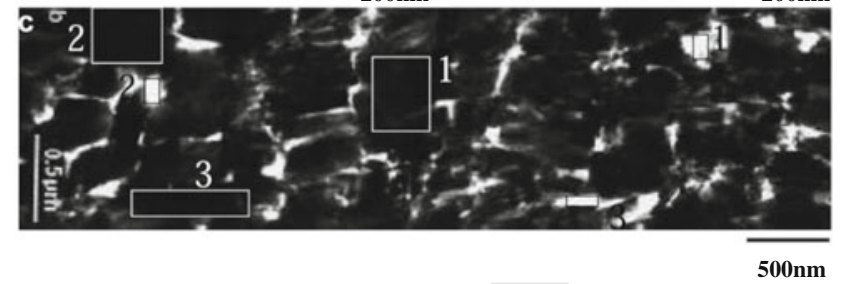

Fig. 6 Transmission electron micrographs of cross sections through: a mineralized turkey leg tendon [122]; b human tibia [122] and $\mathbf{c}$ whale rostrum [159]

\section{Comparison of Independently Derived Values of the Relative Amount of Extrafib- rillar Mineral}

Next, the sample-specific relative amount of extrafibrillar mineral, $\phi_{\mathrm{HA}}^{\text {exfib }}$, of very different bone tissues, derived from the independent methods related to the experiment sets I and II, respectively, are compared, as shown in Fig. 7. It can be seen that the values derived from both experimental data sets are in perfect agreement when comparing similar tissues. This surprisingly good agreement of values obtained from two independent assessment methods provides the sought after evidence that the average mineral concentration in the extrafibrillar and the extracollageneous spaces are indeed equal; see Hellmich and Ulm [63] for further details.

\section{Hydration-Dependent Evolution of Unmineralized Collagenous Tissues}

Hydration of collagenous tissues, consisting of fibrillar and extrafibrillar constituents, causes swelling, as well as mechanical softening (i.e. reduction of stiffness). The underlying mechanism can be quantified in terms of the following mathematical rule [109]: After drying the tissue in air, water remains only in the gap zones between the triple-helical collagen molecules making up $12 \%$ of the total volume [88]. Upon rehydration, the extrafibrillar space is established at volumes directly proportional to 


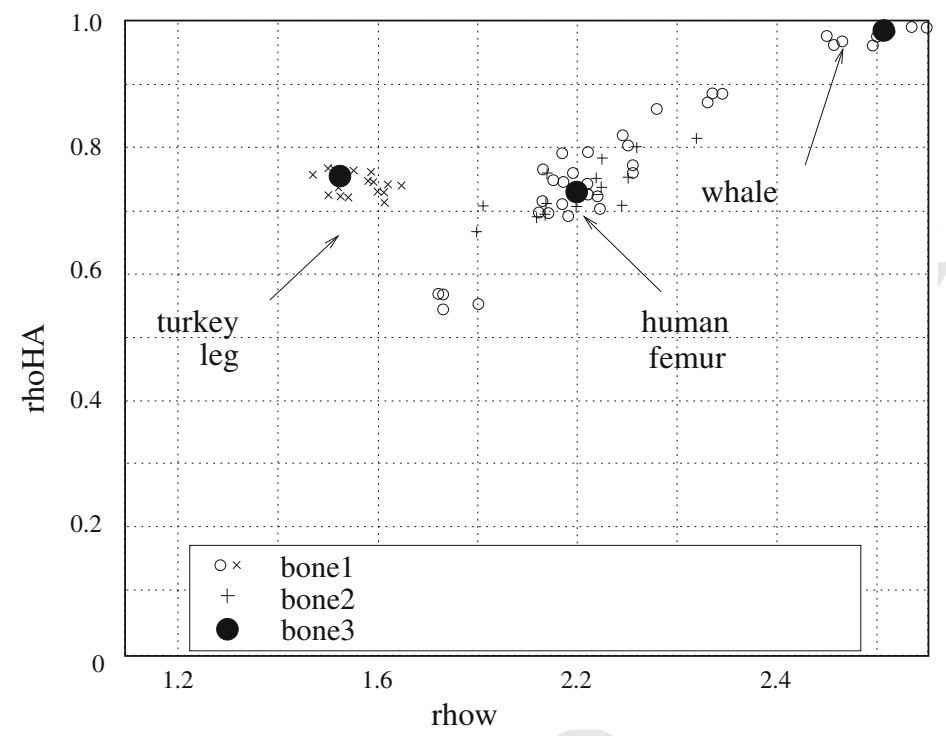

Fig. 7 Relative amount of extrafibrillar mineral, $\phi_{\mathrm{HA}}^{\text {exfib }}$, as a function of extracellular mass density $\rho^{\text {excel }}$, according to Hellmich and Ulm [63]

(a)

(b)

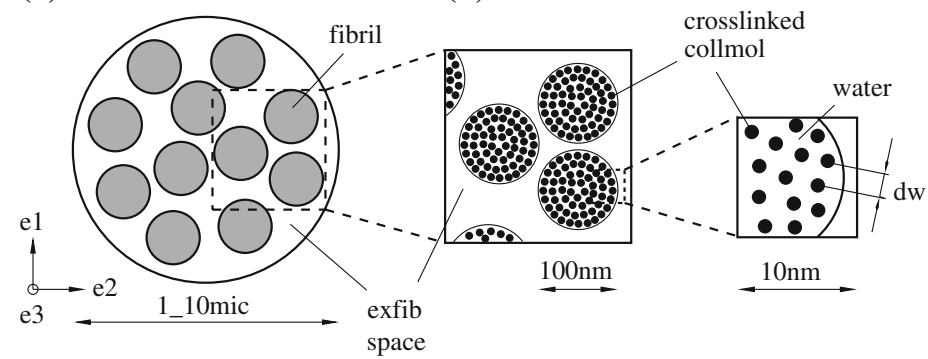

Fig. 8 Scheme concerning hierarchical structure of collagen: a collagenous tissue, $\mathbf{b}$ wet collagen

the hydration-induced swelling of the (micro) fibrils, until the maximum equatorial distance between the long collagen molecules is reached. Thereafter, the volume of the fibrils stays constant, and only the extrafibrillar volume continues to grow. Mathematically, the proportionality between the extrafibrillar space growth and the swelling of fibrils (given that the fibrils still swell, which occurs if they are not fully hydrated) can be expressed as follows

$$
V_{\text {exfib }}^{\text {excel }}=\beta\left(V_{\text {fib }}^{\text {excel }}-V_{\text {dry }}^{\text {col }}\right), \quad V_{\text {dry }}^{\text {col }} \leq V_{\text {fib }}^{\text {excel }} \leq V_{\text {fib,max }}^{\text {excel }},
$$


with $\beta$ as proportionality constant, with $V_{\text {exfib }}^{\text {excel }}$ as the volume of extrafibrillar space within the collageneous tissue, $V_{\text {fib }}^{\text {excel }}$ as fibrillar volume within the collageneous tissue, which is smaller than or equal to the maximum attainable value $V_{\mathrm{fib}, \max }^{\text {excl }}$, and larger than a minimum value $V_{\mathrm{dry}}^{\text {col }}$ corresponding to the dry volume of the collageneous tissue, $V^{\text {excel }}$. The fibrillar and extrafibrillar volumes, $V_{\text {fib }}^{\text {excel }}$ and $V_{\text {exfib }}^{\text {excel }}$, fill the entire tissue volume $V^{\text {excel }}, V_{\mathrm{fib}}^{\text {excel }}+V_{\text {exfib }}^{\text {excel }}=V^{\text {excel }}$, yielding together with (21) a tissue swelling rule in the following form

$$
\frac{V^{\text {excel }}}{V_{\text {dry }}^{\text {col }}}=\beta\left(\frac{V_{\text {fib }}^{\text {excel }}}{V_{\text {dry }}^{\text {col }}}-1\right)+\frac{V_{\text {fib }}^{\text {excel }}}{V_{\text {dry }}^{\text {col }}}, \quad V_{\text {dry }}^{\text {col }} \leq V_{\text {fib }}^{\text {excel }} \leq V_{\text {fib,max }}^{\text {excel }} .
$$

We regard the fibrils as continua with one to several hundreds of nanometers characteristic size, these continua being built up by representative volume elements of several to several tens of nanometers characteristic size, see Fig. 8. Microscopic images [28] show that hydration affects volume changes in a fibril in a homogeneous fashion. Therefore, following the deformation laws of continuum mechanics [131], the current fibrillar volume $V_{\text {fib }}^{\text {excel }}$ is related to the initial volume $V_{\text {dry }}^{\text {col }}$ by the Jacobian $J$, which is standardly expressed by the product of the principal stretches $\lambda_{1}, \lambda_{2}$, and $\lambda_{3}$ of the volume elements, thus

$$
\frac{V_{\text {fib }}^{\text {excel }}}{V_{\text {dry }}^{\text {col }}}=J=\lambda_{1} \cdot \lambda_{2} \cdot \lambda_{3} \text {. }
$$

The principal stretches are defined as the ratio of the current length to the initial length of the line elements $\mathrm{d} \mathbf{x}_{1}, \mathrm{~d} \mathbf{x}_{2}$, and $\mathrm{d} \mathbf{x}_{3}$ attached in the principal deformation directions to the elementary volume elements (see Fig. 8 for the orientations of principal line elements attached to the fibrils) and are related to the ratios of diffraction spacings in the current and initial elementary volumes, in the line of standard stretch measurements in lattice-like microstructures [148, 149]. As regards $\lambda_{1}$ and $\lambda_{2}$, these diffraction spacings are related to the (on-average) lateral (transversal, equatorial) distances between collagen molecules,

$$
\lambda_{1}=\lambda_{2}=\lambda_{\mathrm{tr}}=\frac{d_{\mathrm{w}}}{d_{\mathrm{dry}}},
$$

with $d_{\mathrm{w}}$ as the lateral diffraction spacing related to some more or less hydrated state of the fibril, and $d_{\mathrm{dry}}=1.09 \mathrm{~nm}$ as the lateral diffraction spacing in dry tissues [93]. As regards $\lambda_{3}$, diffraction peaks relate to the axial macroperiod $D_{\mathrm{w}}$ of collagen, comprising repeating units of one gap zone and one overlap zone each, as discovered by Hodge and Petruska [72]; this axial macroperiod increases, albeit only slightly, upon hydration (up to a value of $67 \mathrm{~nm}$ ). Since this increase is clearly less than 5\% when compared to the axial macroperiod, $D_{\text {dry }}=64 \mathrm{~nm}$, measured in dry tissues, we consider $D_{\mathrm{w}}$ as a constant, and hence 


$$
\lambda_{3}=\lambda_{\mathrm{ax}}=\frac{D_{\mathrm{w}}}{D_{\mathrm{dry}}}=1
$$

Finally, the variation of the current fibrillar volume with respect to the initial one reads as

$$
\frac{V_{\text {fib }}^{\text {excel }}}{V_{\text {dry }}^{\text {col }}}=\lambda_{1} \cdot \lambda_{2} \cdot \lambda_{3}=\left(\frac{d_{\mathrm{w}}}{d_{\text {dry }}}\right)^{2} .
$$

However, the diffraction spacings are limited, and cannot exceed a maximum value of $1.38 \mathrm{~nm}$ in the equatorial direction [102]. Therefore, the amount of water which can be accommodated in the fibrils is also limited. Upon further hydration, namely beyond the so-called fibrillar saturation limit, only the extrafibrillar volume continues to grow. The mathematically expressed swelling rule (21), together with volume relations (22) to (26), was experimentally validated by means of the measurement results of Meek et al. [102], Robinson [128], Rougvie and Bear [130]. Therefore, the water-to-organic ratios $\mathscr{R}$ given in these papers, were converted into volumes according to

$$
\frac{V^{\text {excel }}}{V_{\text {dry }}^{\text {col }}}=0.88 \frac{\mathscr{R} \rho_{\text {col }}+\rho_{\mathrm{H}_{2} \mathrm{O}}}{\rho_{\mathrm{H}_{2} \mathrm{O}}},
$$

where $\rho_{\text {col }}=1.42 \mathrm{~g} / \mathrm{cm}^{3}[88]$ and $\rho_{\mathrm{H}_{2} \mathrm{O}}=1 \mathrm{~g} / \mathrm{cm}^{3}$ are the mass densities of molecular collagen and water, respectively; obviously, this equation accounts for the existence of $12 \%$ gap zones in the collagenous dry matrix [72,88], relating to an intermolecular pore saturation limit amounting to $\mathscr{R}^{\text {imsat }}=0.096$. Based on relations (22) and (27), combined with the observations of Meek et al. [102], that the fibrillar swelling stops at a water-to-organic mass ratio of $\mathscr{R}^{\text {fibsat }}=0.82$, one can translate the swelling rule (22) into a mathematical relation between water-to-organic mass ratios and corresponding diffraction spacings,

$$
\mathscr{R}^{\text {pred }}=\frac{1}{\rho_{\text {col }}}\left(\frac{\rho_{\mathrm{H}_{2} \mathrm{O}}}{0.88}\left[(\beta+1)\left(\frac{d_{\mathrm{w}}}{d_{\mathrm{dry}}}\right)^{2}-\beta\right]-\rho_{\mathrm{H}_{2} \mathrm{O}}\right) .
$$

It is directly tested against respective experimental values provided by $\mathrm{Katz}$ and $\mathrm{Li}$ [76], Meek et al. [102], Rougvie and Bear [130], see Fig. 9, with a relative error as low as $0.98 \pm 12.56 \%$ (mean value plus standard deviation), see [109] for further details. Given the excellent confirmation of the swelling rule, it allows for quantifying the evolution of subvolumes and volume fractions in hydrating tissues: during hydration, the fibrillar volume fraction decreases by more than 50\%, see Fig. 10b. At the same time, the tissue is swelling to its triple size, as seen in Fig. 10a. Also during hydration, the volume fraction of molecular collagen within a fibril decreases from 88 to $54.7 \%$, while that of water increases from 0 to $45.3 \%$, see Fig. 11b. At the same time, the fibrils grow by about $60 \%$ in volume, see Fig. 11a. 


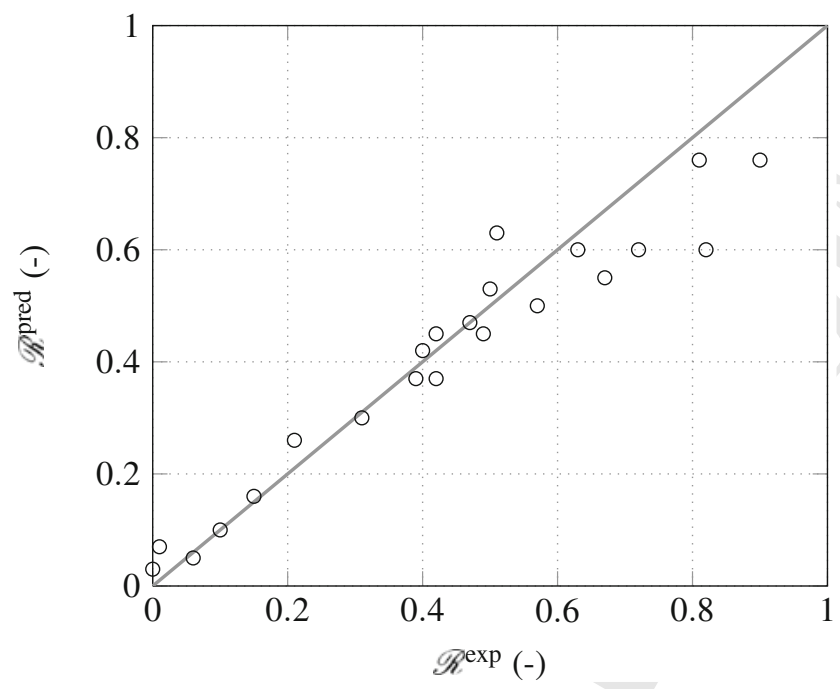

Fig. 9 Water-to-organic mass ratio: diffraction- and swelling rule-based predictions $\mathscr{R}^{\text {pred }}$ versus direct experiments $\mathscr{R}^{\exp }$

(a)

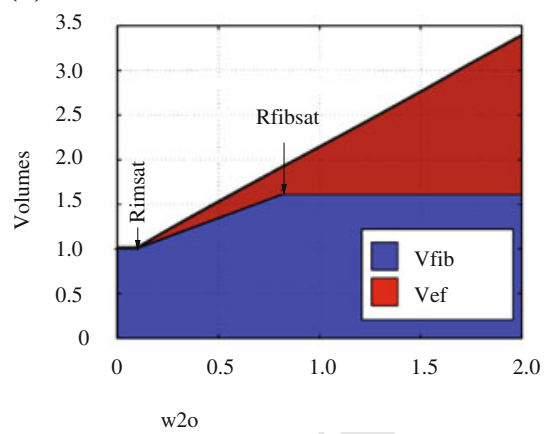

(b)

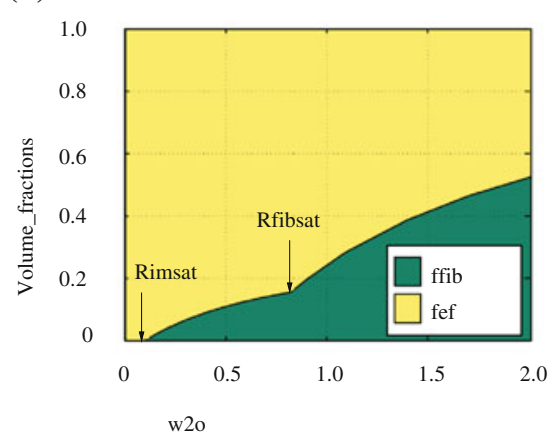

Fig. 10 Tissue swelling (a) and evolution of tissue composition (b) during hydration: a water-toorganic mass ratio $\mathscr{R}$ over the fibrillar and extrafibrillar volumes making up the tissue; $\mathbf{b}$ water-toorganic mass ratio $\mathscr{R}$ over the fibrillar and extrafibrillar volume fractions at the tissue scale

\section{Bone Tissue Evolution During Mineralization}

Inspired by an interesting idea of Lees [87], Morin and Hellmich [107] showed that the volume and structure changes in mineralizing bone tissues can be mathematically predicted when considering the extracellular bone tissue and its subvolumes (both the fibrils and the extrafibrillar space) as closed thermodynamic systems: i.e. if no fluid mass leaves or enters these volumes during the mineralization process, then the precipitation of hydroxyapatite crystals entails that the mass of lost ionic fluid 
(a)

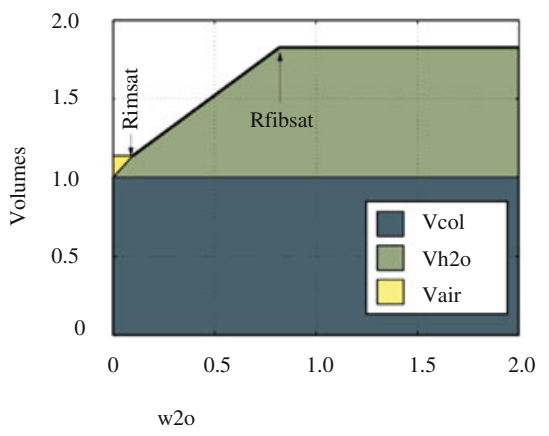

(b)

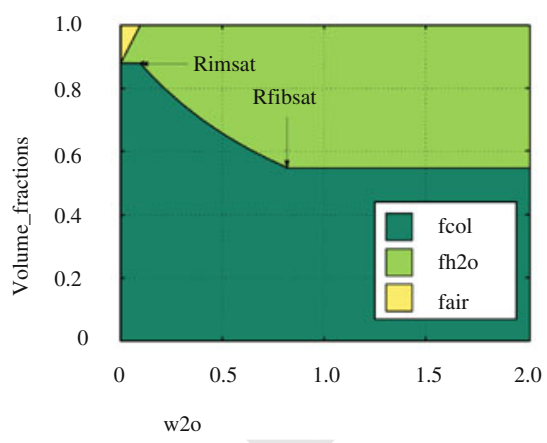

Fig. 11 Fibrillar swelling (a) and evolution of fibrillar composition (b) during hydration: a waterto-organic mass ratio $\mathscr{R}$ over the volumes of molecular collagen, water, and air making up the fibrils; b water-to-organic mass ratio $\mathscr{R}$ over the volume fractions of collagen, water, and air at the tissue scale

equals the mass of formed solid hydroxyapatite crystal in the fibrillar and extrafibrillar subvolumes, as well as in the entire tissue volume, while the collagen mass remains unaltered. The precipitation of dissolved ions into solid mineral crystals is accompanied by an increase in mass density, which, upon overall conservation under closed conditions, leads to a volume decrease (or shrinkage) of the tissues during the biomineralization process. This shrinkage affects both the fibrillar and the extrafibrillar tissue compartments. Thereby, the fibrillar shrinkage can be experimentally accessed through equatorial neutron diffraction spacings $d_{\mathrm{w}, \infty}$, measured on fully mineralized tissues [104, 109]

$$
\left(\frac{d_{\mathrm{w}, \infty}}{d_{\mathrm{w}, 0}}\right)^{2}=\frac{V_{\mathrm{fib}, \infty}^{\text {excel }}}{V_{\mathrm{fib}, 0}^{\text {excel }}},
$$

with $d_{\mathrm{w}, 0}$ as the neutron diffraction spacing at the time of osteoid deposition (i.e. the beginning of the mineralization process), and $V_{\mathrm{fib}, 0}^{\text {excel }}$ and $V_{\mathrm{fib}, \infty}^{\text {excel }}$ as the fibrillar volume in unmineralized and fully mineralized tissues, respectively.

The mass density-diffraction relation $\left(\rho_{\infty}^{\text {excel }}-d_{\mathrm{w}, \infty}\right.$-relation) is derived in three consecutive steps: First, the mineralization-induced tissue shrinkage is evaluated at the tissue level, based on the "universal" composition rules described in Sect.3, yielding [107]

$$
\frac{V_{\infty}^{\text {excel }}}{V_{0}^{\text {excel }}}=\frac{1}{1+\left(\rho_{\mathrm{HA}} / \rho_{\mathrm{fl}}-1\right) \times f_{\mathrm{HA}, \infty}^{\text {excel }}\left(\rho_{\infty}^{\text {excel }}\right)},
$$

with $V_{0}^{\text {excel }}$ and $V_{\infty}^{\text {excel }}$ as the extracellular tissue volumes at the beginning and the end of the mineralization process, $\rho_{\mathrm{HA}}$ and $\rho_{\mathrm{fl}}$ as the mass densities of hydroxyapatite 
and ionic fluid, $f_{\mathrm{HA}, \infty}^{\mathrm{excel}}$ as the mineral volume fraction in the fully mineralized tissue, which depends on the tissue mass density, $\rho_{\infty}^{\text {excel }}$.

Secondly, this relation is downscaled to the extrafibrillar space, by considering the equality of mineral concentrations in the extracollagenous and the extrafibrillar spaces [63], see Sect.4, and the hydration swelling rule for unmineralized tissues [109], as described in Sect. 5. The corresponding volume change reads as [107]

$$
\frac{V_{\text {exfib }, \infty}^{\text {excel }}}{V_{\text {exfib }, 0}^{\text {excel }}}=1+\frac{\left(1-\rho_{\mathrm{HA}} / \rho_{\mathrm{fl}}\right)}{1-f_{\mathrm{col}, 0}^{\text {excel }}} \frac{V_{\infty}^{\text {excel }}}{V_{0}^{\text {excel }}} \times f_{\mathrm{HA}, \infty}^{\text {excel }}\left(\rho_{\infty}^{\text {excel }}\right),
$$

where $V_{\infty}^{\text {excel }} / V_{0}^{\text {excel }}$ obeys Eq. (30), $f_{\mathrm{HA}, \infty}^{\text {excel }}\left(\rho_{\infty}^{\text {excel }}\right)$ follows from the universal composition rules (see Sect. 3), and $f_{\text {col, }, 0}^{\text {excl }}$ is the collagen volume fraction in unmineralized tissue, which can be quantified from the hydration-dependent swelling rules described in Sect. 5, see [109] for details.

Thirdly, the fibrillar shrinkage is analogously derived,

$$
\frac{V_{\text {fib }, \infty}^{\text {excel }}}{V_{\text {fib }, 0}^{\text {excel }}}=\frac{f_{\text {fib }, \infty}^{\text {excel }}}{f_{\text {fib }, 0}^{\text {excel }}} \frac{V_{\infty}^{\text {excel }}}{V_{0}^{\text {excel }}},
$$

where $f_{\text {fib }, \infty}^{\text {excel }}=1-f_{\text {exfib, } \infty}^{\text {excel }}$, and related to the change in diffraction spacing, as given in Eq. (29), with $d_{\mathrm{w}, 0}=d_{\max }=1.52 \mathrm{~nm}$ as the diffraction spacing of fully saturated unmineralized collageneous tissues [23, 39, 76, 93]. Finally, these relations are translated into the sought mass density-diffraction spacing relations, according to continuum geometry and considering negligible length changes in the meridional direction of the tissue [109]. In case of fully-hydrated tissues, this relation reads as

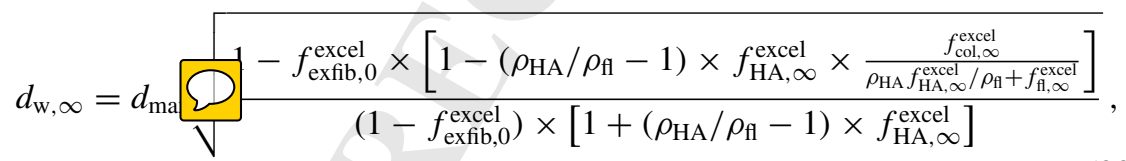

with

$$
f_{\text {exfib }, 0}^{\text {excel }}=1-\frac{1}{0.88}\left(\frac{d_{\text {max }}}{d_{\text {dry }}}\right)^{2} \frac{f_{\text {col }, \infty}^{\text {excel }}}{\rho_{\mathrm{HA}} f_{\mathrm{HA}, \infty}^{\text {excel }} / \rho_{\mathrm{fl}}+f_{\mathrm{fl}, \infty}^{\text {excel }}+f_{\mathrm{col}, \infty}^{\text {excel }}},
$$

where $d_{\max }=1.52 \mathrm{~nm}$ and $d_{\mathrm{dry}}=1.09 \mathrm{~nm}$, and with dependencies $f_{\mathrm{HA}, \infty}^{\text {excel }}, f_{\mathrm{col}, \infty}^{\text {excel }}$, and $f_{\mathrm{fl}, \infty}^{\text {excel }}$ on tissue mass density as given in Sect. 3 (see Eqs. (16) and (17)).

In case of partially dehydrated tissues, some fluid mass (and corresponding volume) will be lost during dehydration,

$$
\Delta f_{\mathrm{fl}, \infty}^{\mu, \mathrm{dh}}=f_{\mathrm{fl}, \infty}^{\mu}-f_{\mathrm{fl}, \infty}^{\mu, \mathrm{dh}}=f_{\mathrm{fl}, \infty}^{\mu}-\mathscr{R}^{\infty, d h} f_{\mathrm{col}, \infty}^{\mu} \rho_{\mathrm{col}} / \rho_{\mathrm{fl}}
$$

with $\mathscr{R}^{\infty, d h}$ as the experimentally measured water-to-organic mass ratio of partially dehydrated tissues at the macroscopic scale, as e.g. given by Lees and Mook [89]. 
The volume fraction of the remaining fluid after dehydration per extracellular bone matrix reads as

$$
f_{\mathrm{fl}, \infty}^{\mathrm{excel}, \mathrm{dh}}=\frac{f_{\mathrm{fl}, \infty}^{\mu}-\min \left(\Delta f_{\mathrm{fl}, \infty}^{\mu, \mathrm{dh}}, f_{\mu \mathrm{por}}\right)}{1-f_{\mu \mathrm{por}}}
$$

The lost fluid volume fraction in the extracellular scale amounts to

$$
\Delta f_{\mathrm{fl}, \infty}^{\text {excel,dh }}=f_{\mathrm{fl}, \infty}^{\text {excel }}-f_{\mathrm{fl}, \infty}^{\text {excel,dh }} .
$$

The mass density-diffraction spacing relation for partially dehydrated tissues reads as

$$
d_{\mathrm{w}, \infty}^{d h}=d_{\mathrm{w}, \infty} \sqrt{1-\frac{\Delta f_{\mathrm{fl}, \infty}^{\mathrm{excel}, \mathrm{dh}}-f_{\mathrm{exfib}, 0}^{\mathrm{excel}} \Delta f_{\mathrm{fl}, \infty}^{\mathrm{excel}, \mathrm{dh}} /\left(1-f_{\mathrm{col}, 0}^{\mathrm{excel}}\right)}{f_{\mathrm{fib}, \infty}^{\mathrm{excl}}}},
$$

with

$$
f_{\mathrm{fib}, \infty}^{\text {excel }}=1-\left\{\frac{f_{\mathrm{exfib}, 0}^{\text {excel }}}{\frac{1}{1+\left(\rho_{\mathrm{HA}} / \rho_{\mathrm{fl}}-1\right) \times f_{\mathrm{HA}, \infty}^{\text {excel }}}}+\frac{f_{\mathrm{exfib}, 0}^{\text {excel }}}{1-f_{\mathrm{col}, 0}^{\text {excel }}} \times\left(1-\rho_{\mathrm{HA}} / \rho_{\mathrm{fl}}\right) \times f_{\mathrm{HA}, \infty}^{\text {excel }}\right\},
$$

and

$$
f_{\mathrm{col}, 0}^{\text {excel }}=\frac{f_{\mathrm{col}, \infty}^{\text {excel }}}{\rho_{\mathrm{HA}} f_{\mathrm{HA}, \infty}^{\text {excel }} / \rho_{\mathrm{fl}}+f_{\mathrm{fl}, \infty}^{\text {excel }}+f_{\mathrm{col}, \infty}^{\text {excel }}} .
$$

Identification of $\Delta f_{\mathrm{fl}, \infty}^{\text {excel,dh }}=f_{\mathrm{fl}, \infty}^{\text {excel }}$ delivers model predictions for the diffraction spacings in fully dried tissues. These mass density-diffraction spacing relations are fed with experimental data for tissue mass density and the corresponding predictions for diffraction spacing are validated through comparison with experimental results $[87,89,93]$. Very low prediction errors of $1.8 \pm 3.1 \%$ underline the relevance of the model-predicted evolutions of the tissue compartment volumes, and of the modelpredicted volume fractions during the mineralization process in different bone tissues (see Fig. 12); and hence, the idea of hydroxyapatite precipitating under closed thermodynamic conditions from an ionic solution in the fibrillar and extrafibrillar spaces of bone tissue. Accordingly, the structural (volumetric) evolution of mineralizing bone tissue can be quantified as follows: during mineralization, the volume of the overall collagenous tissue is shrinking because the mass density of hydroxyapatite is around three times larger than that of liquid ionic solution. In general, the more mineral is present in the tissue, the higher the shrinkage of the volumes of the different compartments (see Fig. 13). More specifically, this volume loss is minimal for low-mineralized tissues at the beginning of the mineralization process (see the left lower corner of Fig. 13), whereas highly mineralized bone tissue has lost up to $60 \%$ of its initial (osteoid) volume (see the right upper corner of Fig. 13).

The compositional evolution can be also quantified in terms of volume fractions: the mineralization process leads to a slight increase of the fibrillar volume frac- 


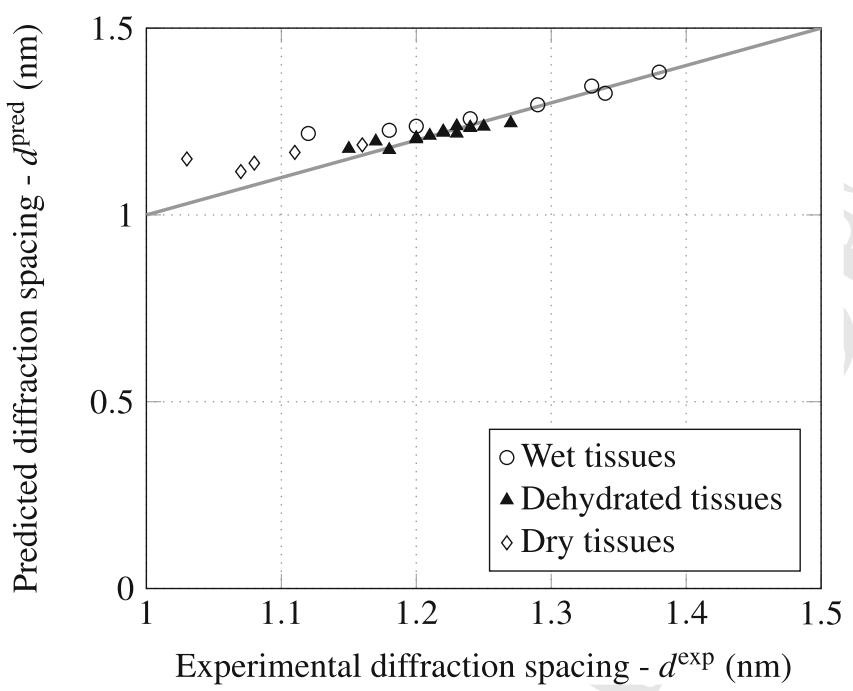

Fig. 12 Predicted versus experimental diffraction spacing for wet, dry, and partially dehydrated, mineralized tissues

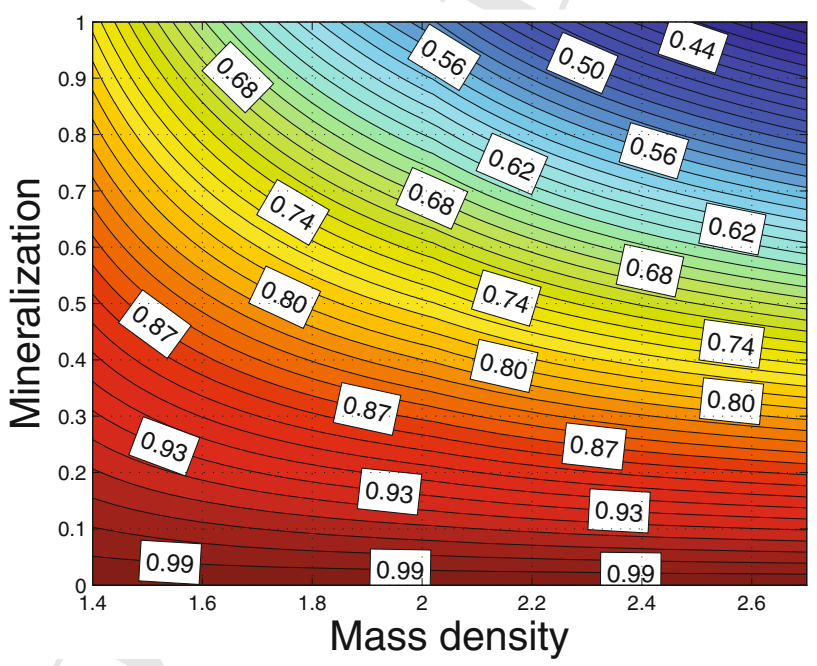

Fig. 13 Normalized tissue volume as function of the mineralization degree for different final tissue mass densities 
(a)

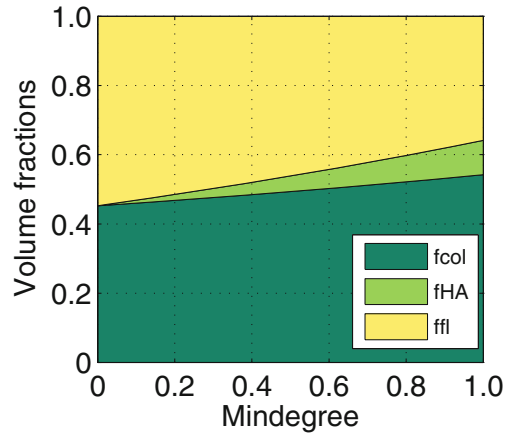

(c)

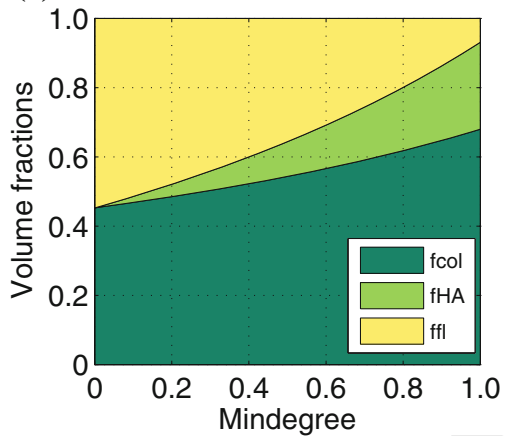

(b)

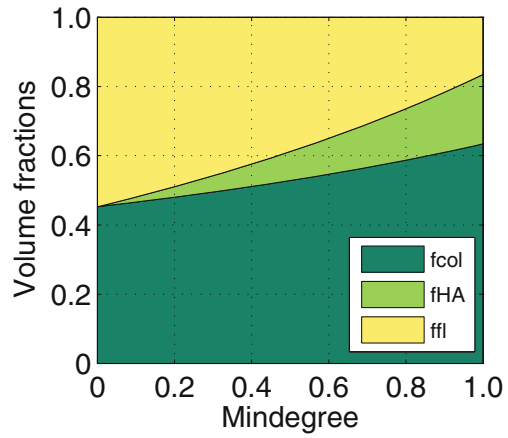

(d)

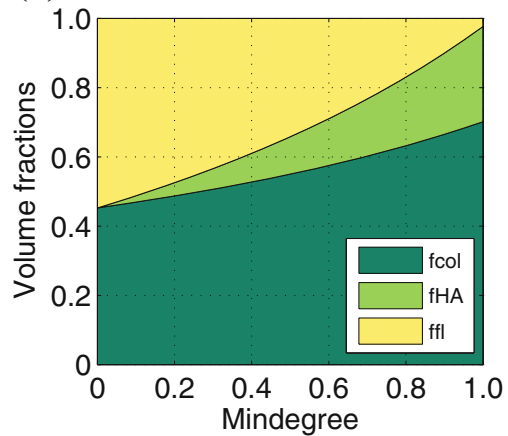

Fig. 14 Normalized tissue volume as function of the mineralization degree, for different final tissue mass densities

tions, since the fibrils, thanks to the presence of chemically inert collagen, are less affected by the fluid-to-crystal transformation-induced volume loss, as compared to the extrafibrillar space. Within the fibrils, the fluid volume fraction, starting from around $50 \%$ in the unmineralized osteoid, is reduced by one third in the case of low-mineralized tissues (see Fig. 14a), while it is almost completely consumed in the case of very highly mineralized tissues (see Fig. 14d). Thereby, lost fluid volume fractions are placed by collagen and mineral volume fractions, at about the same shares (see Fig. 14a-d). In the extrafibrillar space, mineral volume fractions increase overlinearly with the mineralization degree, the more so the more highly the tissue is mineralized. 


\section{Nano- and Microstructural Patterns Governing Anisotropic Tissue Elasticity}

Throughout the last two decades, hierarchical material models for bone $[4,33,53,55$, $56,60,61,64-66,98,108,110,116,118,119,124,132,154]$, developed within the frameworks of homogenization theory and continuum micromechanics [7, 37, 157] and validated through a multitude of biochemical, biophysical, and biomechanical experiments [13, 16, 25, 51, 57, 79, 86, 87, 90-92, 94, 96, 100, 126, 145], have opened the way to translate the chemical composition of extracellular bone material (i.e. the volume fractions of organics, water, and hydroxyapatite) into the tissue's anisotropic elasticity. This section is devoted to briefly introducing the fundamentals of continuum micromechanics, and to presenting how this theoretical framework has elucidated the "construction plans" providing the most fascinating mechanical properties of bone.

\section{Micromechanical Representation of Bone Tissue by Means of Representative Volume Elements (RVEs)}

In continuum micromechanics [37, 71, 156, 157], a material is understood as a macro-homogeneous, but micro-heterogeneous body filling a representative volume element (RVE) with characteristic length $\ell$, which must be both considerably larger than the dimensions of heterogeneities within the RVE, $\Gamma$, and significantly smaller than the characteristic lengths of geometry or loading of a structure built up by the material defined on the RVE, $\mathscr{L}$. The characteristic length of structural loading typically coincides with wave lengths of signals traveling through the structure, or relates to macroscopic stress gradients according to $\mathscr{L} \approx\|\boldsymbol{\Sigma}\| /\|\mathrm{GRAD} \boldsymbol{\Sigma}\|$ [7], with the "macroscopic" stress tensor $\boldsymbol{\Sigma}$. In mathematical terms, the aforementioned separation of scales requirement reads as

$$
\Gamma \ll \ell \ll \mathscr{L}
$$

Hereby, the first inequality sign typically relates to a factor of 2 to 3 [38]; while the second one typically relates to a factor of 5 to 50 [81].

In general, the microstructure within one RVE is so complex that it cannot be described in complete detail. Therefore, quasi-homogeneous subdomains, called material phases, with known physical quantities are reasonably chosen. Quantitative phase properties are volume fractions $f_{r}$ of phases $r=1, \ldots, N_{r}$, (average) elastic properties, as well as the morphological description, as, e.g. the isotropy or the symmetries of anisotropy of the spatial distribution of the phases, the existence of one connected "matrix phase" in which one or several "inclusion phases" with different shapes are embedded (as in reinforced composite material), or the disordered arrangement of all phases (as in a polycrystal).

The central goal of continuum micromechanics is to estimate the mechanical properties (such as elasticity or strength) of the material defined on the RVE from the aforementioned phase properties. This procedure is referred to as homogenization or 
one homogenization step. If a single phase exhibits a heterogeneous microstructure itself, its mechanical behavior can be estimated by introduction of an RVE within this phase [46], with dimensions $\ell_{2} \leq\lceil$, comprising again smaller phases with characteristic length $\Gamma_{2} \ll \ell_{2}$, and so on, leading to a multistep homogenization scheme, as in case of bone (see Fig. 15). In this context, the following "universal" microstructural patterns are considered across the hierarchical organization of bone materials:

- an RVE of wet collagen, with a characteristic length of several nanometers (see Fig. 15a), represents the staggered organization of cylindrical collagen molecules (see Fig. 1h), which are attached to each other by $\sim 1.5 \mathrm{~nm}$ long crosslinks [8, 93, 112]. These crosslinks imply the existence of a contiguous matrix built up by molecular collagen, hosting fluid-filled intermolecular spaces, which are represented by cylindrical inclusions;

- an RVE of extrafibrillar space (hydroxyapatite foam), with a characteristic length of several hundred nanometers (see Fig. 15c), hosts crystal needles (represented through infinitely many uniformly oriented cylindrical hydroxyapatite inclusions) oriented in all space directions; in mutual interaction with spherical, water-filled pores in-between;

- an RVE of extracellular bone matrix or ultrastructure, with a characteristic length of several micrometers (see Fig. 15d), hosts cylindrical, mineralized fibrils being embedded into a contiguous matrix built up by hydroxyapatite foam material;

- an RVE of extravascular bone material, with a characteristic length of several hundred micrometers (see Fig. 15e), hosts spherical, osteocyte-filled cavities called lacunae being embedded into a contiguous matrix built up by the extracellular bone material; and

- an RVE of cortical bone material, with a characteristic length of several millimeters (see Fig. 15f), hosts cylindrical vascular pores being embedded into a matrix of extravascular bone material.

\section{Elasticity Homogenization}

As concerns the homogenization (or upscaling) of the elastic properties of bone, starting from the level of its basic building blocks, up to the level of the bone microstructure, see Fig. 15, we start with focusing on a single RVE built up by phases enumerated by $r$. The second-order strain tensor, $\boldsymbol{\varepsilon}_{r}$, is related to the (average "microscopic") second-order stress tensor in phase $r, \sigma_{r}$, by the phase elasticity tensor $\mathbb{C}_{r}$

$$
\boldsymbol{\sigma}_{r}=\mathbb{C}_{r}: \boldsymbol{\varepsilon}_{r}
$$

The RVE is subjected to homogeneous (macroscopic) strains $\mathbf{E}$ at its boundary [59], prescribed in terms of displacements

$$
\forall \mathbf{x} \in \partial V_{R V E}: \quad \boldsymbol{\xi}(\mathbf{x})=\mathbf{E} \cdot \mathbf{x},
$$

whereby $\mathbf{x}$ is the position vector for locations within or at the boundary of the RVE. As a consequence, the resulting kinematically compatible microstrains $\boldsymbol{\varepsilon}(\mathbf{x})$ throughout 


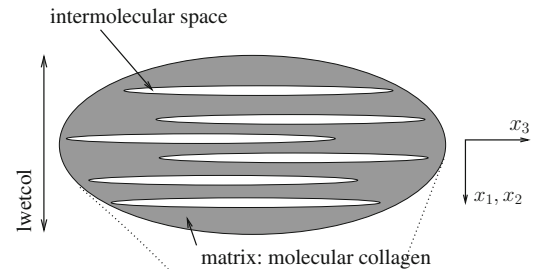

(a) wet collagen

self consistent matrix: with no volume fraction and the elastic properties of the RVE itself

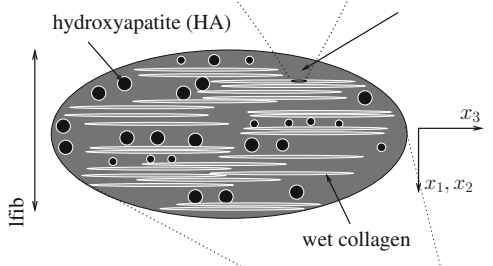

(b) collagen - hydroxyapatite network (fibril)

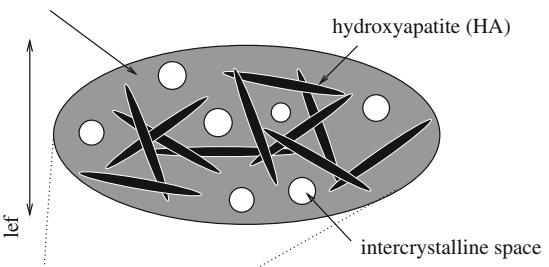

(c) hydroxyapatite foam (extrafibrillar space)

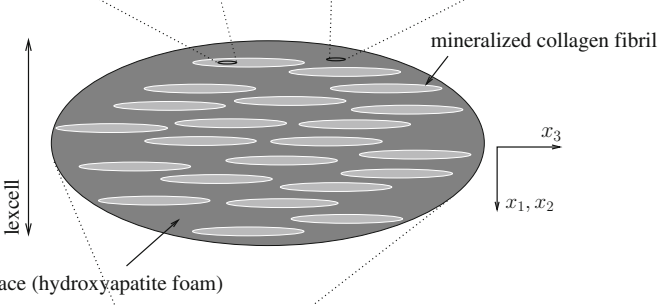

extrafibrillar space (hydroxyapatite foam)

(d) extracellular bone matrix or ultrastructure

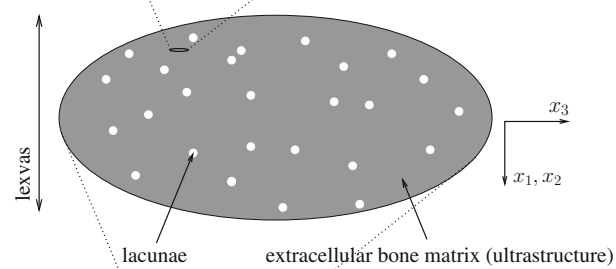

(e) extravascular bone material

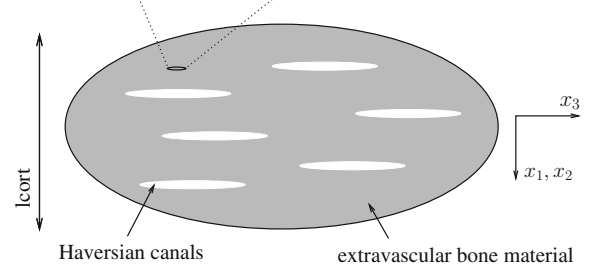

(f) bone microstructure (cortical bone)

Fig. 15 Micromechanical representation of bone material by means of a six-step homogenization scheme, according to Fritsch et al. [48] 
the RVE fulfill the average condition,

$$
\mathbf{E}=\frac{1}{V_{R V E}} \int_{V_{R V E}} \boldsymbol{\varepsilon} d V=\langle\boldsymbol{\varepsilon}\rangle=\sum_{r} f_{r} \boldsymbol{\varepsilon}_{r},
$$

providing link between the (average) microscopic and macroscopic strains. Furthermore, the aforementioned deformations provoke traction forces $\mathbf{T}(\mathbf{x})$ on the boundary of the RVE, and microstresses $\boldsymbol{\sigma}(\mathbf{x})$ throughout the RVE, fulfilling the equilibrium conditions

$$
\begin{array}{lr}
\forall \mathbf{x} \in V_{R V E} & \operatorname{divg}(\mathbf{x})=\theta, \\
\forall \mathbf{x} \in \partial V_{R V E} & \mathbf{T}(\mathbf{x})=\boldsymbol{\sigma}(\mathbf{x}) \cdot \mathbf{n}(\mathbf{x}),
\end{array}
$$

with $\mathbf{n}(\mathbf{x})$ as the normal to the boundary at position $\mathbf{x}$. The external work done by these traction forces reads as

$$
\begin{aligned}
\mathscr{W}^{e x t} & =\int_{\partial V_{R V E}} \mathbf{T}(\mathbf{x}) \cdot \boldsymbol{\xi}(\mathbf{x}) d S=\int_{\partial V_{R V E}}(\mathbf{E} \cdot \mathbf{x}) \cdot[\boldsymbol{\sigma}(\mathbf{x}) \cdot \mathbf{n}(\mathbf{x})] d S \\
& =\mathbf{E}: \int_{V_{R V E}} \boldsymbol{\sigma}(\mathbf{x}) d V,
\end{aligned}
$$

whereby we made use of boundary condition (43) and of the divergence theorem. Hence, the force quantity doing work on the macroscopic strains $\mathbf{E}$ is the volume integral over the microscopic stress, which is independent of microscopic position and of dimension "stress times volume". This induces the existence of the macroscopic stress $\boldsymbol{\Sigma}$ in the form

$$
\boldsymbol{\Sigma}_{\boldsymbol{\lambda}} V_{R V E}=\int_{V_{R V E}} \boldsymbol{\sigma}(\mathbf{x}) d V \Leftrightarrow \boldsymbol{\Sigma}=\frac{1}{V_{R V E}} \int_{V_{R V E}} \boldsymbol{\sigma}(\mathbf{x}) d V=\langle\boldsymbol{\sigma}\rangle=\sum_{r} f_{r} \boldsymbol{\sigma}_{r},
$$

i.e. the well-known stress average rule. Insertion of (47) into the principle of virtual power $[50,99,131]$, which in the case of linearized strains, can be expressed in terms of an expression with the dimension "work",

$$
\mathscr{W}^{e x t}=-\mathscr{W}^{i n t}=\int_{V_{R V E}} \boldsymbol{\sigma}(\mathbf{x}): \boldsymbol{\varepsilon}(\mathbf{x}) d V,
$$

yields the so-called Hill's lemma

$$
\boldsymbol{\Sigma}: \mathbf{E}=\frac{1}{V_{R V E}} \int_{V_{R V E}} \boldsymbol{\sigma}(\mathbf{x}): \boldsymbol{\varepsilon}(\mathbf{x}) d V=\langle\boldsymbol{\sigma}: \boldsymbol{\varepsilon}\rangle .
$$

Linearity of elastic law (42) and of partial differential equation (45) imply a multilinear relation between the homogenized (macroscopic) strain $\mathbf{E}$ and the average (microscopic) strain $\boldsymbol{\varepsilon}_{r}$, expressed by the fourth-order concentration tensors $\mathbb{A}_{r}$ of each of the phases $r$, 


$$
\boldsymbol{\varepsilon}_{r}=\mathbb{A}_{r}: \mathbf{E} .
$$

Insertion of Eq. (50) into (42) and averaging over all phases according to Eq. (47) leads to

$$
\boldsymbol{\Sigma}=\sum_{r} f_{r} \mathbb{C}_{r}: \mathbb{A}_{r}: \mathbf{E}
$$

Equation (51) implies the existence of a macroscopic "homogenized" stiffness tensor linking macroscopic stresses to macroscopic strains in the format

$$
\boldsymbol{\Sigma}=\mathbb{C}^{\text {hom }}: \mathbf{E}
$$

yielding $\mathbb{C}^{\text {hom }}$ as

$$
\mathbb{C}^{\text {hom }}=\sum_{r} f_{r} \mathbb{C}_{r}: \mathbb{A}_{r}
$$

The concentration tensors $\mathbb{A}_{r}$ are estimated from matrix-inclusion problems, pioneered by Eshelby [43]. On a mathematical level, this is achieved by setting the phase strains equal to those in ellipsoidal inclusions in infinitely extending matrices of stiffness $\mathbb{C}^{0}$ subjected to remote strains, and by combining respective semi-analytical relationships [43, 84] with stress and strain average rules [59, 157], yielding

$$
\mathbb{A}_{r}=\left[\mathbb{I}+\mathbb{P}_{r}^{0}:\left(\mathbb{C}_{r}-\mathbb{C}^{0}\right)\right]^{-1}:\left\{\sum_{s} f_{s}\left[\mathbb{I}+\mathbb{P}_{s}^{0}:\left(\mathbb{C}_{s}-\mathbb{C}^{0}\right)\right]^{-1}\right\}^{-1}
$$

Insertion of Eq. (54) into (51) yields an expression for the macroscopic homogenized stiffness tensor as function of their volume fractions, shapes and interactions

$$
\mathbb{C}^{\text {hom }}=\sum_{r} f_{r} \mathbb{C}_{r}:\left[\mathbb{I}+\mathbb{P}_{r}^{0}:\left(\mathbb{C}_{r}-\mathbb{C}^{0}\right)\right]^{-1}:\left\{\sum_{s} f_{s}\left[\mathbb{I}+\mathbb{P}_{s}^{0}:\left(\mathbb{C}_{s}-\mathbb{C}^{0}\right)\right]^{-1}\right\}^{-1},
$$

where $f_{r}$ and $\mathbb{C}_{r}$ are the volume fraction and the elastic stiffness of phase $r, \mathbb{I}$ is the fourth-order unity tensor, $\mathbb{P}_{r}^{0}$ the fourth-order Hill tensor accounting for the characteristic shape of phase $r$, which, in case of ellipsoidal inclusions in anisotropic media $[84,85]$, reads as

$$
P_{r, i j k l}^{0}=\frac{1}{16 \pi \alpha^{1 / 2}} \int_{\Omega} \frac{1}{t^{3}}\left\{\hat{g}_{i l} w_{j} w_{k}+\hat{g}_{i k} w_{j} w_{l}+\hat{g}_{j l} w_{i} w_{k}+\hat{g}_{j k} w_{i} w_{l}\right\} d S(\boldsymbol{w}) .
$$

In Eq. (56), the shape of the ellipsoid is considered by $\alpha=\operatorname{det} \alpha_{i j}$, being related to the equation of the ellipsoid, $\alpha_{i j} x_{i} x_{j}=1, d S(\boldsymbol{w})$ is a surface element of the unit sphere (with surface $\Omega$ ); $w_{1}, w_{2}$ and $w_{3}$ are the components of the unit length vector $\boldsymbol{w}$ pointing from the origin of the sphere to the surface element $d S(\boldsymbol{w})$, and 
$t^{2}=\alpha_{i j}^{-1} w_{i} w_{j}$. Finally, $\hat{g}_{i k}$ are the components of the inverse of the second-order tensor $C_{i j k l}^{0} w_{j} w_{l}$, with $C_{i j k l}^{0}$ denoting the stiffness of anisotropic matrix.

As regards the matrix stiffness, $\mathbb{C}^{0}$, its choice governs the interactions between the phases inside the RVE: $\mathbb{C}^{0}=\mathbb{C}^{\text {hom }}$ relates to a dispersed arrangement of phases where all phases "feel" the overall homogenized material, and the corresponding homogenization scheme is standardly called self-consistent $[69,83]$, well-suited for polycrystalline materials (applied for RVEs depicted in Fig. 15b, c). On the other hand, the matrix may be identified as a phase $m$ itself, $\mathbb{C}^{0}=\mathbb{C}_{m}$, which relates to matrix-inclusion-type composite, and the corresponding homogenization scheme is standardly referred to as Mori-Tanaka scheme [12, 106] (applied for RVEs depicted in Fig. 15a, d, e, f).

Strictly speaking, the RVE of extrafibrillar space (see Fig. 15c) requires a slight (but important) modification of the aforementioned developments: it consists of one pore space and infinitely many cylindrical solid phases which are oriented in all space directions. This requires modification of Eqs. (44), (47), (53), and (55) in terms of integrals over the unit sphere [47]. Accordingly, the homogenized stiffness of the extrafibrillar RVE of Fig. 15c reads as

$$
\begin{aligned}
\mathbb{C}_{\text {exfib }}^{\text {hom }}= & \left\{f_{\mathrm{HA}}^{\text {exfib }} \mathbb{C}_{\mathrm{HA}}: \int_{\varphi=0}^{2 \pi} \int_{\theta=0}^{\pi}\left[\mathbb{I}+\mathbb{P}_{\text {cyl }}^{\text {exfib }}(\theta, \varphi):\left(\mathbb{C}_{\mathrm{HA}}-\mathbb{C}_{\text {exfib }}^{\text {hom }}\right)\right]^{-1} \frac{\sin \theta d \theta d \varphi}{4 \pi}+\right. \\
& \left.\left(1-f_{\mathrm{HA}}^{\text {exfib }}\right) \mathbb{C}_{\mathrm{H}_{2} \mathrm{O}}:\left[\mathbb{I}+\mathbb{P}_{\mathrm{sph}}^{\text {exfib }}:\left(\mathbb{C}_{\mathrm{H}_{2} \mathrm{O}}-\mathbb{C}_{\text {exfib }}^{\text {hom }}\right)\right]^{-1}\right\}: \\
& \left\{f_{\mathrm{HA}} \int_{\varphi=0}^{2 \pi} \int_{\theta=0}^{\pi}\left[\mathbb{I}+\mathbb{P}_{\mathrm{cyl}}^{\text {exfib }}(\theta, \varphi):\left(\mathbb{C}_{\mathrm{HA}}-\mathbb{C}_{\text {exfib }}^{\text {hom }}\right)\right]^{-1} \frac{\sin \theta d \theta d \varphi}{4 \pi}+\right. \\
& \left(1-f_{\mathrm{HA}}^{\text {exfib }}\right)\left[\mathbb{I}+\mathbb{P}_{\mathrm{sph}}^{\text {exfib }}:\left(\mathbb{C}_{\mathrm{H}_{2} \mathrm{O}}-\mathbb{C}_{\text {exfib }}^{\text {hom }}\right)\right]^{-1},
\end{aligned}
$$

with $\mathbb{P}_{\mathrm{cyl}}^{\text {exfib }}$ and $\mathbb{P}_{\mathrm{sph}}^{\text {exfib }}$ standing for the Hill tensor of a cylindrical or a spherical inclusion embedded in a matrix with a stiffness of $\mathbb{C}_{\text {exfib }}^{\text {hom }}$, respectively.

\section{Elasticity of Elementary Components}

The micromechanical representation of Fig. 15 is validated at different observation scales, namely at the extracellular, the extravascular, and the cortical/trabecular scales. All corresponding computations are based on the same elasticity properties assigned to bone's elementary constituents: hydroxyapatite, (molecular) collagen, and water (with some non-collagenous organics). The elastic properties of hydroxyapatite are obtained from tests with an ultrasonic interferometer coupled with a solid media pressure apparatus [77], which reveal the isotropic elastic properties of hydroxyapatite powder,

$$
\mathbb{C}_{\mathrm{HA}}=3 k_{\mathrm{HA}} \mathbb{I}_{\mathrm{vol}}+2 \mu_{\mathrm{HA}} \mathbb{I}_{\mathrm{dev}}
$$


with $\mathbb{I}_{\mathrm{vol}}$ and $\mathbb{I}_{\mathrm{dev}}$ as the volumetric and deviatoric part of the fourth-order identity tensor $\mathbb{I}$, and with $k_{\mathrm{HA}}=82.6 \mathrm{GPa}$ and $\mu_{\mathrm{HA}}=44.9 \mathrm{GPa}$, as the bulk and shear moduli of hydroxyapatite. In view of the largely disordered arrangement of poorly crystalline minerals [42, 45, 62, 63, 65, 95, 117], this isotropic characterization is sufficient for successful bone elasticity upscaling [33, 47, 61, 66, 154], as is also confirmed by the validation diagrams of Figs. 16, 17, 18, 19, 20 and 21. Sasaki and Odajima [133] determined the Young's modulus of molecular collagen by a hybrid mechanical-Xray technique, considering Lees' 1987 packing model [86] for the cross-sectional arrangement of collagen molecules. This resulted in an elastic Young's modulus of $2.9 \mathrm{GPa}$. As they did not account for the additional $12 \%$ microporosity which is still present in "fully dehydrated" collagen [88], the aforementioned values relate to the RVE of Fig. 15a with $12 \%$ intermolecular space. Adopting a Poisson's ratio of 0.34 for such an RVE [35], the corresponding homogenization relation allows for backanalysis of an isotropic estimate of the stiffness tensor of molecular collagen, which reads in Kelvin-Mandel notation (see e.g. Eq. (44) of [68] or Eq. (2a) of [31]) as

$$
\mathbb{C}_{\mathrm{col}}=\left\{\begin{array}{cccccc}
4.86 & 2.39 & 2.39 & 0 & 0 & 0 \\
2.39 & 4.86 & 2.39 & 0 & 0 & 0 \\
2.39 & 2.39 & 4.86 & 0 & 0 & 0 \\
0 & 0 & 0 & 1.23 & 0 & 0 \\
0 & 0 & 0 & 0 & 1.23 & 0 \\
0 & 0 & 0 & 0 & 0 & 1.23
\end{array}\right\} \quad \mathrm{GPa}
$$

with a Young's modulus of $3.28 \mathrm{GPa}$ and a Poisson's ratio of 0.33 . We assign the standard bulk modulus of water, $k_{\mathrm{H}_{2} \mathrm{O}}=2.3 \mathrm{GPa}$, to phases comprising water with mechanically insignificant amounts of non-collagenous organic matter.

\section{Model Validation at the Extracellular Scale}

At the extracellular level, we compare the micromechanical elasticity predictions to ultrasonic tests with $10 \mathrm{MHz}$ frequency, performed on cortical bone samples of bovine, human, elephant, deer, cod, and dugong tissues [91, 92]. Given the measured wave velocities ranging from 2.38 to $4.18 \mathrm{~km} / \mathrm{s}$, the wave exhibited wave lengths between 238 and $418 \mu \mathrm{m}$, being by a factor of 23.8 to 41.8 larger than the RVE of Fig. 15d, hence they characterize the latter according to Eq. (41). As tissuespecific input values for the micromechanical model, the volume fractions entering the RVE descriptions of wet collagen (Fig. 15a), of the fibrillar and extrafibrillar spaces (Fig. 15b, c), and of the extracellular matrix (Fig. 15d) are needed.

As regards the cortical bone samples from bovine tibia [91], the macroscopic mass densities and weight fractions are given, see Table 1. Based on a typical microporosity of $f_{\mu \text { por }}=5 \%$, see our discussion around Eq. (9), the aforementioned quantities are transformed into ultrastructural (extracellular) weight fractions and apparent mass densities according to Eqs. (10)-(13), and into extracellular (ultrastructural) volume fractions according to Eqs. (16) and (17). Then, the mineral distribution rules of Sect. 4, and the swelling and shrinkage rules of Sect. 5 and 6 allow for quantification of the extrafibrillar and fibrillar volume fractions per volume of extracellular matrix as 
Table 7 Experimental characterization of various cortical bone samples by Less et al. [91] ${ }^{\mathrm{a}}$, Less et al. [92] $]^{\mathrm{b}}$, and Less et al. [96] $]^{\mathrm{c}}$; Macroscopic and extracellular bone mass densities, $\rho^{\mu}$ and $\rho^{\text {excel }}$, longitudinal ultrasonic velocities in radial material directions, $v_{1}$, experimental and model-predicted normal stiffness values in radial direction, $C_{1111}^{\exp }$ and $C_{1111}^{\text {pred }}$, respectively

\begin{tabular}{|c|c|c|c|c|c|}
\hline Tissue & $\rho^{\mu}\left(\mathrm{g} / \mathrm{cm}^{3}\right)$ & $\rho^{\text {excel }}\left(\mathrm{g} / \mathrm{cm}^{3}\right)$ & $v_{1}(\mathrm{~km} / \mathrm{s})$ & $C_{1111}^{\exp }(\mathrm{GPa})$ & $C_{1111}^{\text {pred }}(\mathrm{GPa})$ \\
\hline Bovine tibia $^{\mathrm{a}}$ & 2.02 & 2.07 & 3.18 & 21.0 & 24.1 \\
\hline Bovine tibia $^{\mathrm{a}}$ & 1.99 & 2.04 & 3.18 & 20.7 & 22.1 \\
\hline Bovine tibia $^{\mathrm{a}}$ & 1.95 & 2.00 & 3.18 & 20.2 & 19.7 \\
\hline Bovine tibia $^{\mathrm{a}}$ & 2.01 & 2.06 & 3.16 & 20.6 & 22.3 \\
\hline Bovine tibia $^{a}$ & 2.04 & 2.09 & 3.27 & 22.4 & 21.7 \\
\hline Bovine tibia $^{\mathrm{a}}$ & 2.05 & 2.11 & 3.26 & 22.4 & 24.4 \\
\hline Bovine tibia $^{\mathrm{b}}$ & 2.07 & 2.13 & 3.32 & 23.4 & 25.7 \\
\hline Dugong rib ${ }^{b}$ & 2.02 & 2.07 & 3.00 & 18.7 & 22.5 \\
\hline Elephant radius $^{b}$ & 1.94 & 1.99 & 3.05 & 18.5 & 18.1 \\
\hline Human femur ${ }^{b}$ & 1.93 & 1.98 & 3.13 & 19.4 & 17.6 \\
\hline Deer antler ${ }^{b}$ & 1.78 & 1.82 & 2.38 & 10.3 & 12.5 \\
\hline Deer antler ${ }^{b}$ & 1.74 & 1.78 & 2.40 & 10.2 & 11.5 \\
\hline Whale malleus ${ }^{\mathrm{c}}$ & 2.49 & 2.49 & 4.85 & 58.6 & 57.2 \\
\hline Whale malleus ${ }^{c}$ & 2.53 & 2.53 & 4.89 & 60.5 & 61.8 \\
\hline Whale malleus ${ }^{c}$ & 2.51 & 2.51 & 4.55 & 52.0 & 59.4 \\
\hline Whale malleus ${ }^{c}$ & 2.45 & 2.45 & 4.61 & 52.1 & 52.8 \\
\hline Whale incus ${ }^{\mathrm{c}}$ & 2.50 & 2.50 & 4.79 & 57.4 & 58.3 \\
\hline Whale incus ${ }^{\mathrm{c}}$ & 2.46 & 2.46 & 4.70 & 54.3 & 53.9 \\
\hline Whale periotic ${ }^{c}$ & 2.40 & 2.40 & 4.15 & 41.3 & 47.7 \\
\hline Whale periotic ${ }^{c}$ & 2.48 & 2.48 & 4.60 & 52.5 & 56.0 \\
\hline Whale periotic ${ }^{c}$ & 2.50 & 2.50 & 4.53 & 51.3 & 58.3 \\
\hline Whale periotic ${ }^{\mathrm{c}}$ & 2.52 & 2.52 & 4.65 & 54.5 & 60.6 \\
\hline Whale periotic ${ }^{c}$ & 2.58 & 2.58 & 4.84 & 60.4 & 67.9 \\
\hline $\begin{array}{l}\text { Whale typamic } \\
\text { bulla }^{\mathrm{c}}\end{array}$ & 2.54 & 2.54 & 4.60 & 53.7 & 63.0 \\
\hline $\begin{array}{l}\text { Whale typamic } \\
\text { bulla }^{\mathrm{c}}\end{array}$ & 2.50 & 2.50 & 4.53 & 51.3 & 58.3 \\
\hline $\begin{array}{l}\text { Whale typamic } \\
\text { bulla }^{c}\end{array}$ & 2.53 & 2.53 & 4.53 & 51.9 & 61.8 \\
\hline $\begin{array}{l}\text { Whale typamic } \\
\text { bulla }^{c}\end{array}$ & 2.54 & 2.54 & 4.54 & 52.4 & 63.0 \\
\hline $\begin{array}{l}\text { Whale typamic } \\
\text { bulla }^{\mathrm{c}}\end{array}$ & 2.49 & 2.49 & 4.48 & 50.0 & 57.2 \\
\hline
\end{tabular}




$$
\begin{aligned}
f_{\text {exfib }}^{\text {excel }} & =\frac{f_{\text {exfib }, 0}^{\text {excel }}}{\frac{1}{1+\left(\rho_{\mathrm{HA}} / \rho_{\mathrm{fl}}-1\right) \times f_{\mathrm{HA}}^{\text {excel }}}}+\frac{f_{\text {exfib }, 0}^{\text {excel }}}{1-f_{\mathrm{col}, 0}^{\text {excel }}} \times\left(1-\rho_{\mathrm{HA}} / \rho_{\mathrm{fl}}\right) \times f_{\mathrm{HA}}^{\text {excel }}, \\
f_{\mathrm{fib}}^{\text {excel }} & =1-f_{\mathrm{exfib}}^{\text {excel }},
\end{aligned}
$$

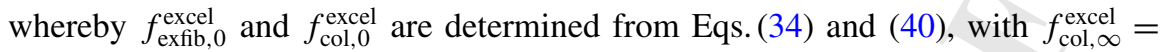
$f_{\text {col }}^{\text {excel }}$ according to Eq. (18), with $f_{\mathrm{HA}, \infty}^{\text {excel }}=f_{\mathrm{HA}}^{\text {excel }}$ according to Eqs. $(16)_{2}$ and $(17)_{2}$. They are the basis for the determination of the phase volume fractions within the lower scale RVEs: In this context, the fact that the average hydroxyapatite concentration in the extracollagenous space is the same inside and outside the fibrils [63], see also Sect. 4, allows for quantification of the mineral and collagen volume fractions within the fibrillar and extrafibrillar compartments. Accordingly, in the extrafibrillar space, the volume fractions of mineral, $f_{\mathrm{HA}}^{\text {exfib }}$, and of the intercrystalline fluid, $f_{\mathrm{ic}}^{\text {exfib }}$, read as [108]

$$
\begin{aligned}
& f_{\mathrm{HA}}^{\text {exfib }}=\frac{f_{\mathrm{HA}}^{\text {excel }} \phi_{\mathrm{HA}}^{\text {exfib }}}{f_{\text {exfib }}^{\text {excel }}} \quad \text { with } \quad \phi_{\mathrm{HA}}^{\text {exfib }}=\frac{1-f_{\text {fib }}^{\text {excel }}}{1-f_{\mathrm{col}}^{\text {excel }}}, \\
& f_{\mathrm{ic}}^{\text {exfib }}=1-f_{\mathrm{HA}}^{\text {exfib }}
\end{aligned}
$$

Within the fibrillar space, the volume fractions of mineral, $f_{\mathrm{HA}}^{\mathrm{fib}}$, and of wet collagen, $f_{\text {wetcol }}^{\text {fib }}$ read as [108]

$$
\begin{aligned}
& f_{\mathrm{HA}}^{\mathrm{fib}}=\frac{f_{\mathrm{HA}}^{\text {excel }}\left(1-\phi_{\mathrm{HA}}^{\text {exfib }}\right)}{f_{\mathrm{fib}}^{\text {excel }}}, \\
& f_{\text {wetcol }}^{\mathrm{fib}}=1-f_{\mathrm{HA}}^{\mathrm{fib}} .
\end{aligned}
$$

Finally, the volume fractions of molecular collagen and the intermolecular space at the wet collagen level, $f_{\text {col }}^{\text {wetcol }}$ and $f_{\text {im }}^{\text {wetcol }}$, can be calculated from the extracellular volume fractions of collagen as [108]

$$
\begin{aligned}
& f_{\text {col }}^{\text {wetcol }}=\frac{f_{\text {col }}^{\text {excel }}}{f_{\text {fib }}^{\text {excel }} f_{\text {wetcol }}^{\text {fib }}}, \\
& f_{\text {im }}^{\text {wetcol }}=1-f_{\text {col }}^{\text {wetcol }} .
\end{aligned}
$$

The corresponding micromechanical elasticity predictions of the bovine tibial bone samples of Lees et al. [91] agree well with the actual experimental data. This is underlined by relative errors of $5.47 \pm 7.01 \%$ for the radial normal stiffness, and of $-2.84 \pm 6.70 \%$ for the axial normal stiffness components, see also Figs. 16 and 17 .

As regards the wet cortical bone samples from deer antler, human femur, elephant radius, and dugong rib of Lees et al. [92], and the various whale bones of Lees et al. [96], the macroscopic mass densities are given, see Table 7. Based on a typical microstructural porosity of $f_{\mu \text { por }}=5 \%$, these macroscopic mass densities are transformed into ultrastructural (extracellular) mass densities, by means of Eq. (9). The 
Table 8 Experimental characterization of various cortical bone samples by Less et al. [91] ${ }^{\mathrm{a}}$ and Less et al. [92] $]^{\text {b }}$ Macroscopic and extracellular bone mass densities, $\rho^{\mu}$ and $\rho^{\text {excel }}$, longitudinal ultrasonic velocities in axial material directions, $\nu_{3}$, experimental and model-predicted normal stiffness values in axial direction, $C_{3333}^{\exp }$ and $C_{3333}^{\mathrm{pred}}$, respectively

\begin{tabular}{l|l|l|l|l|l}
\hline Tissue & $\rho^{\mu}\left(\mathrm{g} / \mathrm{cm}^{3}\right)$ & $\rho^{\text {excel }}\left(\mathrm{g} / \mathrm{cm}^{3}\right)$ & $v_{3}(\mathrm{~km} / \mathrm{s})$ & $C_{3333}^{\text {exp }}(\mathrm{GPa})$ & $C_{3333}^{\text {pred }}(\mathrm{GPa})$ \\
\hline Bovine tibia $^{\mathrm{a}}$ & 2.06 & 2.12 & 3.92 & 32.5 & 32.3 \\
\hline Bovine tibia $^{\mathrm{a}}$ & 2.05 & 2.11 & 3.92 & 32.4 & 31.6 \\
\hline Bovine tibia $^{\mathrm{a}}$ & 2.02 & 2.07 & 3.81 & 30.1 & 27.3 \\
\hline Bovine tibia $^{\mathrm{a}}$ & 2.02 & 2.07 & 3.86 & 30.9 & 27.6 \\
\hline Bovine tibia $^{\mathrm{a}}$ & 2.00 & 2.05 & 3.90 & 31.2 & 28.3 \\
\hline Bovine tibia $^{\mathrm{a}}$ & 2.05 & 2.11 & 3.88 & 31.7 & 30.7 \\
\hline Bovine tibia $^{\mathrm{a}}$ & 2.10 & 2.16 & 3.88 & 32.5 & 35.4 \\
\hline Bovine tibia $^{\mathrm{a}}$ & 2.08 & 2.14 & 3.92 & 32.8 & 33.8 \\
\hline $\begin{array}{l}\text { Bovine tibia } \\
\mathrm{b}\end{array}$ & 2.06 & 2.12 & 4.18 & 37.0 & 34.3 \\
\hline $\begin{array}{l}\text { Elephant } \\
\text { radius }\end{array}$ & 1.93 & 1.98 & 3.89 & 29.9 & 23.5 \\
\hline $\begin{array}{l}\text { Human } \\
\text { femur }\end{array}$ & 1.96 & 2.01 & 3.76 & 28.4 & 25.8 \\
\hline Deer antler & 1.74 & 1.78 & 3.08 & 16.9 & 13.1 \\
\hline Deer antler & 1.73 & 1.77 & 3.15 & 17.5 & 12.8 \\
\hline
\end{tabular}

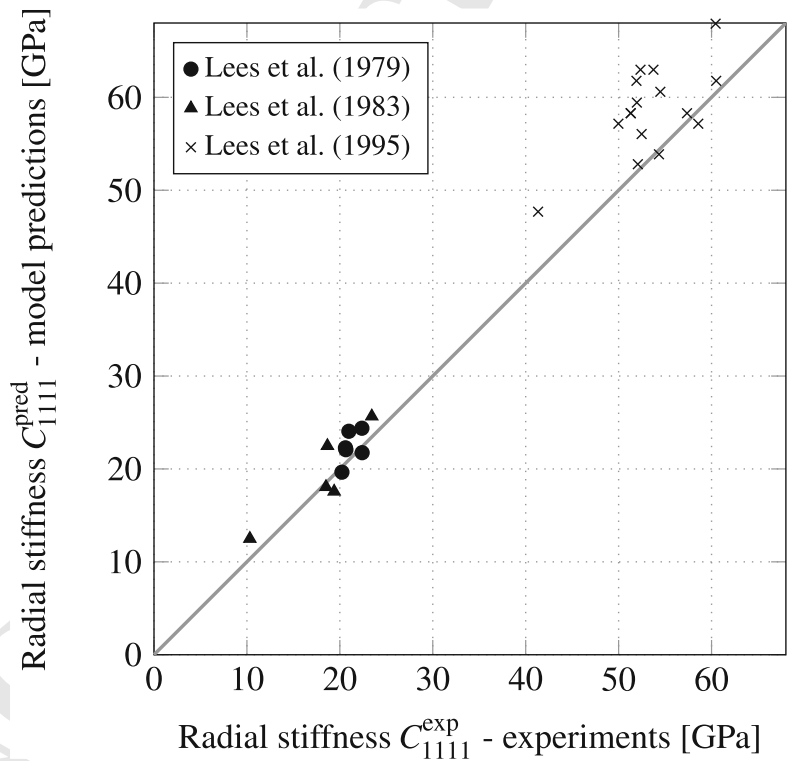

Fig. 16 Comparison between model predictions and experiments of radial normal stiffness values at the extracellular scale (10 MHz experiments: Lees et al. [91, 92, 96], see also Table 7) 


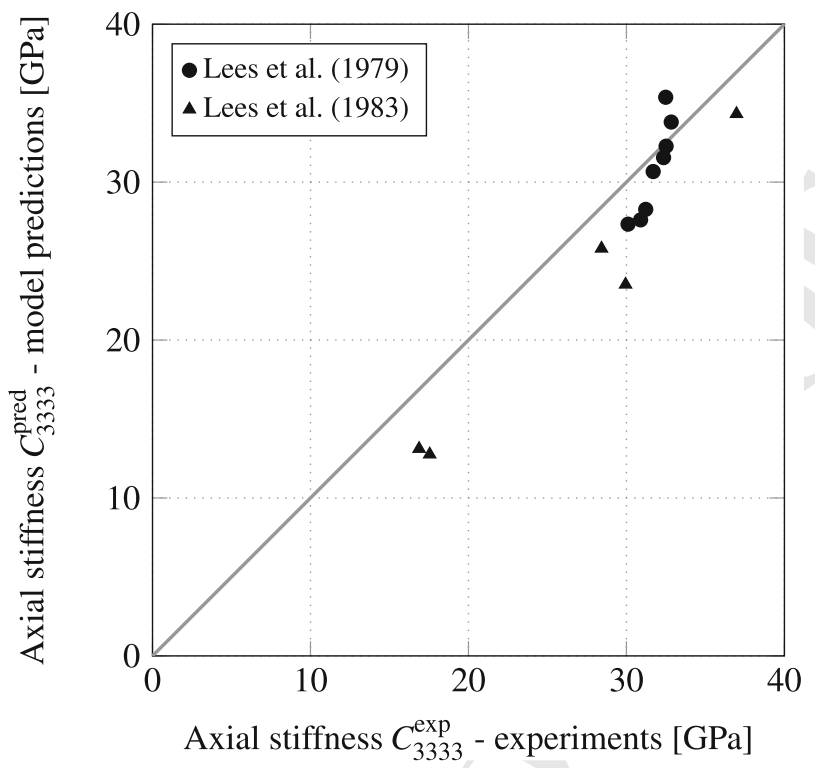

Fig. 17 Comparison between model predictions and experiments of axial normal stiffness values at the extracellular scale (10 MHz experiments: Lees et al. [91, 92], see also Table 8)

latter mass densities then enter the bilinear relation of Fig. 2a, so as to deliver the extracellular volume fractions of mineral, organic and water according to Eqs. (16) and (17). These volume fractions are then used to quantify the composition of the lower scale RVEs of Fig. 1d, e. The corresponding micromechanical elasticity predictions of the bone samples of Lees et al. [92] and of Lees et al. [96] agree well with the actual experimental data. This is underlined by relative errors of $7.18 \pm$ $12.13 \%$ for the radial normal stiffness, and of $-15.61 \pm 6.17 \%$ for the axial normal stiffness components for the different bone tissues reported by Lees et al. [92], and by a relative error of $9.71 \pm 7.21 \%$ for the radial normal stiffness of whale bones reported by Lees et al. [96], see Figs. 16 and 17.

\section{Model Validation at the Extravascular Scale}

At the extravascular level, we compare the micromechanical elasticity predictions to an ultrasonic test carried out by McCarthy et al. [100] on equine bones; at a frequency of $2.25 \mathrm{MHz}$. The measured velocities range from 3.13 to $4.4 \mathrm{~km} / \mathrm{s}$, resulting in a wave length ranging from 1.4 to $2.0 \mathrm{~mm}$. The characteristic length of experimentally characterized RVE of Fig. 15e is by a factor of 14 to 20 smaller, hence they characterize the latter according to Eq. (41). As tissue-specific input values for the micromechanical model, the volume fractions entering the RVE descriptions of wet collagen (Fig. 15a), of the fibrillar and extrafibrillar spaces (Fig. 15b, c), of the extracellular matrix (Fig. 15d), and of the extravascular matrix (Fig. 15e) are needed. 
Table 9 Experimental characterization of equine cortical bone samples by McCarthy et al. [100]; Macroscopic and extravascular bone mass densities, $\rho^{\mu}$ and $\rho^{\text {exvas }}$, longitudinal ultrasonic velocities in radial and axial material directions, $v_{1}$ and $v_{3}$, experimental and model-predicted normal stiffness values in radial and axial direction, $C_{1111}^{\exp }, C_{3333}^{\exp }, C_{1111}^{\text {pred }}, C_{3333}^{\text {pred }}$, respectively

\begin{tabular}{|c|c|c|c|c|c|c|c|}
\hline $\begin{array}{l}\rho^{\mu} \\
\left(\mathrm{g} / \mathrm{cm}^{3}\right)\end{array}$ & $\begin{array}{l}\rho^{\text {exvas }} \\
\left(\mathrm{g} / \mathrm{cm}^{3}\right)\end{array}$ & $v_{1}(\mathrm{~km} / \mathrm{s})$ & $v_{3}(\mathrm{~km} / \mathrm{s})$ & $\begin{array}{l}C_{1111}^{\exp } \\
(\mathrm{GPa})\end{array}$ & $\begin{array}{l}C_{3333}^{\exp } \\
(\mathrm{GPa})\end{array}$ & $\begin{array}{l}C_{1111}^{\mathrm{pred}} \\
(\mathrm{GPa})\end{array}$ & $\begin{array}{l}C_{3333}^{\text {pred }} \\
\text { (GPa) }\end{array}$ \\
\hline 2.03 & 2.14 & 3.60 & 4.30 & 27.8 & 39.7 & 27.4 & 37.5 \\
\hline 2.02 & 2.11 & 3.55 & 4.20 & 26.6 & 37.2 & 25.1 & 34.3 \\
\hline 2.01 & 2.13 & 3.45 & 4.10 & 25.4 & 35.9 & 26.8 & 36.6 \\
\hline 2.01 & 2.09 & 3.65 & 4.40 & 27.8 & 40.4 & 23.7 & 32.4 \\
\hline 2.00 & 2.10 & 3.55 & 4.20 & 26.5 & 37.0 & 24.5 & 33.5 \\
\hline 2.00 & 2.08 & 3.40 & 4.20 & 24.0 & 36.6 & 23.1 & 31.5 \\
\hline 2.00 & 2.06 & 3.58 & 4.30 & 26.5 & 38.2 & 22.4 & 30.5 \\
\hline 1.98 & 2.11 & 3.42 & 4.10 & 24.7 & 35.5 & 25.4 & 34.8 \\
\hline 1.98 & 2.11 & 3.35 & 4.15 & 23.7 & 36.4 & 25.4 & 34.8 \\
\hline 1.98 & 2.09 & 3.50 & 4.15 & 25.6 & 36.0 & 23.9 & 32.6 \\
\hline 1.98 & 2.09 & 3.60 & 4.30 & 27.1 & 38.6 & 23.9 & 32.6 \\
\hline 1.97 & 2.08 & 3.50 & 4.03 & 25.5 & 33.7 & 23.2 & 31.7 \\
\hline 1.97 & 2.10 & 3.35 & 4.20 & 23.6 & 37.1 & 24.7 & 33.8 \\
\hline 1.96 & 2.08 & 3.50 & 4.03 & 25.5 & 33.8 & 23.3 & 31.8 \\
\hline 1.96 & 2.07 & 3.60 & 4.20 & 26.8 & 36.5 & 22.6 & 30.8 \\
\hline 1.95 & 2.10 & 3.52 & 3.95 & 26.1 & 32.8 & 24.9 & 34.0 \\
\hline 1.95 & 2.04 & 3.40 & 4.03 & 23.6 & 33.2 & 21.3 & 28.9 \\
\hline 1.95 & 2.08 & 3.35 & 4.10 & 23.3 & 35.0 & 23.3 & 31.8 \\
\hline 1.95 & 2.16 & 3.42 & 4.10 & 25.2 & 36.3 & 28.4 & 38.8 \\
\hline 1.95 & 2.07 & 3.45 & 4.15 & 24.6 & 35.6 & 22.6 & 30.8 \\
\hline 1.95 & 2.10 & 3.55 & 4.15 & 26.5 & 36.2 & 24.9 & 34.0 \\
\hline 1.93 & 2.06 & 3.35 & 4.03 & 23.1 & 33.4 & 22.0 & 30.0 \\
\hline 1.93 & 2.02 & 3.30 & 4.10 & 22.0 & 34.0 & 20.1 & 27.2 \\
\hline 1.93 & 2.07 & 3.48 & 4.25 & 25.1 & 37.4 & 22.7 & 31.0 \\
\hline 1.92 & 2.05 & 3.35 & 4.00 & 23.0 & 32.7 & 21.4 & 29.1 \\
\hline 1.92 & 2.02 & 3.40 & 4.03 & 23.4 & 32.8 & 20.1 & 27.2 \\
\hline 1.92 & 2.05 & 3.35 & 4.20 & 23.0 & 36.1 & 21.4 & 29.1 \\
\hline 1.92 & 2.03 & 3.40 & 4.20 & 23.5 & 35.9 & 20.7 & 28.1 \\
\hline 1.91 & 2.03 & 3.35 & 4.13 & 22.8 & 34.7 & 20.7 & 28.2 \\
\hline 1.91 & 2.17 & 3.48 & 4.17 & 26.2 & 37.7 & 29.0 & 39.5 \\
\hline 1.91 & 2.11 & 3.45 & 4.35 & 25.1 & 39.9 & 25.2 & 34.4 \\
\hline 1.90 & 2.20 & 3.13 & 3.95 & 21.6 & 34.3 & 31.3 & 42.7 \\
\hline 1.90 & 2.02 & 3.40 & 4.00 & 23.4 & 32.4 & 20.1 & 27.3 \\
\hline 1.82 & 1.90 & 3.30 & 4.00 & 20.7 & 30.4 & 14.9 & 18.9 \\
\hline 1.76 & 2.09 & 3.20 & 3.85 & 21.4 & 30.9 & 23.7 & 32.4 \\
\hline
\end{tabular}


McCarthy et al. [100] reported the macroscopic mass densities, $\rho^{\mu}$, and the vascular porosities $f_{\text {vas }}$, which give access, based on the typical lacunar and canalicular porosities of $1.3 \%$ and $0.7 \%$, respectively, to the extravascular and extracellular mass densities, $\rho^{\text {exvas }}$ and $\rho^{\text {excel }}$. The latter enters the bilinear relations given by Eqs. (16) and (17), delivering the extracellular volume fractions of hydroxyapatite, collagen and water. The volume fractions of the lower scale RVEs of Fig. 15 follow from Eqs. (60)-(63). The corresponding micromechanical elasticity prediction of the equine metacarpal bone samples of McCarthy et al. [100] agree well with the actual experimental data. This is underlined by relative errors of $-4.23 \pm 11.33 \%$ for the radial normal stiffness, and of $-9.78 \pm 10.52 \%$ for the axial normal stiffness components, see Fig. 18.

In order to check the predictive capabilities of the micromechanical model concerning the off-diagonal and shear stiffness components of the elasticity tensor, we consider the stiffness tensor given by Ashman et al. [6] on the basis of $2.25 \mathrm{MHz}$ ultrasonic tests on human femoral samples, reading in Kelvin-Mandel notation (see e.g. Eq. (44) of Helnwein [68] or Eq. (20) of Cowin [31]) as

$$
\mathbb{C}^{\exp }=\left\{\begin{array}{cccccc}
18.0 & 9.98 & 10.1 & 0 & 0 & 0 \\
9.98 & 20.2 & 10.7 & 0 & 0 & 0 \\
10.1 & 10.7 & 27.6 & 0 & 0 & 0 \\
0 & 0 & 0 & 12.46 & 0 & 0 \\
0 & 0 & 0 & 0 & 11.22 & 0 \\
0 & 0 & 0 & 0 & 0 & 9.04
\end{array}\right\} \quad \text { GPa. }
$$

It should be noted that Ashman et al. [6] use macroscopic mass density values for the evaluation of the ultrasonic velocity measurements, while $2.25 \mathrm{MHz}$, as stated previously, actually refer to the extravascular RVE of Fig. 1d. Accordingly, the values given in (64) need to be corrected by a factor of

$$
\frac{\rho^{\text {exvas }}}{\rho^{\mu}}=\frac{\rho^{\mu}-\rho_{\mathrm{H}_{2} \mathrm{O}} f_{\text {vas }}}{\left(1-f_{\text {vas }}\right) \rho^{\mu}}=1.04
$$

taking $\rho^{\mu}=1.90 \mathrm{~g} / \mathrm{cm}^{3}$ from the tests of Ashman et al. [6]. Considering a typical vascular porosity of $8 \%$ in human femoral bone [19, 20, 30, 36, 140], yields

$$
\mathbb{C}_{\text {exvas }}^{\exp }=\left\{\begin{array}{cccccc}
18.74 & 10.39 & 10.52 & 0 & 0 & 0 \\
10.39 & 21.03 & 11.14 & 0 & 0 & 0 \\
10.52 & 11.14 & 28.74 & 0 & 0 & 0 \\
0 & 0 & 0 & 12.97 & 0 & 0 \\
0 & 0 & 0 & 0 & 11.68 & 0 \\
0 & 0 & 0 & 0 & 0 & 9.41
\end{array}\right\} \quad \text { GPa. }
$$

Applying the mass-density based volume fraction evaluation procedure to the same human femur sample provided by Ashman et al. [6] delivers the volume fractions entering the RVEs at all scales of Fig. 15. Based on a microporosity of $f_{\mu \text { por }}=$ 


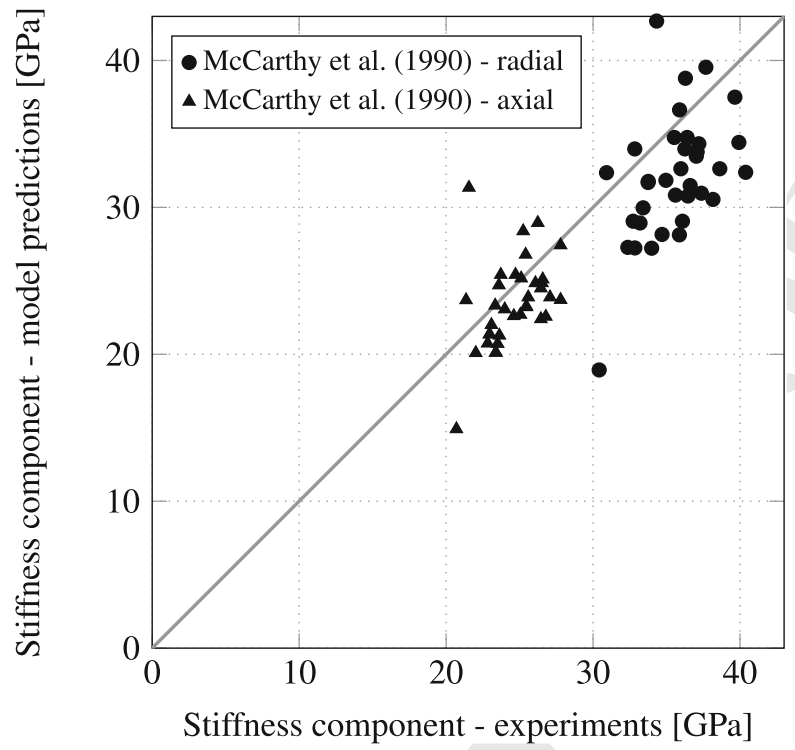

Fig. 18 Comparison between model predictions and experiments of radial and axial normal stiffness values at the extravascular scale (2.25 MHz experiments: McCarthy et al. [100], see also Table 9)

$10 \%$ in consistency with the vascular porosity value given further above and the lacunar and canalicular porosities given below Eq. (8), the macroscopic mass density $\rho^{\mu}=1.90 \mathrm{~g} / \mathrm{cm}^{3}$ is translated into an extracellular mass density entering Eq. (16). The volume fractions of the lower scale RVEs then follow from Eqs. (61)-(63). The corresponding micromechanical model prediction reads as

$$
\mathbb{C}_{\text {exvas }}^{\text {pred }}=\left\{\begin{array}{cccccc}
17.71 & 6.88 & 6.76 & 0 & 0 & 0 \\
6.88 & 17.71 & 6.76 & 0 & 0 & 0 \\
6.76 & 6.76 & 23.92 & 0 & 0 & 0 \\
0 & 0 & 0 & 11.09 & 0 & 0 \\
0 & 0 & 0 & 0 & 11.09 & 0 \\
0 & 0 & 0 & 0 & 0 & 9.68
\end{array}\right\} \quad \text { GPa. }
$$

The satisfactory agreement between model prediction and experimental data is underlined by an absolute error of $-9.13 \pm 7.8 \%$ for the diagonal stiffness components. The off-diagonal stiffness components are less well predicted; however, these components are particularly prone to experimental errors, see e.g. [44, 80, 82, 114].

\section{Model Validation at the Macroscopic Scale}

At the trabecular level, we compare the micromechanical elasticity predictions to ultrasonic tests $[126,145]$ on bovine femoral and human tibial tissues; at a frequency of $50 \mathrm{kHz}$, as well as to mechanical tests of Keaveny et al. [79] on bovine tibial tissue samples. Given a typical wave propagation velocity of $3 \mathrm{~km} / \mathrm{s}$ in the tested bone 


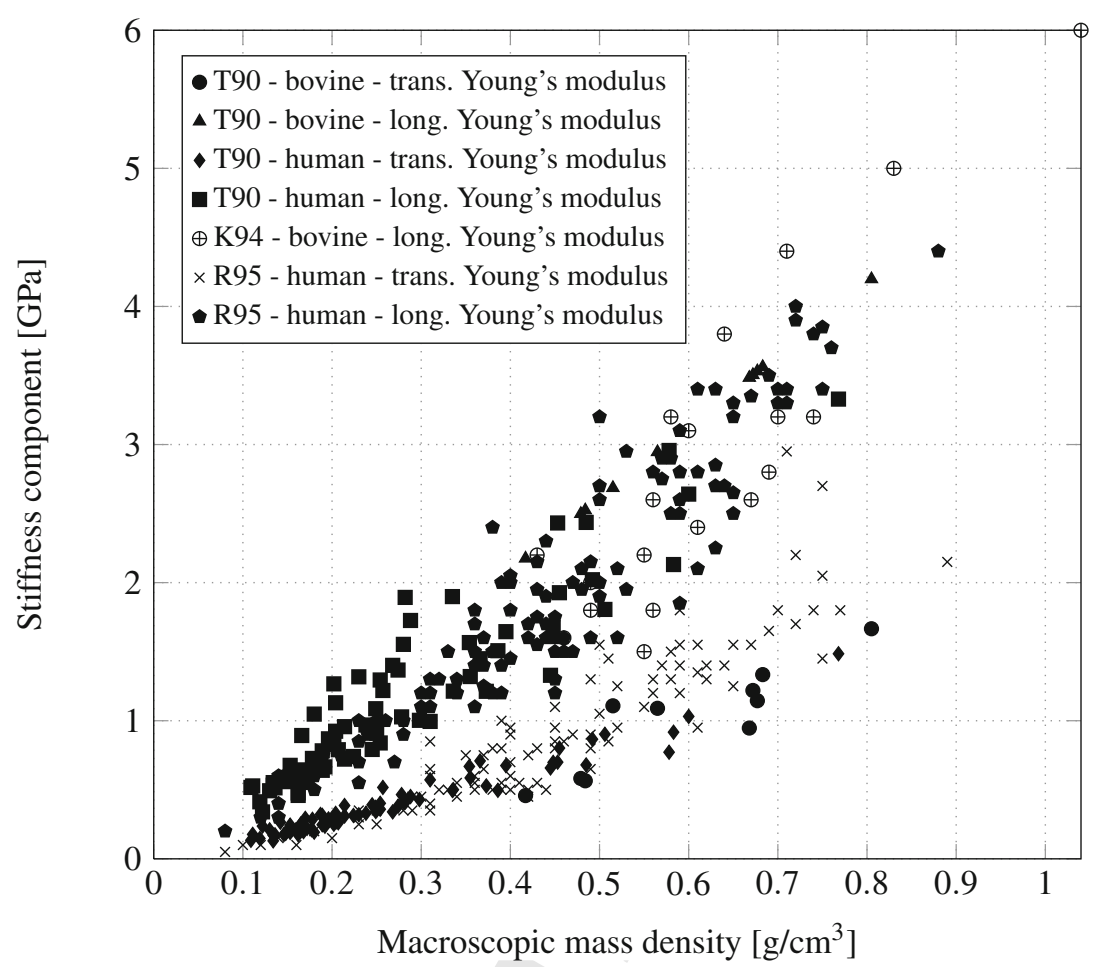

Fig. 19 Experimental data used for model validation: Macroscopic elastic stiffness constants of trabecular bone as a function of macroscopic mass density $\rho^{\mu}$; T90...[145], K94... [79], R95... [126]

specimens, the characteristic wave length was of the order of $6 \mathrm{~cm}$, being by a factor of 60 larger than the RVE of Fig. 15f, hence they characterize the latter according to Eq. (41). As tissue-specific input values for the micromechanical model, the volume fractions entering the RVE descriptions of wet collagen (Fig. 15a), of the fibrillar and extrafibrillar spaces (Fig. 15b, c), of the extracellular matrix (Fig. 15d), of the extravascular matrix (Fig. 15e), and of the bone microstructure (Fig. 15f) are needed.

For marrow-cleared trabecular bone, as tested by Keaveny et al. [79], Rho et al. [126], Turner et al. [145], the corresponding volume fractions can be derived from the measured macroscopic mass density, $\rho^{\mu}$, see Fig. 19. For the extravascular mass density of bone, we take $\rho^{\text {exvas }}=1.74 \mathrm{~g} / \mathrm{cm}^{3}$ for bovine, and $\rho^{\text {exvas }}=1.76 \mathrm{~g} / \mathrm{cm}^{3}$ for human bone specimens [5]. Assuming that the lacunar-canalicular volume fraction per extravascular bone, $f_{\text {lac }+ \text { can }}^{\text {exva }}=0.021$, is the same in cortical and trabecular bone, the extracellular mass density follows from

$$
\rho^{\text {excel }}=\frac{\rho^{\text {exvas }}-\rho_{\mathrm{H}_{2} \mathrm{O}} \times f_{\text {lac }+c a n}^{\text {exvas }}}{1-f_{\text {lac }+c a n}^{\text {exvas }}} .
$$




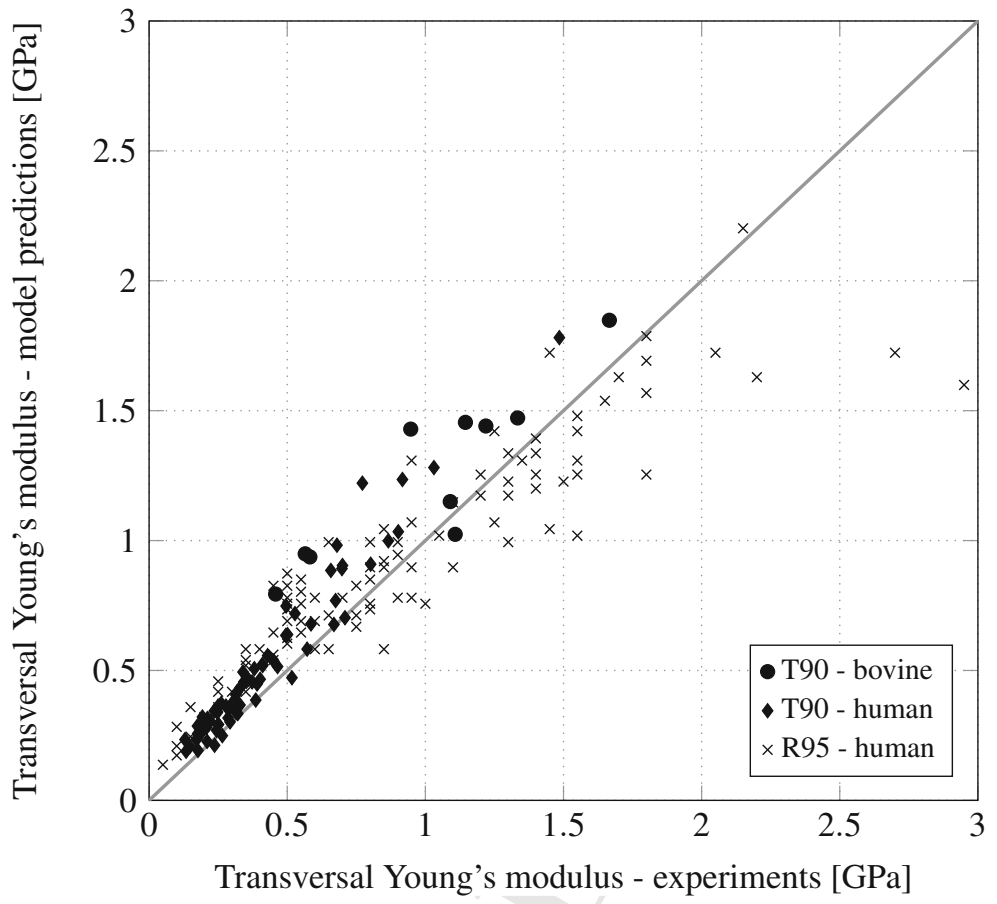

Fig. 20 Comparison between model predicted and experimental macroscopic elastic stiffness constants of trabecular bone in transversal direction $(50 \mathrm{kHz}$ ultrasonic and mechanical experiments); T90...[145], K94... [79], R95... [126]

The sought volume fractions can be computed from Eqs. (16), (17) and (60)-(63). The relative errors of the corresponding micromechanical elasticity predictions amount to $23.62 \pm 16.75 \%$ in radial, and $23.39 \pm 30.83 \%$ in axial direction for the bovine samples of Turner et al. [145]; $24.67 \pm 20.72 \%$ in radial, and $31.45 \pm 25.45 \%$ in axial direction for the human samples of Turner et al. [145]; $12.72 \pm 21.40 \%$ in radial direction for the bovine samples of Keaveny et al. [79]; and $0.09 \pm 28.44 \%$ in radial, and $28.26 \pm 17.03 \%$ in axial direction for the human samples of Rho et al. [126], see Figs. 20 and 21.

\section{Concluding Remarks}

Multiscale homogenization schemes similar to the one of Fig. 15 can also be employed for successful upscaling of mechanical properties of bone beyond the realm of elasticity. This was reported for poroelasticity [60, 64, 67, 108], for strength [48], and for viscoelasticity [40]. While we refer to the aforementioned references concerning experimental data bases used for micromechanics model validation, we note 


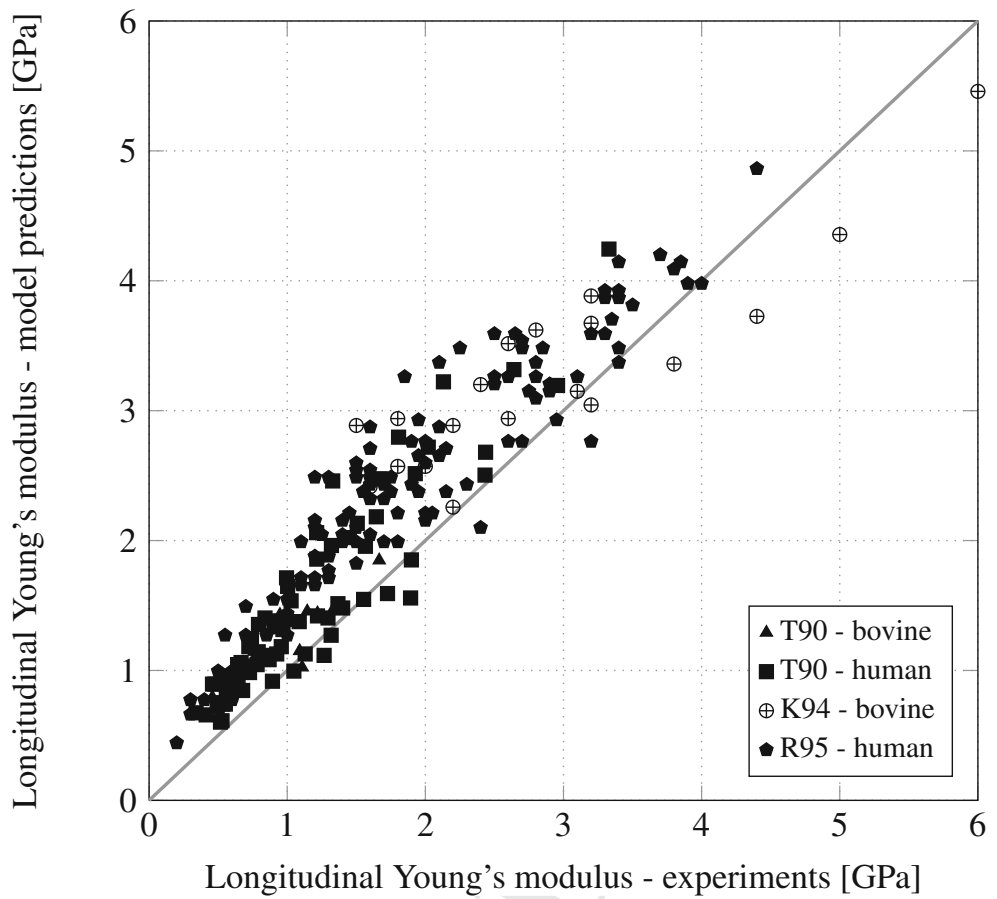

Fig. 21 Comparison between model predicted and experimental macroscopic elastic stiffness constants of trabecular bone in longitudinal direction $(50 \mathrm{kHz}$ ultrasonic and mechanical experiments); T90...[145], K94... [79], R95... [126]

in passing that a satisfactory performance of the strength and viscoelastic upscaling schemes stems from the consideration of sliding processes between the nanoscaled mineral crystals. This is in line with ongoing discussions in the bone materials science at large, be it in the context of Mohr-Coulomb-type, non-granular behavior elucidated by nanoindentation and atomic force microscopy [141]; or in the context of interface nanomechanics cast in the framework of molecular dynamics simulations [123]. The aforementioned poromechanics approaches are particularly valuable for quantifying the mechanical state in the vascular and lacunar pore spaces when the biological cells reside, i.e. the oscillating hydrostatic pressure to which they respond in a chemical fashion, see [136] and references therein. They also provide a natural link between micromechanics on the one hand, and system biology and cell population models on the other hand $[134,135]$. This results in a rather "rigorously" derived "mechano-biology of bone". Finally, multiscale micromechanics models can be readily combined with physics results, then allowing for the in-depth use and evaluation of clinical X-ray data from Computed Tomography yielding micromechanics-based Finite Element models at the organ scale. The latter elucidates the fascinating load carrying behavior of these organs, and also pave the way to patient-specific bone fracture risk assessment $[14,15]$. 


\section{References}

1. J. Aaron, Histology and micro-anatomy of bone, in Calcium, Phosphate and Magnesium Metabolism: Clinical Physiology and Diagnostic Procedures, ed. by B.E.C. Nordin (Churchill Livingstone, New York, 1971), pp. 298-356

2. B. Alexander, T.L. Daulton, G.M. Genin, J. Lipner, J.D. Pasteris, B. Wopenka, S. Thomopoulos, The nanometre-scale physiology of bone: steric modelling and scanning transmission electron microscopy of collagen-mineral structure. J. R. Soc. Interface 9, 1774-1786 (2012)

3. H.C. Anderson, The role of matrix vesicles in growth plate development and biomineralization. Front. Biosci. 10, 822-837 (2005)

4. B. Aoubiza, J.M. Crolet, A. Meunier, On the mechanical characterization of compact bone structure using the homogenization theory. J. Biomech. 29(12), 1539-1547 (1996)

5. R.B. Ashman, J. Rho, Elastic modulus of trabecular bone material. J. Biomech. 21(3), 177181 (1988)

6. R.B. Ashman, S.C. Cowin, W.C. van Buskirk, J.C. Rice, A continuous wave technique for the measurement of the elastic properties of cortical bone. J. Biomech. 17(5), 349361 (1984)

7. J.-L. Auriault, C. Boutin, C. Geindreau, Homogenization of Coupled Phenomena in Heterogenous Media (Wiley, New York, 2009)

8. A.J. Bailey, R.G. Paul, L. Knott, Mechanisms of maturation and ageing of collagen. Mech. Ageing Dev. 106(1-2), 1-56 (1998)

9. Y. Bala, D. Farlay, P. Delmas, P. Meunier, G. Boivin, Time sequence of secondary mineralization and microhardness in cortical and cancellous bone from ewes. Bone 46, 1204-1212 (2010)

10. D. Baylink, J. Wergedal, Bone formation and resorption by osteocytes, (1971), pp. 257-289

11. L.S. Bell, M. Kayser, C. Jones, The mineralized osteocyte: a living fossil. Am. J. Phys. Anthropol. 137, 449-456 (2008)

12. Y. Benveniste, A new approach to the application of Mori-Tanaka's theory in composite materials. Mech. Mater. 6(2), 147-157 (1987)

13. R. Biltz, E. Pellegrino, The chemical anatomy of bone. J. Bone Joint Surg. 51-A(3), 456-466 (1969)

14. R. Blanchard, A. Dejaco, E. Bongaers, C. Hellmich, Intravoxel bone micromechanics for microCT-based finite element simulations. J. Biomech. 46, 2710-2721 (2013)

15. R. Blanchard, C. Morin, A. Malandrino, A. Vella, S. Zdenka, C. Hellmich, Patient-specific fracture risk assessment of vertebrae: a multiscale approach coupling X-ray physics and continuum micromechanics. Numer. Methods Biomed. Eng. 32(9), XX (2016)

16. L.C. Bonar, S. Lees, H.A. Mook, Neutron diffraction studies of collagen in fully mineralized bone. J. Mol. Biol. 181(2), 265-270 (1985)

17. L. Bonewald, M. Johnson, Osteocytes, mechanosensing and Wnt signaling. Bone 42(4), 606615 (2008)

18. E. Bonucci, The osteocyte: the underestimated conductor of the bone orchestra. Rend. Lincei Sci. Fis. e Nat. 20, 237-254 (2009)

19. V. Bousson, C. Bergot, A. Meunier, F. Barbot, C. Parlier-Cuau, A.-M. Laval-Jeantet, J.-D. Laredo, CT of the middiaphyseal femur: cortical bone mineral density and relation to porosity. Radiology 217(1), 179-187 (2000)

20. V. Bousson, A. Meunier, C. Bergot, É. Vicaut, M.A. Rocha, M.H. Morais, A.-M. Laval-Jeantet, J.-D. Laredo, Distribution of intracortical porosity in human midfemoral cortex by age and gender. J. Bone Miner. Res. 16(7), 1308-1317 (2001)

21. L. Bozec, M. Horton, Topography and mechanical properties of single molecules of type I collagen using atomic force microscopy. Biophys. J. 88(6), 4223-4231 (2005)

22. J. Bradley, Interactive image display for the $x$ window system. version 3.10a, 2nd edn. (1994), http://www.trilon.com/xv/manual/xv-3.10a

23. B. Brodsky, E.F. Eikenberry, K.C. Belbruno, K. Sterling, Variations in collagen fibril structure in tendons. Biopolymers 21(5), 935-951 (1982) 
24. J.A. Buckwalter, M.J. Glimcher, R.R. Cooper, R. Recker, Bone biology, part I: structure, blood supply, cells, matrix, and mineralization. J. Bone Joint Surg. 77-A(8), 1256-1275 (1995)

25. C.M. Burns, The effect of the continued ingestion of mineral acid on growth of body and bone and on the composition of bone and of the soft tissues. Biochem. J. 23(5), 860-867 (1929)

26. A. Buxboim, I. Ivanovska, D. Discher, Matrix elasticity, cytoskeletal forces and physics of the nucleus: how deeply do cells feel outside and in? J. Cell Sci. 123(3), 297-308 (2010)

27. D.R. Carter, W.C. Hayes, The compressive behavior of bone as a two-phase porous structure. J. Bone Joint Surg. 59(7), 954-962 (1977)

28. K.-H. Chung, K. Bhadriraju, T.A. Spurlin, R.F. Cook, A.L. Plant, Nanomechanical properties of thin films of type I collagen fibrils. Langmuir 26(5), 3629-3636 (2010)

29. D.M.L. Cooper, A.L. Turinsky, C.W. Sensen, Hallgrímsson, Quantitative 3D analysis of the canal network in cortical bone by micro-computed tomography. Anat. Rec. 4274B(1), 169179 (2003)

30. D.M.L. Cooper, C.D.L. Thomas, J.G. Clement, A.L. Turinsky, C.W. Sensen, B. Hallgrímsson, Age-dependent change in the 3D structure of cortical porosity at the human femoral midshaft. Bone 40, 957-965 (2014)

31. S. Cowin, A recasting of anisotropic poroelasticity in matrices of tensor components. Transp. Porous Media 50, 35-56 (2003)

32. S. Cowin, The significance of bone microstructure in mechanotransduction. J. Biomech. 40 (2007)

33. J.M. Crolet, B. Aoubiza, A. Meunier, Compact bone: numerical simulation of mechanical characteristics. J. Biomech. 26(6), 677-687 (1993)

34. J.D. Currey, The effect of porosity and mineral content on the Young's modulus of elasticity of compact bone. J. Biomech. 21(2), 131-139 (1988)

35. S. Cusack, A. Miller, Determination of the elastic constants of collagen by Brillouin light scattering. J. Mol. Biol. 135(1), 39-51 (1979)

36. P. Dong, S. Haupert, B. Hesse, M. Langer, P.-J. Gouttenoire, V. Bousson, F. Peyrin, 3D osteocyte lacunar morphometric properties and distributions in human femoral cortical bone using synchrotron radiation micro-CT images. Bone 60, 172-185 (2014)

37. L. Dormieux, D. Kondo, F.-J. Ulm, Microporomechanics 66(6), 1036-1059 (2006)

38. W.J. Drugan, J.R. Willis, A micromechanics-based nonlocal constitutive equation and estimates of representative volume element size for elastic composites. J. Mech. Phys. Solids 44(4), 497-524 (1996)

39. E. Eanes, D. Lundy, G. Marti, X-ray diffraction study of the mineralization of turkey leg tendon. Calcif. Tissue Int. 6, 239-248 (1970)

40. L. Eberhardsteiner, C. Hellmich, Layered water in crystal interfaces as source for bone viscoelasticity: arguments from a multiscale approach. Comput. Methods Biomech. Biomed. Eng. 17(1), 48-63 (2014)

41. A. Engler, S. Sen, H. Sweeney, D. Discher, Matrix elasticity directs stem cell lineage specification. Cell 126(4), 677-689 (2006)

42. M. Epple, Solid-state chemical methods to investigate the nature of calcified deposits. Zeitschrift für Kardiologie 390(3) (2001)

43. J.D. Eshelby, The determination of the elastic field of an ellipsoidal inclusion, and related problems. Proc. R. Soc. Lond. Ser. A Math. Phys. Sci. 241(1226), 376-396 (1957)

44. A. Every, W. Sachse, Sensitivity of inversion algorithms for recovering elastic constants of anisotropic solids from longitudinal wavespeed data. Ultrasonics 30, 43-48 (1992)

45. P. Fratzl, S. Schreiber, K. Klaushofer, Bone mineralization as studied by small-angle x-ray scattering. Connect. Tissue Res. 34(4) (1996)

46. A. Fritsch, C. Hellmich, Universal microstructural patterns in cortical and trabecular, extracellular and extravascular bone materials: micromechanics-based prediction of anisotropic elasticity. J. Theor. Biol. 244(4), 597-620 (2007)

47. A. Fritsch, L. Dormieux, C. Hellmich, Porous polycrystals built up by uniformly and axisymmetrically oriented needles: homogenization of elastic properties. Comptes Rendus Mécanique 334(3), 151-157 (2006) 
48. A. Fritsch, C. Hellmich, L. Dormieux, Ductile sliding between mineral crystals followed by rupture of collagen crosslinks: experimentally supported micromechanical explanation of bone strength. J. Theor. Biol. 260(2), 230-252 (2009)

49. H.M. Frost, Micropetrosis. J. Bone Joint Surg. 42, 144-150 (1960)

50. P. Germain, The method of virtual power in continuum mechanics. part 2: microstructure. SIAM J. Appl. Math. 25(3), 556-575 (1973)

51. J. Gong, J. Arnold, S.H. Cohn, Composition of trabecular and cortical bone. The Anat. Rec. 149, 325-332 (1964)

52. S.J. Gould, R.C. Lewontin, The spandrels of San Marco and the Panglossian paradigm: a critique of the adaptationist programme. Proc. R. Soc. Lond. Ser. B Biol. Sci. 205, 581-598 (1979)

53. Q. Grimal, G. Rus, W.J. Parnell, P. Laugier, A two-parameter model of the effective elastic tensor for cortical bone. J. Biomech. 44(8), 1621-1625 (2011)

54. M. Hahn, M. Vogel, M. Pompesious-Kempa, G. Delling, Trabecular bone pattern factora new parameter for simple quantification of bone microarchitecture. Bone 13(4), 327-330 (1992)

55. E. Hamed, Y. Lee, I. Jasiuk, Multiscale modeling of elastic properties of cortical bone. Acta Mech. 213(1), 131-154 (2010)

56. E. Hamed, E. Novitskaya, J. Li, I. Jasiuk, J. McKittrick, Experimentally-based multiscale model of the elastic moduli of bovine trabecular bone and its constituents. Mater. Sci. Eng. C 54, 207-216 (2015)

57. F.S. Hammet, A biochemical study of bone growth. I Changes in the ash, organics matter and water during growth (mus norvegicus albinus). J. Biol. Chem. 64, 409-428 (1925)

58. F. Hang, A.H. Barber, Nano-mechanical properties of individual mineralized collagen fibrils from bone tissue. J. R. Soc. Interface (2010)

59. Z. Hashin, Analysis of composite materials a survey. J. Appl. Mech. 50(3), 481 (1983)

60. C. Hellmich, Microelasticity of Bone, in Applied Micromechanics of Porous Materials - CISM Courses and Lectures, vol. 480, ed. by L. Dormieux, F.-J. Ulm (2005)

61. C. Hellmich, F.-J. Ulm, Micromechanical model for ultrastructural stiffness of mineralized tissues. J. Eng. Mech. 128(8), 898-908 (2002)

62. C. Hellmich, F.-J. Ulm, Are mineralized tissues open crystal foams reinforced by crosslinked collagen? - some energy arguments. J. Biomech. 535(9), 1199-1212 (2002)

63. C. Hellmich, F.-J. Ulm, Average hydroxyapatite concentration is uniform in the extracollagenous ultrastructure of mineralized tissues: evidence at the 1-10-microm scale. Biomech. Model. Mechanobiol. 2(1), 21-36 (2003)

64. C. Hellmich, F.-J. Ulm, Drained and undrained poroelastic properties of healthy and pathological bone: a poro-micromechanical investigation. Transp. Porous Media 58(3), 243-268 (2005)

65. C. Hellmich, J.-F. Barthélémy, L. Dormieux, Mineralcollagen interactions in elasticity of bone ultrastructure a continuum micromechanics approach. Eur. J. Mech. A/Solids 23(5), 783-810 (2004)

66. C. Hellmich, F.-J. Ulm, L. Dormieux, Can the diverse elastic properties of trabecular and cortical bone be attributed to only a few tissue-independent phase properties and their interactions? Biomech. Model. Mechanobiol. 2(4), 219-238 (2004)

67. C. Hellmich, D. Celundova, F.-J. Ulm, Multiporoelasticity of hierarchically structured materials: micromechanical foundations and application to bone. J. Eng. Mech. 135(5), 382-394 (2009)

68. P. Helnwein, Some remarks on the compressed matrix representation of symmetric secondorder and fourth-order tensors. Comput. Methods Appl. Mech. Eng. 190(2223), 2753-2770 (2001)

69. A.V. Hershey, The elasticity of an isotropic aggregate of anisotropic cubic crystals. J. Appl. Mech. Trans. ASME 21(3), 236-240 (1954)

70. B. Hesse, P. Varga, M. Langer, A. Pacureanu, S. Schrof, N. Männicke, H. Suhonen, P. Maurer, P. Cloetens, F. Peyrin, K. Raum, Canalicular network morphology is the major determinant of the spatial distribution of mass density in human bone tissue: evidence by means of synchrotron radiation phase-contrast nano-CT. J. Bone Miner. Res. 30(2), 346-356 (2015) 
71. R. Hill, Elastic properties of reinforced solids: some theoretical principles. J. Mech. Phys. Solids 11(5), 357-372 (1963)

72. A.J. Hodge, J.A. Petruska, Recent studies with the electron microscope on ordered aggregates of the tropocollagen molecule, in Aspects of Protein Structure - Proceedings of a Symposium held in Madras 14-18 January 1963 and organized by the University of Madras, India, ed. by G.N. Ramachandran (Academic Press, New York, 1963), pp. 289-300

73. G.K. Hunter, P.V. Hauschka, R.A. Poole, L.C. Rosenberg, H.A. Goldberg, Nucleation and inhibition of hydroxyapatite formation by mineralized tissue proteins. Biochem. J. 317(1), 59-64 (1996)

74. R. Jilka, R. Weinstein, T. Bellido, A. Parfitt, S. Manolagas, Osteoblast programmed cell death (apoptosis): modulation by growth factors and cytokines. J. Bone Miner. Res. 13(5), 793-802 (1998)

75. J. Jowsey, Age changes in human bone. Clin. Orthop. 17, 210-218 (1960)

76. E.P. Katz, S.T. Li, Structure and function of bone collagen fibrils. J. Mol. Biol. 80(1), 1-15 (1973)

77. J.L. Katz, K. Ukraincik, On the anisotropic elastic properties of hydroxyapatite. J. Biomech. 4(3), 221-227 (1971)

78. J.L. Katz, H.S. Yoon, S. Lipson, R. Maharidge, A. Meunier, P. Christel, The effects of remodeling on the elastic properties of bone. Calcif. Tissue Int. 36(1), 31-36 (1984)

79. T.M. Keaveny, E.F. Wachtel, C.M. Ford, W.C. Hayes, Differences between the tensile and compressive strengths of bovine tibial trabecular bone depend on modulus. J. Biomech. 27(9), 1137-1146 (1994)

80. C. Kohlhauser, C. Hellmich, Determination of Poissons ratios in isotropic, transversely isotropic, and orthotropic materials by means of combined ultrasonic-mechanical testing of normal stiffnesses: application to metals and wood. Eur. J. Mech. A/Solids 33, 82-98 (2012)

81. C. Kohlhauser, C. Hellmich, Ultrasonic contact pulse transmission for elastic wave velocity and stiffness determination: influence of specimen geometry and porosity. Eng. Struct. 47, $115-133$ (2013)

82. R. Kriz, W. Stinchcomb, Elastic moduli of transversely isotropic graphite fibers and their composites. Exp. Mech. 19(2), 41-49 (1979)

83. E. Kröner, Berechnung der elastischen Konstanten des Vielkristalls aus den Konstanten des Einkristalls. Zeitschrift für Physik 151(4), 504-518 (1958)

84. N. Laws, The determination of stress and strain concentrations at an ellipsoidal inclusion in an anisotropic material. J. Elast. 7(1), 91-97 (1977)

85. N. Laws, A note on penny-shaped cracks in transversely isotropic materials. Mech. Mater. 4(2), 209-212 (1985)

86. S. Lees, Considerations regarding the structure of the mammalian mineralized osteoid from viewpoint of the generalized packing model. Connect. Tissue Res. 16, 281-303 (1987)

87. S. Lees, Mineralization of type I collagen. Biophys. J. 85, 204-207 (2003)

88. S. Lees, J. Heeley, Density of a sample bovine cortical bone matrix and its solid constituent in various media. Calcif. Tissue Int. 33, 499-504 (1981)

89. S. Lees, H.A. Mook, Equatorial diffraction spacing as a function of water content in fully mineralized cow bone determined by neutron diffraction. Connect. Tissue Res. 39, 291-292 (1986)

90. S. Lees, E.A. Page, A study of some properties of mineralized turkey leg tendon. Connect. Tissue Res. 28(4), 263-287 (1992)

91. S. Lees, P.F. Cleary, J.D. Heeley, E.L. Gariepy, Distribution of sonic plesio-velocity in a compact bone sample. J. Acoust. Soc. Am. 66(3), 641-646 (1979)

92. S. Lees, J.M. Ahern, M. Leonard, Parameters influencing the sonic velocity in compact calcified tissues of various species. J. Acoust. Soc. Am. 74(1), 28-33 (1983)

93. S. Lees, L.C. Bonar, H.A. Mook, A study of dense mineralized tissue by neutron diffraction. Int. J. Biol. Macromol. 6(6), 321-326 (1984)

94. S. Lees, D. Hanson, E.A. Page, H. Mook, Comparison of dosage-dependent effects of betaaminopropionitrile, sodium fluoride, and hydrocortisone on selected physical properties of cortical bone. J. Bone Miner. Res. 9(9), 1377-1389 (1994) 
95. S. Lees, K.S. Prostak, V.K. Ingle, K. Kjoller, The loci of mineral in turkey leg tendon as seen by atomic force microscope and electron microscopy. Calcif. Tissue Int. 55, 180-189 (1994)

96. S. Lees, D. Hanson, E.A. Page, Some acoustical properties of the otic bones of a fin whale. J. Acoust. Soc. Am. 99(4), 2421-2427 (1995)

97. V. Lemaire, F.L. Tobin, L.D. Greller, C.R. Cho, L.J. Suva, Modeling the interactions between osteoblast and osteoclast activities in bone remodeling. J. Theor. Biol. 229, 293-309 (2004)

98. J. Martínez-Reina, J. Domínguez, J.M. García-Aznar, Effect of porosity and mineral content on the elastic constants of cortical bone: a multiscale approach. Biomech. Model. Mechanobiol. 210(3), 309-322 (2011)

99. G.A. Maugin, The principle of virtual power: from eliminating metaphysical forces to providing an efficient modelling tool. Contin. Mech. Thermodyn. 5(2), 127-146 (2013)

100. R.N. McCarthy, L.B. Jeffcott, R.N. McCartney, Ultrasound speed in equine cortical bone: effects of orientation, density, porosity and temperature. J. Biomech. 23(11), 1139-1143 (1990)

101. E.A. McNally, H.P. Schwarcz, A model for the ultrastructure of bone based on electron microscopy of ion-milled sections. PLOS one 7(1), e29258 (2012)

102. K.M. Meek, N.J. Fullwood, P.H. Cooke, G.F. Elliott, D.M. Maurice, A.J. Quantock, R.S. Wall, C.R. Worthington, Synchrotron X-ray diffraction studies of the cornea, with implications for stromal hydration. Biophys. J. 60(2), 467-474 (1991)

103. T.A. Metzger, T.C. Kriepke, T.J. Vaughan, L.M. McNamara, G.L. Niebur, The in situ mechanics of trabecular bone marrow: the potential for mechanobiological response. J. Biomech. Eng. 137(1), 011006 (2015)

104. C. Miles, M. Ghelashvili, Polymer-in-a-box mechanism for the thermal stabilization of collagen molecules in fibers. Biophys. J. 76(6), 3243-3252 (1999)

105. A. Miller, S.B. Parker, The organic matrix of bone. Phil. Trans. R. Soc. B 304, 455-477 (1984)

106. T. Mori, K. Tanaka, Average stress in matrix and average elastic energy of materials with misfitting inclusions. Acta Metall. 21(5), 571-574 (1973)

107. C. Morin, C. Hellmich, Mineralization-driven bone tissue evolution follows from fluid-tosolid phase transformations in closed thermodynamic systems. J. Theor. Biol. 335, 185-197 (2013)

108. C. Morin, C. Hellmich, A multiscale poromicromechanical approach to wave propagation and attenuation in bone. Ultrasonics 54(5), 1251-1269 (2014)

109. C. Morin, C. Hellmich, P. Henits, Fibrillar structure and elasticity of hydrating collagen: a quantitative multiscale approach. J. Theor. Biol. 317, 384-393 (2013)

110. S. Nikolov, D. Raabe, Hierarchical modeling of the elastic properties of bone at submicron scales: the role of extrafibrillar mineralization. Biophys. J. 94(11), 4220-4232 (2008)

111. B.S. Noble, The osteocyte lineage. Arch. Biochem. Biophys. 473, 106-111 (2008)

112. J.P.R.O. Orgel, T.C. Irving, A. Miller, T.J. Wess, Microfibrillar structure of type i collagen in situ. Proc. Nat. Acad. Sci. U. S. A. 103(24), 9001-9005 (2006)

113. P.E. Palacio-Mancheno, A.I. Larriera, S.B. Doty, L. Cardoso, S. Fritton, 3D assessment of cortical bone porosity and tissue mineral density using high resolution $\mu \mathrm{CT}$ : effects of resolution and threshold method. J. Bone Miner. Res. 29(1), 142-150 (2012)

114. E. Papadakis, T. Patton, Y. Tsai, D. Thompson, R. Thompson, The elastic moduli of a thick composite as measured by ultrasonic bulk wave pulse velocity. J. Acoust. Soc. Am. 89(6), 2753-2757 (1991)

115. A.M. Parfitt, The physiologic and clinical significance of bone histomorphometric data, in Histomorphometry, Techniques and Interpretation, ed. by R.R. Recker (CRC Press Inc, Boca Raton, 1983), pp. 143-223

116. W.J. Parnell, Q. Grimal, The influence of mesoscale porosity on cortical bone anisotropy. Investigations via asymptotic homogenization. J. R. Soc. Interface 6, 97-109 (2009)

117. F. Peters, K. Schwarz, M. Epple, The structure of bone studied with synchrotron X-ray diffraction, X-ray absorption spectroscopy and thermal analysis. Thermochim. Acta 361(1-2) (2000) 
118. R.M.V. Pidaparti, D.B. Burr, Collagen fiber orientation and geometry effects on the mechanical properties of secondary osteons. J. Biomech. 25(8) (1992)

119. R.M.V. Pidaparti, A. Chandran, Y. Takano, C.H. Turner, Bone mineral lies mainly outside collagen fibrils: predictions of a composite model for osternal bone. J. Biomech. 29(7) (1996)

120. S. Pradhan, D. Katti, K. Katti, Steered molecular dynamics study of mechanical response of full length and short collagen molecules. J. Micromech. Microeng. 1(3), 104110 (2011)

121. K. Prostak, S. Lees, The locus of mineral crystallites in bone. Connect. Tissue Res. 18(1), 41-54 (1988)

122. K.S. Prostak, S. Lees, Visualization of crystal-matrix structure. In situ demineralization of mineralized turkey leg tendon and bone. Calcif. Tissue Int. 59(6), 474-479 (1996)

123. T. Qu, D. Verma, M. Shahidi, B. Pichler, Mechanics of organic-inorganic biointerfacesImplications for strength and creep properties. MRS Bull. 40(4), 349-358 (2015)

124. A.G. Reisinger, D.H. Pahr, P.K. Zysset, Sensitivity analysis and parametric study of elastic properties of an unidirectional mineralized bone fibril-array using mean field methods. Biomech. Model. Mechanobiol. 9(5) (2010)

125. J.-Y. Rho, M.E. Roy, T.Y. Tsui, G.M. Pharr, Elastic properties of microstructural components of human bone tissue as measured by nanoindentation. J. Biomed. Mater. Res. 45(1), 48-54 (1998)

126. J.Y. Rho, M.C. Hobatho, R.B. Ashman, Relations of mechanical properties to density and CT numbers in human bone. Med. Eng. Phys. 17(5), 347-355 (1995)

127. R. Riedl, A systems-analytical approach to macro-evolutionary phenomena. Q. Rev. Biol. 52(4), 351-370 (1977)

128. R.A. Robinson, Chemical analysis and electron microscopy of bone, in Bone as Tissue, ed. by K. Rodahl, J.T. Nicholson, E.M. Brown Jr. (McGraw-Hill, New-York, 1960), pp. 186-250

129. P.J.M. Roholl, E. Blauw, C. Zurcher, J.A.M.A. Dormans, H.M. Theuns, Evidence for a diminished maturation of preosteoblasts into osteoblasts during aging in rats: an ultrastructural analysis. J. Bone Miner. Res. 9(3), 355-366 (1994)

130. M.A. Rougvie, R.S. Bear, An X-Ray diffraction investigation of swelling by collagen. J. Am. Leather Chem. Assoc. 48(12), 735-751 (1953)

131. J. Salençon, Handbook of Continuum Mechanics (Springer, Berlin, 2001)

132. V. Sansalone, S. Naili, V. Bousson, C. Bergot, F. Peyrin, J. Zarka, J.D. Laredo, G. Haiat, Determination of the heterogeneous anisotropic elastic properties of human femoral bone: from nanoscopic to organ scale. J. Biomech. 43(10) (2010)

133. N. Sasaki, S. Odajima, Stress-strain curve and Young's modulus of a collagen molecule as determined by the X-ray diffraction technique. J. Biomech. 29(5), 655-658 (1996)

134. S. Scheiner, P. Pivonka, C. Hellmich, Coupling systems biology with multiscale mechanics, for computer simulations of bone remodeling. Comput. Methods Appl. Mech. Eng. 254, 181-196 (2013)

135. S. Scheiner, P. Pivonka, C. Hellmich, Mathematical modeling of postmenopausal osteoporosis and its treatment by the anti-catabolic drug denosumab. Numer. Methods Biomed. Eng. 30, $127(2014)$

136. S. Scheiner, P. Pivonka, C. Hellmich, Poromicromechanics reveals that physiological bone strains induce osteocyte-stimulating lacunar pressure. Biomech. Model. Mechanobiol. 15(1), 928 (2016)

137. P. Schneider, M. Stauber, R. Voide, M. Stampanoni, L.R. Donahue, R. Müller, Ultrastructural properties in cortical bone vary greatly in two inbred strains of mice as assessed by synchrotron light based micro- and nano-CT. J. Bone Miner. Res. 22(10), 1557-1570 (2007)

138. P. Schneider, M. Meier, R. Wepf, R. Müller, Serial FIB/SEM imaging for quantitative 3D assessment of the osteocyte lacuno-canalicular network. Bone 49(2), 304-311 (2011)

139. H.P. Schwarcz, E.A. McNally, G.A. Botton, Dark-field transmission electron microscopy of cortical bone reveals details of extrafibrillar crystals. J. Struct. Biol. 188(3), 240-248 (2014)

140. W.K. Sietsema, Animal models of cortical porosity. Bone 17(4), 297-305 (1995)

141. K.T. Tai, F.-J. Ulm, C. Ortiz, Nanogranular origins of the strength of bone. Nanoletters 6(11), $2520-2525$ (2006) 
142. N.-J. Tao, S.M. Lindsay, S. Lees, Studies of compact hard tissues and collagen by means of brillouin light scattering. Connect. Tissue Res. 24(3-4), 187-205 (1990)

143. S. Teitelbaum, Bone resorption by osteoclasts. Science 289, 1504-1508 (2000)

144. S.M. Tommasini, A. Trinward, A.S. Acerbo, F. De Carlo, L.M. Miller, S. Judex, Changes in intracortical microporosities induced by pharmaceutical treatment of osteoporosis as detected by high resolution micro-CT. Bone 50, 596-604 (2012)

145. C.H. Turner, S.C. Cowin, J.Y. Rho, R.B. Ashman, J.C. Rice, The fabric dependence of the orthotropic elastic constants of cancellous bone. J. Biomech. 23(6), 549-561 (1990)

146. M.R. Urist, R.J. DeLange, G.A. Finerman. Bone cell differentiation and growth factors. Science (1983)

147. J. Vuong, C. Hellmich, Bone fibrillogenesis and mineralization: quantitative analysis and implications for tissue elasticity. J. Theor. Biol. 287, 115-130 (2011)

148. B.E. Warren, X-ray diffraction methods. J. Appl. Phys. 12(5), 375-384 (1941)

149. B.E. Warren, B.L. Averbach, The effect of cold-work distortion on X-ray patterns. J. Appl. Phys. 21(6), 595-599 (1950)

150. S. Weiner, H.D. Wagner, The material bone: structure-mechanical function relations. Annu. Rev. Mater. Sci. 28, 271-298 (1998)

151. S. Weiner, T. Arad, I. Sabanay, W. Traub, Rotated plywood structure of primary lamellar bone in the rat: orientations of the collagen fibril arrays. Bone 20, 509-514 (1997)

152. J. Wergedal, Baylink, Electron microprobe measurements of bone mineralization rate in vivo. Am. J. Physiol. 226(2), 345-352 (1974)

153. H.P. Wiesmann, U. Meyer, U. Plate, H.J. Hhling, Aspects of collagen mineralization in hard tissue formation. Int. Rev. Cytol. 242, 121-156 (2005)

154. Y.J. Yoon, S.C. Cowin, The estimated elastic constants for a single bone osteonal lamella. Biomech. Model. Mechanobiol. 7(1) (2008)

155. A. Zajac, D. Discher, Cell differentiation through tissue elasticity-coupled, myosin-driven remodeling. Curr. Opin. Cell Biol. 20(6), 609-615 (2008)

156. A. Zaoui, Structural morphology and constitutive behavior of microheterogeneous materials, Continuum Micromechanics (Springer, Berlin, 1997), pp. 291-347

157. A. Zaoui, Continuum micromechanics: survey. J. Eng. Mech. 128(8), 808-816 (2002)

158. J.-X. Zhu, Y. Sasano, I. Takahashi, I. Mizogushi, M. Kagayama, Temporal and spatial gene expression of major bone extracellular matrix molecules during embryonic mandibular osteogenesis in rats. Histochem. J. 33, 25-35 (2001)

159. L. Zylberberg, W. Traub, V. de Buffrenil, F. Allizard, T. Arad, S. Weiner, Rostrum of a toothed whale: ultrastructural study of a very dense bone. Bone 23, 241-247 (1998) 


\section{Author Queries}

Chapter 4

\begin{tabular}{|c|l|l|}
\hline Query Refs. & Details Required & Author's response \\
\hline AQ1 & $\begin{array}{l}\text { Please check and confirm if the authors and their respective affil- } \\
\text { iations have been correctly identified. Amend if necessary. }\end{array}$ & \\
\hline AQ2 & $\begin{array}{l}\text { The citation of "Lees et al. (1992)" has been modified to "Lees } \\
\text { and Page [90]". Please check, and correct if necessary. }\end{array}$ & \\
\hline
\end{tabular}




\section{Please correct and return this set}

Please use the proof correction marks shown below for all alterations and corrections. If you wish to return your proof by fax you should ensure that all amendments are written clearly in dark ink and are made well within the page margins.

\begin{tabular}{|c|c|c|}
\hline Instruction to printer & Textual mark & Marginal mark \\
\hline Leave unchanged & ... under matter to remain & ( ) \\
\hline $\begin{array}{l}\text { Insert in text the matter } \\
\text { indicated in the margin }\end{array}$ & $h$ & $\begin{array}{l}\text { New matter followed by } \\
h \text { or } h \otimes\end{array}$ \\
\hline Delete & $\begin{array}{l}\text { I through single character, rule or underline } \\
\text { or }\end{array}$ & $\sigma$ or $\sigma / 2$ \\
\hline $\begin{array}{l}\text { Substitute character or } \\
\text { substitute part of one or } \\
\text { more word(s) }\end{array}$ & I through letter or & $\begin{array}{l}\text { new character / or } \\
\text { new characters / }\end{array}$ \\
\hline Change to italics & — under matter to be changed & $\leftarrow$ \\
\hline Change to capitals & $\equiv$ under matter to be changed & $\equiv$ \\
\hline Change to small capitals & $=$ under matter to be changed & $=$ \\
\hline Change to bold type & $\sim$ under matter to be changed & $\sim$ \\
\hline Change to bold italic & $\bar{\sim}$ under matter to be changed & 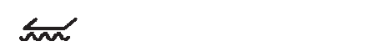 \\
\hline Change to lower case & Encircle matter to be changed & $\Rightarrow$ \\
\hline Change italic to upright type & (As above) & \\
\hline Change bold to non-bold type & (As above) & nor \\
\hline Insert 'superior' character & $\begin{array}{l}/ \text { through character or } \\
\alpha \text { where required }\end{array}$ & $\begin{array}{l}y^{\prime} \text { or } y \\
\text { under character } \\
\text { e.g. } y^{2} \text { or } y^{2}\end{array}$ \\
\hline Insert 'inferior' character & (As above) & $\begin{array}{l}\lambda \\
\text { over character } \\
\text { e.g. } \hat{\Sigma}\end{array}$ \\
\hline Insert full stop & (As above) & $\odot$ \\
\hline Insert comma & (As above) & , \\
\hline Insert single quotation marks & (As above) & $\begin{array}{l}\dot{y} \text { or } \dot{x} \text { and/or } \\
\dot{y} \text { or } \dot{y}\end{array}$ \\
\hline Insert double quotation marks & (As above) & $\begin{array}{l}\ddot{y} \text { or } \ddot{x} \text { and/or } \\
\ddot{y} \text { or } \ddot{x}\end{array}$ \\
\hline Insert hyphen & (As above) & 1 \\
\hline Start new paragraph & 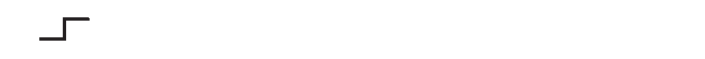 & 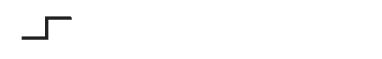 \\
\hline No new paragraph & $\omega$ & 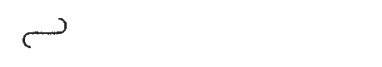 \\
\hline Transpose & $\sqcup$ & $\sqcup$ \\
\hline Close up & linking $\bigcirc$ characters & \\
\hline $\begin{array}{l}\text { Insert or substitute space } \\
\text { between characters or words }\end{array}$ & $\begin{array}{l}\text { I through character or } \\
\Lambda \text { where required }\end{array}$ & \\
\hline $\begin{array}{l}\text { Reduce space between } \\
\text { characters or words }\end{array}$ & $\begin{array}{l}\text { between characters or } \\
\text { words affected }\end{array}$ & $T$ \\
\hline
\end{tabular}

